CAROLINA CARVALHO PREVIDI NUNES

DEPOSIÇÃO DE FILMES FINOS DE SILÍCIO AMORFO HIDROGENADO POR SPUTTERING REATIVO

São Paulo 
CAROLINA CARVALHO PREVIDI NUNES

\title{
DEPOSIÇÃO DE FILMES FINOS DE SILÍCIO AMORFO HIDROGENADO POR SPUTTERING REATIVO
}

\author{
Dissertação apresentada à Escola \\ Politécnica da Universidade de São \\ Paulo para obtenção do Título de Mestre \\ em Engenharia Elétrica.
}




\title{
DEPOSIÇÃO DE FILMES FINOS DE SILÍCIO AMORFO HIDROGENADO POR SPUTTERING REATIVO
}

\author{
Dissertação apresentada à Escola \\ Politécnica da Universidade de São \\ Paulo para obtenção do Título de Mestre \\ em Engenharia Elétrica.
}

Área de concentração: Microeletrônica

Orientador:

Prof. Dr. Luis da Silva Zambom

São Paulo 


\section{DEDICATÓRIA}

Dedico este trabalho ao meu pai, Pedro Torres Pereira Nunes, que muito me apoiou neste trabalho. 


\section{AGRADECIMENTOS}

Ao professor Dr. Luis da Silva Zambom pela orientação.

Aos professores Carlos Eduardo Viana pelas discussões e disponibilização de material, Ronaldo Domingues Mansano pelas deposições dos filmes de silício amorfo hidrogenado, Manfredo Harri Tabacniks, pelo apoio e inspiração e Henrique Estanislau Maldonado Peres pelas opiniões construtivas.

Aos amigos Marina Sparvoli de Medeiros pelas contribuições acadêmicas, Mario Andrés Raffo Jara, pela amizade adquirida assim como suporte nos momentos difíceis, Nahim Santos Carvalho Silva, por ter me acompanhado nesta fase importante da minha vida e a todos os que colaboraram direta ou indiretamente para a execução deste trabalho. 


\section{RESUMO}

Neste trabalho filmes finos de silício amorfo hidrogenado (a-Si:H) foram depositados no reator magnetron sputtering do laboratório de sistemas integráveis (LSI), a temperaturas menores que $100^{\circ} \mathrm{C}$, pela introdução do gás hidrogênio junto com o de argônio para pulverização de um alvo de silício policristalino. As condições de deposição investigadas estão compreendidas em pressões totais de 5 e $10 \mathrm{mT}$ orr para as quais a potência de RF variou de 150 a $300 \mathrm{~W}$, para a menor pressão, e de 200 a 300 W, para a maior pressão, sendo que para cada condição de potência a concentração de hidrogênio nos gases de descarga variou de pelo menos $0 \%$ a no máximo $60 \%$. Como os substratos utilizados foram carbono vítreo, lâminas oxidadas de silício e placas de vidro para microscópio óptico os filmes depositados sobre o carbono foram caracterizados por RBS, os depositados sobre as lâminas oxidadas de silício por FTIR e medidas IV e os depositados sobre o vidro por espectroscopia de absorção óptica na região do ultravioleta-visível. A caracterização RBS forneceu informações tanto sobre o tipo e quantidade de impurezas eventualmente incorporadas durante a deposição como sobre a densidade superficial do silício que permitiu a obtenção da densidade volumétrica pela utilização dos parâmetros de espessura obtidos pela técnica de perfilometria. Através da análise dos espectros FTIR o hidrogênio incorporado pode ser quantificado na forma de mono e polihidretos de silício. As medidas IV foram realizadas através de contatos de alumínio, evaporados sobre os filmes, para a obtenção tanto da condutividade de escuro como da fotocondutividade e a análise dos espectros de absorção óptica dos filmes permitiu a obtenção tanto dos valores de energia do "gap" óptico, pelo método Tauc, como do parâmetro B que é inversamente proporcional à largura da cauda das bandas de valência e de condução que por sua vez aumentam com o aumento da densidade de defeitos dos filmes. Desta forma os filmes que apresentaram as maiores fotosensibilidades (razão entre a fotocondutividade e a condutividade de escuro), consideradas para a escolha dos melhores resultados, foram os depositados a 10 mTorr uma vez que eles apresentam uma maior concentração tanto de ligações $\mathrm{SiH}_{2}$ como de $\mathrm{SiH}_{3}$ e menores concentrações totais de hidrogênio incorporado ao filme que os filmes depositados a 5 mTorr o que acabou contribuindo para a diminuição da densidades de estados localizados da banda de mobilidade, provavelmente devido a nucleação de cristais, o que ocorre tipicamente para filmes depositados por sistemas magnetron sputtering a grandes pressões totais e grandes pressões parciais de hidrogênio, estando, desta forma, tanto as ligações $\mathrm{SiH}_{2}$ como $\mathrm{SiH}_{3}$ situadas nos contornos de grão. Assim os filmes depositados a $10 \mathrm{mTorr}$ apresentam concentrações quase nula de ligações $\mathrm{SiH}$, mas as maiores fotosensibilidades.

Palavras-chave: silício amorfo hidrogenado, sputtering reativo, filmes finos, densidade de defeitos, condutividade, ligações entre silício e hidrogênio e energia do "gap". 


\begin{abstract}
In this work thin films of hydrogenated amorphous silicon (a-Si:H) were deposited in the magnetron sputtering reactor of the laboratório de sistemas integráveis (LSI), at temperatures lower than $100{ }^{\circ} \mathrm{C}$, by the introduction of hydrogen and argon gasses for the sputtering of a policrystalline silicon target. The deposition conditions investigated are total pressures of 5 and $10 \mathrm{mTorr}$ for which the RF power varied from 150 to $300 \mathrm{~W}$, for the lowest pressure, and from 200 to $300 \mathrm{~W}$, for the highest pressure. For each power condition the hydrogen concentration in the discharge gases ranged from $0 \%$ to maximum $60 \%$. The substrates used were glassy carbon, for RBS characterization, oxidized silicon wafers for FTIR and IV measurements and glass plate for optical microscope and visible-ultraviolet spectroscopy absorption. The RBS characterization provided information about both the type and quantity of impurity incorporated during the deposition and the amorphous silicon superficial density that allowed obtaining the volumetric density by the utilization of the thickness parameter obtained by the profilometry technique. Through the analyses of the FTIR spectra the hydrogen incorporated could be quantified in the form of mono and poli silicon hydrides. The IV measurements were performed, through aluminum contacts evaporated on the films, to obtain the dark and photoconductivity and the films ultraviolet-visible absorption spectra. Through ultraviolet-visible analysis was possible to obtain both the optical energy gap values, by the Tauc method, and the B parameter, which is inversely proportional to the valence and conduction tail width. The B parameter increases with the defect density of the films. Thus, the films that showed the biggest photosensitivity (relation between the photoconductivity and dark conductivity) were deposited at 10 mTorr. These films showed a higher concentration of both $\mathrm{SiH}_{2}$ and $\mathrm{SiH}_{3}$ bonds but a lower concentration of total hydrogen incorporated, which contributed to the decrease of the density of states in the mobility band, probably due to the nucleation of crystals typical of films deposited by the magnetron sputtering system at high pressure and high hydrogen concentration. In this way the $\mathrm{SiH}_{2}$ and $\mathrm{SiH}_{3}$ would be in the grain boundary. So the films deposited at 10 mTorr showed almost null concentration of $\mathrm{SiH}$ bonds, but the highest photosensitivities.
\end{abstract}

Keyword: hydrogenated amorphous silicon, reactive sputtering, thin films, density of defects, conductivity, silicon and hydrogen bonds, and energy gap. 


$\begin{array}{ll}\text { a-Si:H } & \text { Silício amorfo hidrogenado } \\ \text { a-Si } & \text { Silício amorfo } \\ \text { c-Si } & \text { Silício monocristalino } \\ \text { CVD } & \text { Deposição química a vapor } \\ \text { CPM } & \text { Método de fotocorrente constante } \\ \text { DOS } & \text { Densidade de estados } \\ \text { Eg } & \text { Energia do "gap" } \\ \text { FTIR } & \text { Espectroscopia de infravermelho e transformada de Fourier } \\ \text { GD } & \text { "Glow dicharge" } \\ \text { IF } & \text { Instituto de física } \\ \text { IQ } & \text { Instituto de química } \\ \text { LACIFID } & \text { Laboratório de cristais iônicos, filmes finos e datação } \\ \text { LAMFI } & \text { Laboratório de análise de materiais por feixe iônico } \\ \text { LCD } & \text { Display de cristal líquido } \\ \text { LEM } & \text { Laboratório de espectroscopia molecular } \\ \text { LME } & \text { Laboratório de microeletrônica } \\ \text { LSI } & \text { Laboratório de sistemas integráveis } \\ \text { PDS } & \text { Espectroscopia de deflexão fototérmica } \\ \text { PECVD } & \text { Deposição química a vapor enriquecida por plasma } \\ \text { RF } & \text { Radio freqüência } \\ \text { Si-poli } & \text { Silício policristalino } \\ \text { TFT } & \text { Transistor de filme fino } \\ \end{array}$




\section{LISTA DE SÍMBOLOS}

\begin{tabular}{|c|c|}
\hline$\sigma$ & Condutividade \\
\hline$\rho$ & Densidade \\
\hline$\Omega$ & Ohm \\
\hline $\mathrm{cm}$ & Centímetro \\
\hline $\mathrm{m}$ & Metro \\
\hline $\mathrm{mm}$ & Milímetro \\
\hline $\min$ & Minuto \\
\hline s & Segundo \\
\hline ppm & Partes por milhão \\
\hline$\AA$ & Angstron \\
\hline$\alpha$ & Coeficiente de absorção \\
\hline$\omega$ & Número de onda \\
\hline$\phi$ & Diâmetro \\
\hline $\mathrm{V}$ & Volt \\
\hline eV & Elétron-volt \\
\hline $\mathrm{L}$ & Litro \\
\hline W & Watt \\
\hline${ }^{\circ} \mathrm{C}$ & Graus Celsius \\
\hline $\mathrm{E}_{\mathrm{C}}$ & Energia da banda de condução \\
\hline $\mathrm{E}_{\mathrm{V}}$ & Energia da banda de valência \\
\hline $\mathrm{E}_{\mathrm{F}}$ & Energia de Fermi \\
\hline
\end{tabular}




\section{SUMÁRIO}

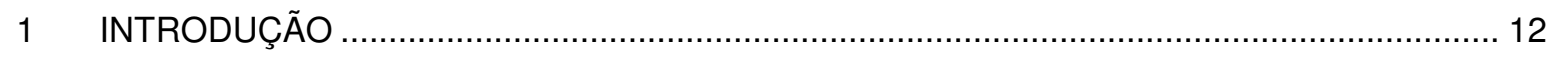

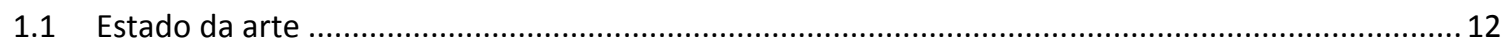

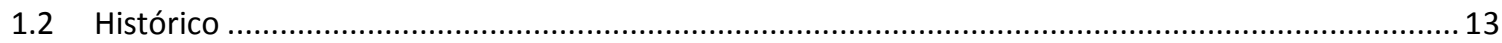

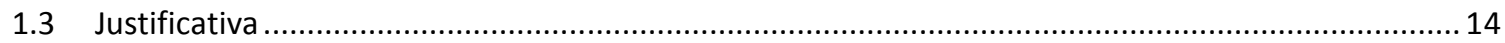

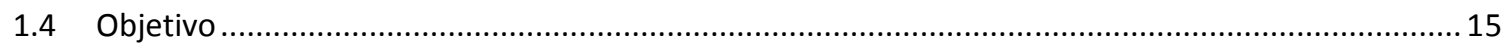

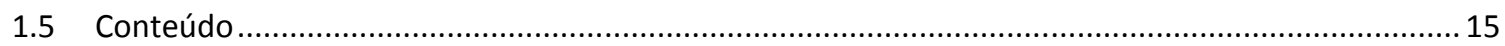

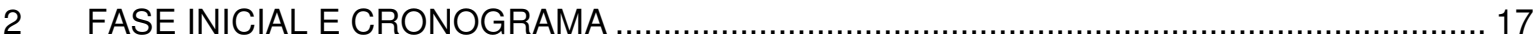

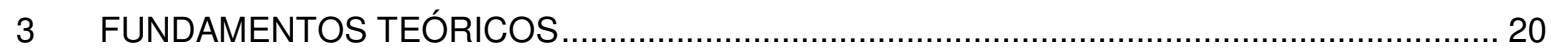

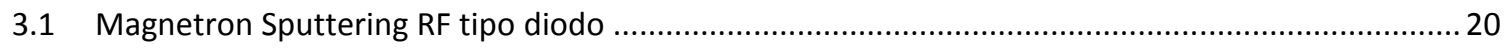

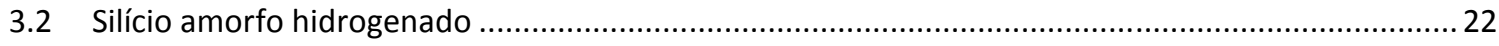

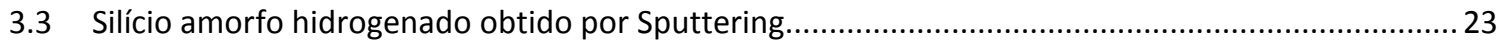

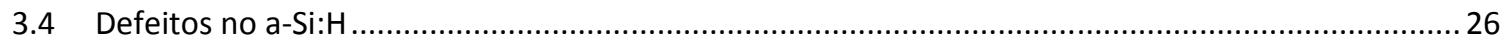

3.5 Estrutura atômica e densidade eletrônica de estados ........................................................................ 27

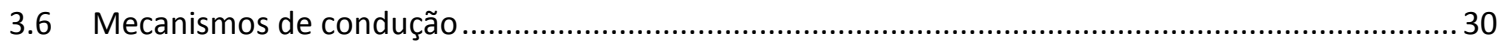

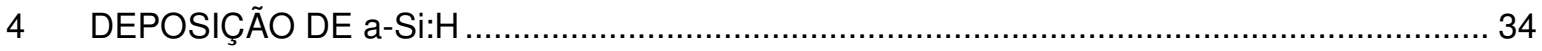

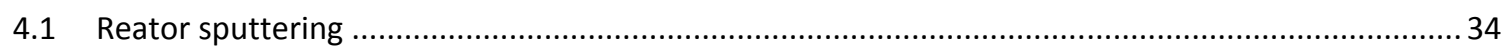

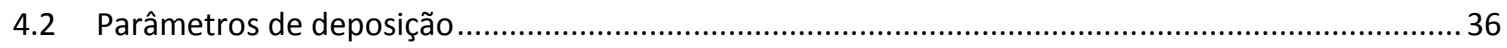

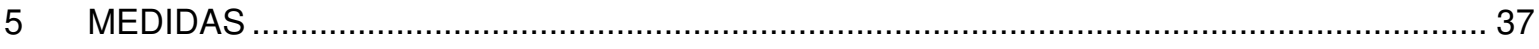

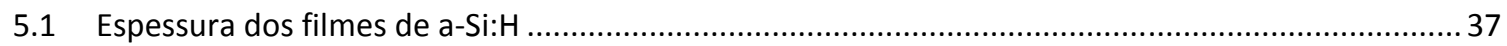

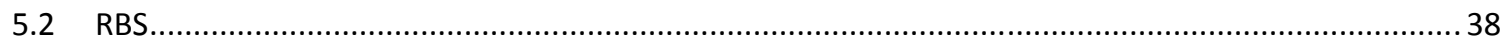

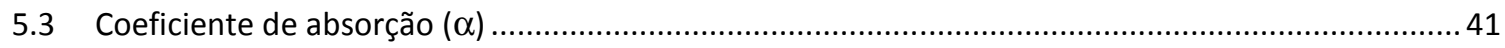

5.4 FTIR

5.5 Espectroscopia de absorção no ultravioleta-visível ........................................................................... 47

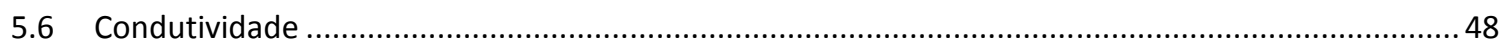

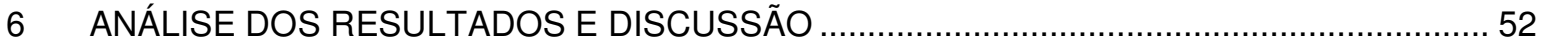

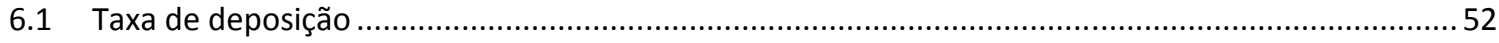

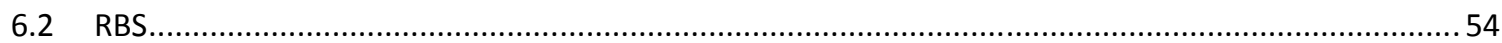

6.3 FTIR

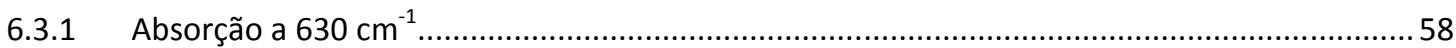

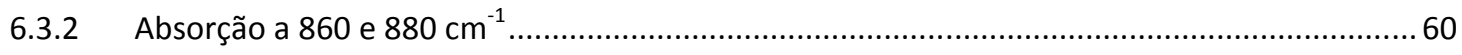

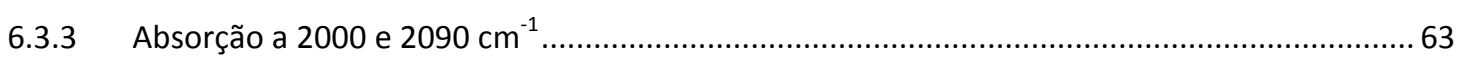

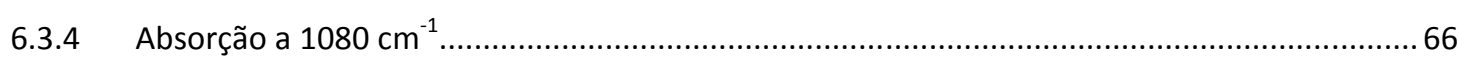

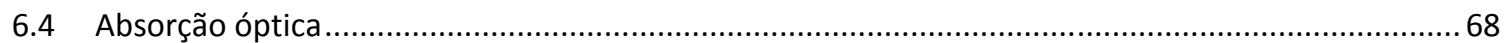




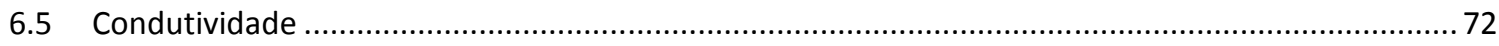

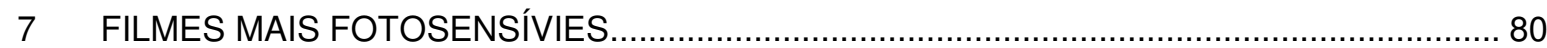

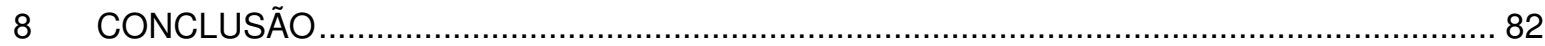

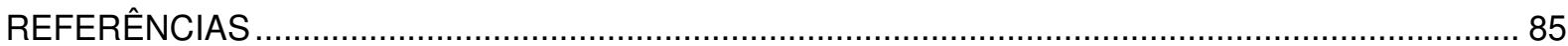

APÊNDICE A - Gráficos de absorção óptica na região do ultravioleta-visível................................... 90

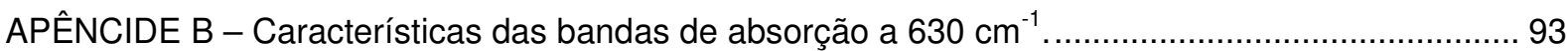

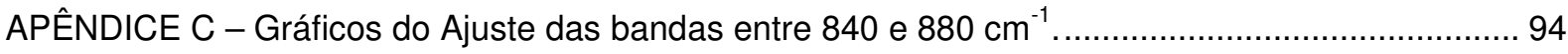

APÊNDICE D - Caracterização das bandas de absorção a 2000 e $2090 \mathrm{~cm}^{-1}$................................. 98

APÊNDICE E - Gráficos de condutividade de escuro e fotocondutividade .......................................99 


\section{INTRODUÇÃO}

\subsection{Estado da arte}

Filmes finos de a-Si:H são comumente obtidos por técnicas PECVD, Foto-CVD, HW-CVD [1] a temperaturas entre 200 e $300^{\circ} \mathrm{C}$ e empregados para a fabricação de dispositivos sobre substratos de vidro o que tem possibilitado a produção de transistores de filme fino (TFT's) para displays de LCD, detectores de sensibilidade luminosa, diodos emissores de luz, células solares de filmes finos e dispositivos de imagem [2], apesar de seu baixo desempenho com relação à tecnologia de silício monocristalino, devido à sua alta densidade de estados na banda proibida [3, 4]. Esta debilidade tem sido compensada pelo aumento do tamanho dos elementos do circuito integrado [5], sendo que para esta tecnologia de filme fino, a principal preocupação está na obtenção de dispositivos sobre áreas cada vez maiores [5]. Seu processo de obtenção possibilita a deposição sobre vários tipos de substratos, com diferentes propriedades, tendo praticamente como única limitação a temperatura a qual este substrato pode ser submetido. A não limitação do tamanho dos elementos eletrônicos e a utilização de substratos de baixo custo tornam esta tecnologia cada vez mais barata o que justifica o grande interesse científico e industrial neste tipo de material, cuja pesquisa tem sido realizada com o intuito de se obter filmes semicondutores, principalmente a base de silício [6], a temperaturas cada vez menores e qualidade cada vez maior, em termos principalmente de fotosensibilidade, no caso da aplicação em células solares [7], e mobilidade de portadores, no caso também de transistores de filmes finos [8]. Neste sentido, apesar da diminuição da temperatura de deposição acarretar na obtenção de filmes com uma maior densidade de defeitos, tem se conseguindo obter filmes finos de aSi:H a temperaturas tão baixas, quanto a temperatura ambiente, com propriedades tão boas quanto as obtidas para os filmes depositados a $200-300{ }^{\circ} \mathrm{C}$, após tratamentos de recozimento posteriores a $150{ }^{\circ} \mathrm{C}$, inclusive com filmes obtidos com a técnica de deposição por sputtering [9], abrindo espaço para a utilização de substratos de plásticos com aplicação em displays flexíveis de grande interesse de desenvolvimento científico e industrial da atualidade, inclusive para a produção de 
células solares, que já estão no mercado, ou de células solares flexíveis integradas a roupas, displays AMOLED's e baterias de filme fino que estão em fase de protótipo. Atualmente foram obtidos filmes de nc-Si:H e $\mu c-S i: H ~[10]$, com a vantagem de apresentarem uma degradação induzida pela luz reduzida [11], além de uma maior mobilidade de portadores (cerca de $500 \mathrm{~cm}^{2} / \mathrm{Vs}$ em vez de cerca de 1 $\mathrm{cm}^{2} / \mathrm{Vs}$ do a-Si:H), a temperaturas tão baixas quanto a temperatura ambiente, inclusive utilizando o sistema magnetron sputtering [11]. Esta conquista se deu com base no fato de que seria necessário mudar as condições de deposição para favorecer uma nova constituição estrutural, no caso cristalina [12]. E justamente, no processo de deposição com o sistema magnetron sputtering, constatou-se que o aumento tanto da pressão total de deposição como da taxa de fluxo de hidrogênio, favorecia a formação deste tipo de filme, até mesmo depositados a temperatura ambiente [13, 14]. Assim, apesar de terem se obtidos com o sistema magnetron sputtering filmes de nc-Si:H tão bons quanto os obtidos pelas técnicas CVD e da maior segurança, baixo custo e facilidade de deposição sobre grandes áreas sua utilização em escala industrial ainda não foi implementada, sendo todavia, considerada por vários autores uma técnica promissora de deposição destes tipos de filmes [15].

\subsection{Histórico}

O estudo do a-Si:H foi iniciado com a técnica "glow discharge" (GD) por Chittick e coautores (Chittick, Alexander e Sterling 1969) [16] após um período de intensa investigação do a-Si que por, sua vez, era comumente depositado por sputtering ou evaporação. Esta técnica GD, que emprega a dissociação da molécula de silana para a formação do filme, foi posteriormente estudada por Spear que concluiu que o a-Si:H tinha boas propriedades optoeletrônicas para a microeletrônica e a tecnologia de células solares, como resultado de sua densidade de estado (DOS) muito menor que a do a-Si (Spear, Loveland e Al-Sharbaty 1974) [16] resultante da saturação das ligações incompletas de silício neste material por átomos de hidrogênio que acarretam tanto a diminuição da densidade de defeitos como em uma maior ordem estrutural deste material devido ao estreitamento dos estados de cauda das bandas [15]. Durante este período Paul do grupo de Harvard [16] chegou a esta mesma 
conclusão quando adicionou hidrogênio em seu sistema de deposição por sputtering, produzindo a-Si:H.

Ao longo dos anos o sistema GD, que evoluiu para o PECVD, se tornou a técnica dominante de deposição de a-Si:H devido a aparente formação destes filmes com características ligeiramente melhores que as obtidas pelos filmes depositados pelo sistema magnetron sputtering RF [16]. De fato os filmes de a-Si:H produzidos por estas duas técnicas apresentam características estruturais diferentes uma vez que na deposição pela técnica magnetron sputtering, defeitos são introduzidos no filme durante seu crescimento devido ao bombardeio por átomos energéticos de silício, já que estes sistemas de deposição magentron sputtering empregam uma menor pressão de deposição (tipicamente de 5 mTorr) e maiores níveis de densidade de potência RF (aproximadamente 1,6 W.cm ${ }^{-2}$ ) comparados com sistemas PECVD [17].

Atualmente filmes de boa qualidade obtidos por PECVD apresentam condutividade de escuro de $10^{-11}$ a $10^{-10}(\Omega . \mathrm{cm})^{-1}$, fotocondutividade de $10^{-5}$ a $10^{-4}$ $(\Omega . \mathrm{cm})^{-1}$, razão entre fotocondutividade e condutividade de escuro (fotosensibilidade) da ordem de $10^{6}$, valores de "gap" óptico entre 1.7 e 1.8 eV e conteúdo de hidrogênio de 10 a 18 at. \% [18, 19] e filmes de boa qualidade obtidos pelo sistema magnetron sputtering apresentam condutividade de escuro na faixa de $10^{-11}$ a $10^{-9}$ $(\Omega . \mathrm{cm})^{-1}$ para concentração de 6 a 25 at. \% de hidrogênio, valores de energia do "gap" óptico de 1.7 a $1.85 \mathrm{eV}$ e fotosensibilidade de $10^{5}$ a $10^{6}$ [20, 21]. Outras variações do sistema magnetron sputtering foram utilizadas para a obtenção de filmes com características ainda melhores como o sistema de jato de plasma [22] e o que emprega polarização do substrato [23].

\subsection{Justificativa}

Sistemas como o PECVD, Foto-CVD e HWCVD [1] têm sido amplamente usados no meio científico para a deposição de filmes finos de a-Si:H. Por outro lado há uma menor quantidade de trabalhos para estes filmes depositados pelo sistema magnetron sputtering [1]. Apesar disto este sistema é uma alternativa viável de deposição de filmes de a-Si:H utilizáveis para a aplicação em dispositivos 
comerciais. Assim, o estudos de filmes finos de a-Si:H depositados pelo sistema magnetron sputtering é de grande importância por ser uma técnica promissora de deposição deste material. Sua vantagem está na simplicidade, baixo custo, e não utilização de gases tóxicos o que justamente torna estes sistemas mais seguros e baratos [24]. Outra vantagem é o controle maior, com relação à técnica PECVD, da concentração de hidrogênio incorporada aos filmes que ocorre pelo ajuste da concentração deste gás no reator de deposição.

\subsection{Objetivo}

Tendo em vista que a tecnologia de obtenção de filmes finos a base de silício a baixa temperatura é um assunto muito investigado na atualidade, devido seu grande interesse tecnológico e industrial, já que estes filmes podem ser depositados sobre substratos flexíveis de baixo custo e alta versatilidade, e que o sistema magnetron sputtering RF tem sido amplamente usado para a deposição destes filmes no meio científico, surgindo como uma alternativa simples aos sistemas CVD comerciais, o objetivo deste trabalho foi obter filmes finos de a-Si:H a baixa temperatura $\left(<100{ }^{\circ} \mathrm{C}\right)$ em diversas condições de deposição pelo sistema magnetron sputtering RF do Laboratório de Sistemas Integráveis (LSI) para a sua caracterização química, óptica e elétrica, comparação destas com as obtidas em outros trabalhos e identificação das condições de deposição que favoreceram a formação de filmes com as maiores fotosensibilidade. Sendo identificadas as condições de deposição que produziram filmes com as maiores fotosensibilidades, estas poderão ser reproduzidas para a fabricação de transistores de filmes finos (TFT's) em trabalhos futuros.

\subsection{Conteúdo}

No capítulo 2 deste trabalho é apresentado o que foi feito na fase inicial deste trabalho, mas que não foi continuado devido a limitação da técnica, no capítulo 3 são apresentados os fundamentos teóricos importantes referentes à estrutura e mecanismos de transporte eletrônico do a-Si:H, além de uma discussão sobre a faixa de parâmetros operacionais a partir dos quais alguns autores obtiveram filmes 
de boa qualidade pelo sistema sputtering. Ainda o conceito de defeito para estes filmes é introduzido para filmes de a-Si:H. No capítulo 4 o reator magnetron sputtering utilizado para a deposição dos filmes de a-Si:H investigados neste trabalho é descrito, assim como os parâmetros de deposição utilizados. No capítulo 5 é apresentada a metodologia de caracterização dos filmes obtidos e alguns resultados parciais. No capítulo 6 os dados obtidos são analisados e discutidos através da comparação com os resultados de outros autores. No capítulo 7 é feito um levantamento dos filmes mais fotosensíveis obtidos neste trabalho e no capítulo 8 o trabalho é concluído. 


\section{FASE INICIAL E CRONOGRAMA}

Na primeira fase deste trabalho lidamos com o silício amorfo sem hidrogênio (aSi) depositado pelo sistema magnetron sputtering RF para se tentar obter silício policristalino (poli-Si) através do processo de cristalização em fase sólida (SPC Solid Phase crystallization) que consiste no recozimento a temperaturas de aproximadamente $600^{\circ} \mathrm{C}$ por tempos de aproximadamente 15 horas, que aumentam com a diminuição da temperatura, para a transformação do material amorfo em policristalido. Esta temperatura de recozimento é limitada pelo substrato de vidro de interesse tecnológico o qual se pretendia trabalhar após a caracterização dos filmes depositados efetivamente neste trabalho sobre lâminas oxidadas de silício que imitariam a sílica (dióxido de silício que é o composto básico do vidro).

Desta forma, tendo sido obtidos filmes de a-Si a $250 \mathrm{~W}$ de potência RF e 5 mTorr de pressão total de Ar, eles foram recozidos por 4, 7, 10 e 13 horas em um forno de difusão com gás $N_{2}$ de arraste, ajustado com uma vazão de 1,3 L/min.

Apesar destes tratamentos térmicos terem sido realizados nos filmes de a-Si, tanto as imagens de microscopia eletrônica de varredura como as análises dos difratogramas produzidos pela técnica de difração de raio-X (XRD) não indicaram a presença de cristalitos em nenhum destes filmes recozidos. Este resultado pode ser justificado por estudos que indicaram que, para os filmes depositados pelo sistema magnetron sputtering $\mathrm{RF}$, ocorreria a cristalização caso a pressão de deposição fosse alta [25] e fossem utilizadas temperaturas de recozimento de $800^{\circ} \mathrm{C}$ [26].

Apesar dos filmes não terem se cristalizado, foram efetuados processos de hidrogenação em plasma de $\mathrm{H}_{2}$, como normalmente realizado para a passivação das ligações incompletas nos contornos de grão em filmes cristalizados, no sistema PECVD do LME a uma temperatura de $300^{\circ} \mathrm{C}$, vazão de $100 \mathrm{sccm}$ de $\mathrm{H}_{2}$, potência de 100 e 150 W e tempo de 0,5 e 1 hora, não resultando em nenhuma integração de hidrogênio na estrutura amorfa, conforme observado nos espectros FTIR.

Foram realizadas também etapas de implantação iônica de fósforo a 20, 40 e 60 $\mathrm{keV}$ com dose de $5 \times 10^{15} \mathrm{~cm}^{-2}$, tanto nos filmes de a-Si sem tratamento térmico como nos filmes recozidos por 4, 7, 10 e 13 horas. Após a implantação iônica nos filmes de a-Si recém depositados, houve o recozimento de algumas destas amostras por 7 horas a $600{ }^{\circ} \mathrm{C}$. 
Com estes procedimentos esperava-se, caso houvesse a cristalização, que os filmes implantados e depois cristalizados apresentassem melhores características elétricas e eventualmente grãos até maiores, já que normalmente o procedimento de dopagem por esta técnica ocorre com a implantação posterior à cristalização, seguida de outra etapa de recozimento para a ativação dos dopantes. Todavia, como o material não cristalizou e o a-Si tem uma densidade de defeitos grande demais para poder ser observado efeitos na introdução de dopantes em sua resistividade, a caracterização elétrica pela técnica perfil de resistência de espraiamento (SRP) não indicou regiões de menor resistividade devido ao fósforo, apenas a difusão de oxigênio para dentro do filme com o aumento do tempo de cristalização, que agiu como passivador das ligações incompletas dos átomos de silício na estrutura amorfa, reduzindo assim a resistência na interface entre o filme e o dióxido de silício. 
CRONOGRAMA

\begin{tabular}{|c|c|c|c|c|c|c|c|c|c|c|c|c|c|c|c|c|c|c|c|c|c|c|c|c|c|c|c|c|c|c|c|c|c|c|c|c|c|}
\hline \multirow{2}{*}{ Atividades } & \multicolumn{5}{|c|}{2007} & \multicolumn{12}{|c|}{2008} & \multicolumn{12}{|c|}{2009} & \multicolumn{8}{|c|}{2010} \\
\hline & 08 & 09 & 10 & 11 & 12 & 01 & 02 & 03 & 04 & 05 & 06 & 07 & 08 & 09 & 10 & 11 & 12 & 01 & 02 & 03 & 04 & 05 & 06 & 07 & 08 & 09 & 10 & 11 & 12 & 01 & 02 & 03 & 04 & 05 & 06 & 07 & 08 \\
\hline Disciplinas & & $\mathrm{X}$ & $\mathrm{X}$ & $\mathrm{X}$ & $\mathrm{X}$ & & & $\mathrm{X}$ & $\mathrm{X}$ & $\mathrm{X}$ & $\mathrm{X}$ & $\mathrm{X}$ & $\mathrm{X}$ & & & & & & & $\mathrm{X}$ & $\mathrm{X}$ & $\mathrm{X}$ & & & & & & & & & & & & & & & \\
\hline Dep. a-Si & $\mathrm{X}$ & $\mathrm{X}$ & & & & & & & & & & & & & & & & & & & & & & & & & & & & & & & & & & & \\
\hline Dep. a-Si:H & & & & & & & & & & & $\mathrm{X}$ & & & & & & & $\mathrm{X}$ & $\mathrm{X}$ & & & & & & & & & & & & & & $\mathrm{X}$ & $\mathrm{X}$ & & & \\
\hline Imp. lônica & & & & $\mathrm{X}$ & $\mathrm{X}$ & & & & & & $\mathrm{X}$ & & & & & & & & & & & & & & & & & & & & & & & & & & \\
\hline Hidrogenação & & & & & & & & & $\mathrm{X}$ & $\mathrm{X}$ & & & $\mathrm{X}$ & & & & & & & & & & & & & & & & & & & & & & & & \\
\hline SPC & & & & & & & & $\mathrm{X}$ & $\mathrm{X}$ & $\mathrm{X}$ & & $\mathrm{X}$ & & & & & & & & & & & & & & & & & & & & & & & & & \\
\hline Trat. Térmico & & & & & & & & & & & & & & & & & & & & & & & & & & & & & & & $\mathrm{X}$ & $\mathrm{X}$ & & & & & \\
\hline PIXE/RBS & & & $\mathrm{X}$ & & & $\mathrm{X}$ & & & & & & & & & $\mathrm{X}$ & $\mathrm{X}$ & & & & & & & & & & & & & & & & & & & & & \\
\hline XRD & & & & & & $X$ & & $\mathrm{X}$ & & & $\mathrm{X}$ & & & & & & & & & & & & & & & & & & & & & & & & & & \\
\hline MEV & & & & & & & & & $\mathrm{X}$ & & & & & & & & & & & & & & & & & & & & & & & & & & & & \\
\hline FTIR & & & & & & & & & $\mathrm{X}$ & $\mathrm{X}$ & & $\mathrm{X}$ & $\mathrm{X}$ & & & & & & & $\mathrm{X}$ & & & & & & & & $\mathrm{X}$ & & & & & & $X$ & & & \\
\hline SRP & & & & & & & $\mathrm{X}$ & & $\mathrm{X}$ & & & $\mathrm{X}$ & & & & & & & & & & & & & & & & & & & & & & & & & \\
\hline Abs. Opt. & & & & & & & & & & & & & & & & & & & & $\mathrm{X}$ & & & & & & $\mathrm{X}$ & $\mathrm{X}$ & & & & & & & & $\mathrm{X}$ & & \\
\hline Mob. Hall & & & & & & & $\mathrm{X}$ & $\mathrm{X}$ & & & & $\mathrm{X}$ & & & & $\mathrm{X}$ & $\mathrm{X}$ & & & & $\mathrm{X}$ & $\mathrm{X}$ & & & & & & & & & & & & & & & \\
\hline Perfilometria & & & $\mathrm{X}$ & & & & & & & & & & & & & & & & & $\mathrm{X}$ & & & & & & & & & & & & & & & $X$ & & \\
\hline I-V & & & & & & & & & & & & & & & & & & & & & & & $\mathrm{X}$ & $X$ & $\mathrm{X}$ & $X$ & & & & & & $\mathrm{X}$ & $X$ & $\mathrm{X}$ & $\mathrm{X}$ & & \\
\hline Escrita & & & & & & & & & & & & & & & & & & & & & & & & & & & & & $\mathrm{X}$ & $\mathrm{X}$ & & & & & & $\mathrm{X}$ & $\mathrm{X}$ \\
\hline
\end{tabular}




\section{FUNDAMENTOS TEÓRICOS}

\subsection{Magnetron Sputtering RF tipo diodo}

O Magnetron Sputtering RF tipo diodo é constituído por dois eletrodos e um ímã e está esquematicamente mostrado na figura 1. Ele foi desenvolvido na metade da década de 70 , sendo atualmente muito utilizado como técnica para a deposição física de filmes finos com alta qualidade, boa uniformidade, pouca impureza agregada e taxas razoáveis de deposição em substratos que suportam pouco aquecimento. Como eles podem ser utilizados na deposição de filmes sobre grandes áreas são muito utilizados, por exemplo, para a cobertura de painéis de display e paredes internas de tubos cerâmicos [27].

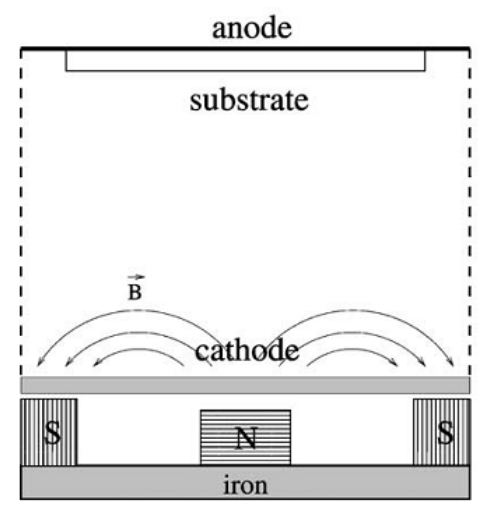

Figura 1: Diagrama esquemático de um sistema típico magnetron sputtering [28].

O mecanismo físico envolvido na deposição é o bombardeamento iônico de um alvo com a acomodação no substrato dos átomos espalhados. O sistema utilizado consiste em uma câmara de vácuo com duas placas paralelas onde o alvo é colocado no catodo e o substrato no anodo normalmente aterrado. Em seu funcionamento, a partir da pressão base de $10^{-6}$ torr um gás inerte é injetado no sistema, até ser atingida a pressão de descarga entre 0,1 e $10^{-3}$ torr. Uma tensão negativa aplicada de 400 a $600 \mathrm{~V}$ no catodo abre a descarga com a emissão de elétrons pelo alvo. Os íons gerados pela interação entre os elétrons e os átomos do gás batem no alvo produzindo elétrons secundários que, por sua vez, ajudam a manter o plasma.

Da aplicação de uma tensão negativa no catodo, surge uma região de carga espacial positiva composta por íons. Esta região, chamada de bainha, tem uma 
grande importância no processamento a plasma [KAKATI], pois os íons acelerados por ela em direção ao alvo causam o desbaste iônico e, simultaneamente, os elétrons acelerados na direção contrária, ionizam o gás. Esta bainha é necessária para a neutralidade do sistema, com a compensação do potencial negativa, sendo sua espessura caracterizada pelo comprimento de Debye do elétron $\left(\lambda_{D}\right)$.

O ímã com configuração planar campo magnético é o mais amplamente usada [29]. Sua função principal é aumentar a eficiência do processo de desbaste. Como pode ser visto na figura 2, onde são representadas as linhas de campo magnético, o vetor campo elétrico perpendicular à superfície do catodo, fica totalmente perpendicular ao campo magnético em uma dada região do alvo. À medida que isso vai acontecendo, o movimento dos elétrons ao longo do raio do disco vai ficando mais definidamente espiralado, com efeito de seu confinamento sobre o catodo.

Com o aumentado da probabilidade de ionização do gás, uma região de plasma com alta densidade é definida junto ao catodo. Ataques iônicos mais freqüentes passam a ocorrer em pressões e tensões de ruptura menores que seriam necessárias na ausência do ímã. Portanto, com o maior livre caminho médio, tanto os íons que se movem em direção ao alvo, como os átomos arrancados do mesmo se movem sofrendo menos colisões com o gás neutro, o que reduz o espalhamento atômico para as paredes do sistema e preserva a energia cinética das partículas [28].

Com o impedimento da expansão do plasma para todo o reator não ocorre o ataque iônico das paredes da câmara e nem o sobre-aquecimento do substrato pelos elétrons. Assim os sistemas sputtering que não utilizam ímãs depositam filmes com muita contaminação.

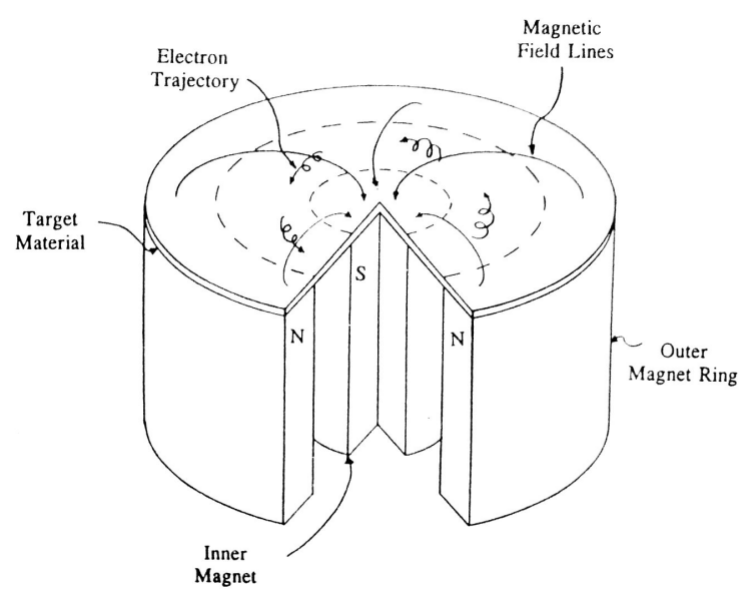

Figura 2: Esquema de um catodo magnético planar e circular, ilustrando o confinamento magnético e a trajetória do elétron [30]. 
Os alvos dos sistemas magnetron sputtering são circularmente erodidos [31] onde os campos elétricos e magnéticos ficam totalmente perpendiculares entre si. Nesta região, os átomos são mais densamente arrancados o que acarreta na modificação contínua da geometria do catodo e conseqüentemente as condições do plasma e de deposição. Desta forma, a distribuição da taxa de erosão do alvo afeta a distribuição de espessura dos filmes depositados, sobre parâmetros específicos de bombardeamento iônico. Já que ocorre um grande desperdício de material do alvo, de normalmente $75 \%$, geometrias mais econômicas podem ser usadas para melhor a uniformidade e eficiência de desbaste $[32,33]$.

No sistema magnetron sputtering RF o material do alvo pode ser tanto condutores como isolantes por causa da utilização de um potencial de alta freqüência. As freqüências utilizadas são de 13,56 ou $27 \mathrm{MHz}$ definidas pela FCC para aplicação industrial ou médica, sendo a primeira mais usada por proporcionar maiores taxas de deposição, devido ao maior bombardeamento iônico do alvo [34, 35].

Neste sistema RF os elétrons secundários não são tão críticos como em sistemas DC porque os elétrons do próprio plasma têm energia suficiente para a ionização direta e eficiente do gás. Isso ocorre em decorrência da oscilação dos elétrons nos ciclos alternados da tensão RF aplicada [34]. Devido às menores pressões de trabalho os elétrons secundários do alvo acabam, em sua grande maioria, passando através da região de descarga sem contribuir com o plasma, sendo perdidos para o substrato ou paredes.

\subsection{Silício amorfo hidrogenado}

O silício amorfo hidrogenado (a-Si:H) é uma material que apresenta uma ordem estrutural maior e uma densidade de estados na banda proibida muito menor que a do silício amorfo (a-Si) justamente pela presença de átomos de hidrogênio em sua liga que promovem tanto o relaxamento da rede, pela sua reação com ligações fracas de grande tensão mecânica, como a redução da densidade de estados na banda proibida, pela saturação de ligações incompletas, pela formação de ligações entre silício e hidrogênio, responsáveis pela presença de estados localizados na 
banda proibida. Desta forma a presença de átomos de hidrogênio gera nos filmes de silício amorfo um efeito de remoção de defeitos [36], melhorando suas características fotoelétricas, tornando-os utilizáveis para a produção de dispositivos.

Tendo o hidrogênio, adicionado à estrutura amorfa do silício, a função de completar as ligações incompletas, formadas devido à falta de ligação com outros quatro átomos deste mesmo elemento, estas ligações acabam aprisionando elétrons dos portadores de carga durante a condução eletrônica do filme de a-Si:H, que ocorre quando uma diferença de potencial é aplicada no material. Apesar de a diminuição da concentração de ligações incompletas ocorrer com a passivação destas por átomos de hidrogênio, se a concentração de hidrogênio for muito baixa ou muito alta, as estruturas de silício formadas podem apresentar respectivamente muitas ligações incompletas ou muitos átomos de silício ligados a mais que um átomo de hidrogênio, o que resulta, no ultimo caso, em uma estrutura polimérica, diferente da do diamante em pequena escala que caracteriza filmes com propriedades diferentes das de semicondutores a base de silício.

\subsection{Silício amorfo hidrogenado obtido por Sputtering}

Desde 1980 foram realizados estudos comparativos das propriedades dos filmes de a-Si:H depositados em reatores do tipo magnetron sputtering. Autores como Paul e Lewis [36] utilizaram uma pressão parcial de argônio de 5 a 10 mTorr, uma pressão parcial de hidrogênio de 0 a 10 mTorr, temperatura do substrato de 25 a $450{ }^{\circ} \mathrm{C}$ e potência RF de 50 a $400 \mathrm{~W}$, para a obtenção de parâmetros operacionais que produzissem filmes com melhores propriedades optoeletrônicas. Nestes mesmos estudos procurou-se também entender os mecanismos envolvidos na formação de filmes de silício amorfo hidrogenado pelo sistema magnetron sputtering RF.

O mecanismo de deposição do a-Si:H envolve a remoção do silício do alvo, pelos íons de argônio, que reagem com o hidrogênio atômico do plasma para a formação de espécies $\mathrm{SiH}_{\mathrm{x}}$ [16]. Estas espécies adquirem a energia fornecida pela potência de RF e colidem com o substrato para a formação do filme. Como a pressão de trabalho no sistema magnetron sputtering é menor que a do PECVD, as espécies $\mathrm{SiH}_{\mathrm{x}}$ formadas na região de alta densidade do plasma, localizada perto do 
alvo devido ao campo magnético gerado pelo ímã acoplado, dirigem-se ao substrato com poucas colisões ao longo do caminho. Diferentemente do processo CVD em que a pressão é alta o suficiente para favorecer a reação das espécies do plasma na superfície do filme em crescimento [16], no sistema magnetron sputtering RF a forma de assentamento do filme se deve ao ajuste balanceado tanto da potência como da temperatura do substrato. Assim potências muito baixas fornecem pouca energia às espécies $\mathrm{SiH}_{\mathrm{x}}$ que acabam se ligando fracamente ao filme em crescimento, ao passo que potências muito altas destroem os pequenos aglomerados de ordem local eventualmente formados [36]. Sendo um equilíbrio estabelecido para a potência RF, a energia do radical $\mathrm{SiH}_{\mathrm{x}}$ acaba sendo suficiente para predominantemente remover ligações fracas entre átomos de silício.

Uma vez que estas espécies $\mathrm{SiH}_{\mathrm{x}}$ tenham colidido com a superfície em crescimento, no seu estabelecido como um filme seus componentes elementares possuem pouca energia para se moverem e se acomodarem em sítios de pouca tensão mecânica, o que gera tensão na rede e muitos espaços vazios. O aquecimento do substrato durante a deposição reduz a magnitude e quantidade destes focos de tensão, devido ao aumento da mobilidade dos átomos, responsáveis pela geração de defeitos no filme em crescimento. Estes, agora com mais energia, promovem o relaxamento da rede através tanto da quebra de ligações fracas de grande tensão mecânica entre átomos de silício como do estabelecimento de ligações entre silício e hidrogênio [16]. Assim temperaturas típicas empregadas para a formação de filmes de a-Si:H com relativamente baixa densidade de defeitos estão entre 200 e $300{ }^{\circ} \mathrm{C}$.

Nas baixas pressões de deposição do método magnetron sputtering RF um outro equilíbrio deve também ser estabelecido entre as pressões parciais de hidrogênio e argônio para que a estrutura amorfa da matriz de silício não apresente muitas ligações incompletas, como ocorre quando a pressão parcial de hidrogênio é muito baixa, ou muitos polihidretos de silício, como ocorre quando esta pressão é muito alta, o que favorece a máxima concentração de ligações de silício com apenas um hidrogênio, em filmes relativamente densos. Desta forma o hidrogênio neste processo tem o papel de completar as ligações incompletas e não modificar a estrutura do filme. A pressão parcial de argônio por sua vez não deve ser muito alta para que não haja muitos átomos deste elemento aprisionados nos espaços vazios do filme. Considerando a velocidade de bombeamento constante, o ajuste das 
pressões parciais pela taxa de fluxo gasoso estabelece o tempo de residência tanto do argônio como do hidrogênio no reator.

O parâmetro de potência, por sua vez, está diretamente relacionado com a taxa de crescimento do filme. Se em sistemas de CVD este parâmetro estabelece a taxa de dissociação da silana, em sistemas magnetron sputtering RF ele se relaciona tanto com a taxa de dissociação da molécula de hidrogênio como com a taxa de ionização do argônio. O aumento da quantidade de argônio ionizado produz um aumento do ataque iônico do alvo e, portanto, uma maior remoção de átomos silício que por sua vez se ligam a uma maior quantidade de hidrogênio dissociado disponível, para a formação de mais espécies $\mathrm{SiH}_{\mathrm{x}}$ que formam o filme em uma maior taxa.

Uma alternativa para o aquecimento do substrato durante a deposição, responsável pela produção de filmes com baixa densidade de defeitos, seria um recozimento posterior à deposição do filme durante um tempo prolongado. Esta opção pode ou não funcionar dependendo da estrutura do filme depositado. $\mathrm{Na}$ figura 1 é apresentada a comparação da fotocondutividade de um filme obtido à temperatura ambiente e depois recozido a $250{ }^{\circ} \mathrm{C}$ durante 1 hora com filmes depositados em temperaturas maiores e diferentes pressões parciais de hidrogênio [37].

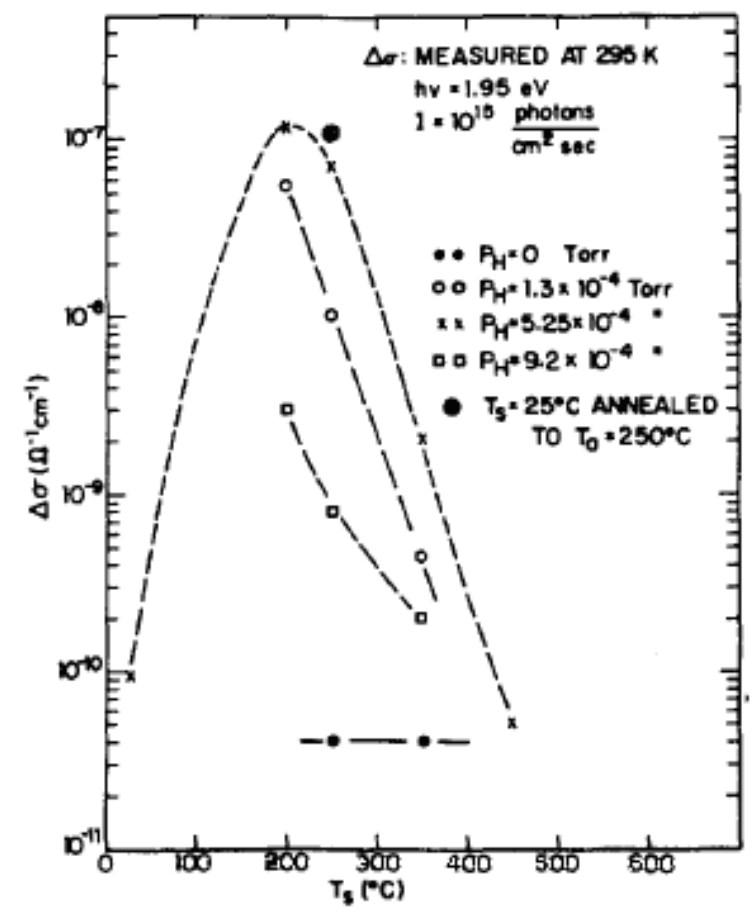

Figura 3 - Fotocondutividade a temperatura ambiente versus $T_{S}$ para amostras preparadas em diferentes. $\mathbf{P}_{\mathbf{H}}[37]$. 
A partir desta discussão sobre a influência dos parâmetros de deposição no comportamento estrutural dos filmes, pode-se dizer que as propriedades dos filmes de a-Si:H dependem fortemente das condições de deposição que modificam a quantidade de átomos de hidrogênio ligados à estrutura amorfa da matriz de silício. Apesar de temperaturas de deposição da ordem de $250{ }^{\circ} \mathrm{C}$ serem favoráveis para a produção de filmes com baixas densidades de defeitos, a obtenção e caracterização de filmes depositados a temperaturas menores que $200{ }^{\circ} \mathrm{C}$ é de grande interesse tecnológico atualmente, devido à possibilidade de utilização de substratos flexíveis que limitam a temperatura de processamento.

\subsection{Defeitos no a-Si:H}

A ordem de pequeno alcance da estrutura dos filmes amorfos é diretamente responsável por propriedades semicondutoras observáveis, tais como bordas de absorção óptica de fótons, que são absorvidos pela rede até que os elétrons excitados da banda de valência tenham energia suficiente para passarem para a banda de condução, e condutividade elétrica apropriada para este tipo de material, podendo desta forma ser aumentada pela introdução de dopantes [38]. Nesta magnitude a estrutura amorfa pode apresentar defeitos referentes às diferenças entre a estrutura amorfa considerada ideal. Como nesta estrutura ideal todas as ligações da estrutura amorfa são satisfeitas, todo átomo de silício tem número de coordenação quatro e está ligado a no máximo um átomo de hidrogênio que por sua vez deve apresentar número de coordenação igual a um.

Nos processos de deposição para se tentar desfazer-se das ligações incompletas, ao invés da abordagem de ligá-las entre si, átomos como o de hidrogênio e oxigênio ou até mesmo o de nitrogênio ou o de flúor podem ser usados para a terminação destas ligações através, por exemplo, da introdução destes no sistema de deposição. Desta forma ao passivarem os defeitos da estrutura de silício amorfo, contanto que todas as ligações destes átomos introduzidos estejam completas, a densidade de defeitos do filme de a-Si:H diminui. Todavia átomos como o de carbono ou o de germânio que possuem número de coordenação quatro agem apenas como substitutos dos átomos de silício, não podendo, desta forma, contribuir com a diminuição da quantidade de ligações incompletas. Apesar da 
introdução destes átomos poder reduzir a densidade de defeitos, ocorre também uma modificação de certas propriedades do silício com relação o material puro, como o aumento da largura da banda proibida no caso da introdução de hidrogênio em filmes de a-Si:H, que é característica da liga formada [38], como têm-se observado. Desta forma, caso fosse possível produzir filmes finos de a-Si:H sem qualquer defeito, ainda assim a largura da banda proibida seria maior no a-Si:H que no silício monocristalino.

Nos defeitos de coordenação um átomo tem um estado de ligação diferente do ideal [16], como ocorre quando o silício assume número de coordenação três. Neste caso o átomo de silício em seu estado neutro fica com uma ligação incompleta devido ao seu elétron desemparelhado. Neste processo o acúmulo de elétrons ou lacunas gera estados entre a banda de valência e a de condução que agem como centro de armadilhamento ou recombinação de carga durante o transporte eletrônico. Todavia no caso dos defeitos como os de espaços vazios, uma estrutura local diferente da do resto da rede amorfa é formada, como ocorre em amostras com muitos polihidretos de silício. Para este tipo de defeito fica difícil distinguir um espaço vazio de uma rede ideal, do ponto de vista de coordenação atômica.

\subsection{Estrutura atômica e densidade eletrônica de estados}

Para o silício se ligar a outros átomos de silício, tanto no material cristalino como no amorfo, são formadas quatro ligações híbridas $\mathrm{sp}^{3}$ com energia situada entre os dois orbitais s e p [19], tal como indicado na figura 4. Estas quatro ligações se arranjam geometricamente para a formação de uma estrutura tetraédrica que se repete periodicamente no caso do silício monocristalino e se estende em pequenas distâncias (aproximadamente $1 \mathrm{~nm}$ ) no caso do silício amorfo.

Quando os orbitais $\mathrm{sp}^{3}$ são preenchidos com elétrons de quatro átomos vizinhos de silício, estes orbitais adquirem uma energia menor e maior ao se dividirem em estados de ligação e anti-ligação, respectivamente. Num sólido, devido à atração coulombiana entre os núcleos e elétrons, estes estados separados formam estados estendidos contínuos correspondentes respectivamente às bandas de valência e de condução. Estas etapas para formação das bandas são representadas esquematicamente na também na figura 4 . 


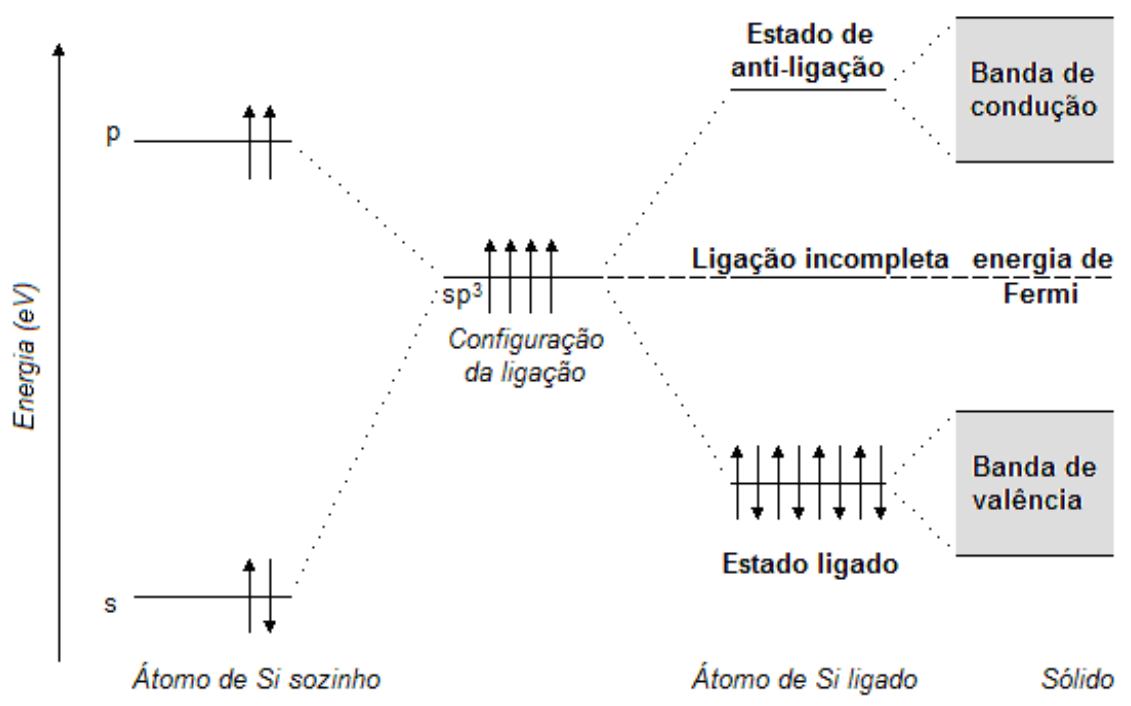

Figura 4 - Níveis de energia dos elétrons em diferentes estados de ligação [19].

Devido ao aspecto desordenado do material de a-Si:H são encontradas variações nos comprimentos e ângulos das ligações entre os átomos de silício. A tensão mecânica gerada por estas variações torna estas ligações fracas, provocando perturbações nos estados de energia de ligação e anti-ligação. Como conseqüência ocorre a formação de estados de cauda localizados dentro da banda proibida, indicadas na figura 5. Assim a concentração de ligações fracas está diretamente relacionada ao comprimento dos estados de cauda e, portanto, à largura total da banda de mobilidade.

Continuamente as ligações fracas se deformam e acabam facilmente se rompendo. Este rompimento das ligações fracas com alta tensão mecânica resulta na geração de duas ligações incompletas com o nível de energia da configuração $\mathrm{sp}^{3}$ preenchida com $50 \%$ de elétrons. Como o nível de Fermi corresponde à energia em que a probabilidade de ocupação eletrônica do estado é de $50 \%$ o nível de energia $\mathrm{sp}^{3}$ corresponde ao nível de Fermi. Assim, o a-Si:H é ligeiramente tipo $\mathrm{n}$ porque o nível de energia $\mathrm{sp}^{3}$ se aproxima um pouco mais da banda de condução que da de valência. Comparativamente falando, no material amorfo, o nível de Fermi é uma região de estados localizados presentes devido a existência de ligações incompletas com nível de energia $\mathrm{sp}^{3}$ e no material monocristalino esta energia é desprovida de estados. Na figura 5 a densidade eletrônica de estados em função da energia de Fermi está representada esquematicamente para o a-Si:H. 


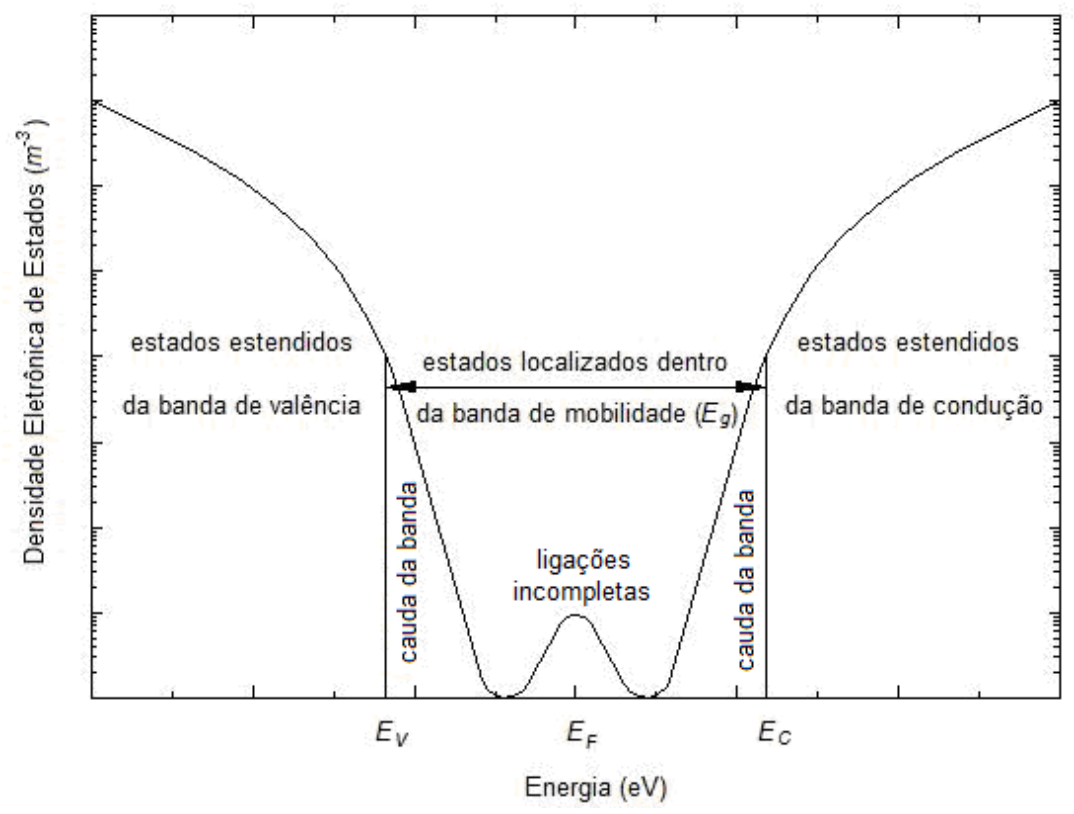

Figura 5 - Diagrama esquemático da densidade eletrônica de estados para um semicondutor amorfo, tal como o a-Si:H [19].

A quantidade e o tipo de ligações incompletas depende da forma estrutural da rede e aglomerados de rede no a-Si:H. Assim, as perturbações produzidas, além de formarem uma distribuição de elétrons dentro da banda proibida se dividem em três níveis para os estados de ligações incompletas: o nível abaixo da energia de Fermi, sendo ocupado por dois elétrons e, portanto, negativamente carregado; o nível de Fermi em si, sendo ocupado com apenas um elétron e, portanto, não carregado; e o nível ligeiramente acima do nível de Fermi não ocupado por elétrons, sendo, portanto, positivamente carregado.

As ligações rompidas eventualmente voltam a se ligar, sendo um equilíbrio estabelecido entre a quebra de ligações fracas com grande tensão mecânica e a união de ligações incompletas. Na dinâmica de formação de ligações incompletas a tensão mecânica local é liberada, podendo-se dizer que a largura das caudas das bandas diminui já que houve uma diminuição da densidade de estados localizados nas regiões perto dos estados estendidos das bandas. A liberação de tensão da rede produz um aumento da densidade de estados no nível de Fermi devido ao aumento do número de ligações incompletas.

O hidrogênio introduzido no sistema consome as ligações incompletas para a formação de ligações entre silício e hidrogênio. Neste processo o número de ligações incompletas diminui, assim como a densidade de estados no meio da banda proibida. Devido à diminuição de ligações fracas, com grande tensão 
mecânica, a tensão da rede é reduzida. Assim, como resultado da introdução de hidrogênio, a banda proibida aumenta com a diminuição da largura das caudas das bandas.

Atualmente para filmes de a-Si:H de boa qualidade depositados por PECVD, emprega-se aproximadamente 10 at. \% de hidrogênio. Até esta concentração aproximadamente, obtida pela espectroscopia de infravermelho e transformada de Fourier (FTIR), os átomos de silício se ligam preferencialmente com apenas um átomo hidrogênio. Na figura 6 é representado como os átomos de hidrogênio ficam próximos quando se ligam a ligações incompletas formadas pela quebra de ligações fracas com alta tensão mecânica. Para concentrações de hidrogênio maiores que 10 at. \%, dois átomos de hidrogênio acabam se ligando a um átomo de silício. Esta configuração propicia a formação de estruturas poliméricas lineares, como as observadas em alcanos lineares de carbono [19]. Maiores aumentos na concentração de hidrogênio acarretam na segregação do hidrogênio em micro-poros que podem ser grandes o suficiente para conter uma molécula.

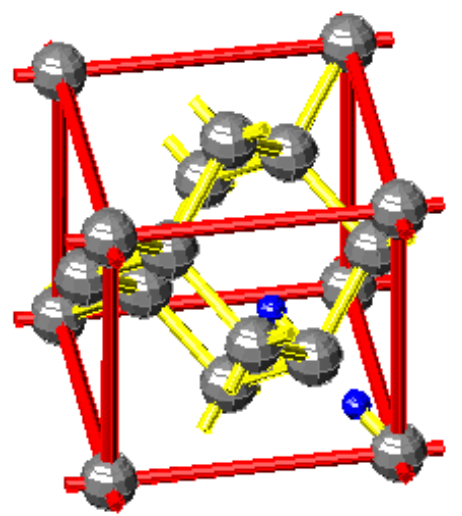

$\square$ Estrutura imaginária da célula unitária

Ligações químicas

Átomos de silício

Átomos de hidrogênio

Figura 6 - Representação de dois átomos de hidrogênio legados a dois átomos de silício em uma célula unitária onde havia uma ligação fraca.

\subsection{Mecanismos de condução}

Nos semicondutores amorfos considera-se que estados estendidos tanto da banda de valência como da banda de condução fazem fronteira com estados localizados de cauda nos limites da banda de mobilidade. Como nos estados estendidos a função de onda dos elétrons, que eventualmente ocupam estes estados, preenche todo o volume do material, nos estados de caudas das bandas os elétrons podem ocupar apenas estados localizados, fazendo com que a mobilidade 
dos portadores nos estados estendidos seja ordens de magnitude superior que a dos portadores nos estados de cauda.

Fazendo uma simplificação do modelo de bandas pela não distinção entre os estados localizados de cauda e os estados do nível de Fermi e considerando apenas um elétron em trânsito, os mecanismos de condução podem ser melhores descritos a partir do diagrama esquemático da figura 7 . Neste diagrama estão representados os estados localizados e estendidos da banda de valência e condução. $O$ eixo vertical corresponde à energia e o horizontal à distância ao longo do material. Nesta figura ainda é destacado que apenas os estados abaixo do nível de Fermi são preferencialmente preenchidos por elétrons.

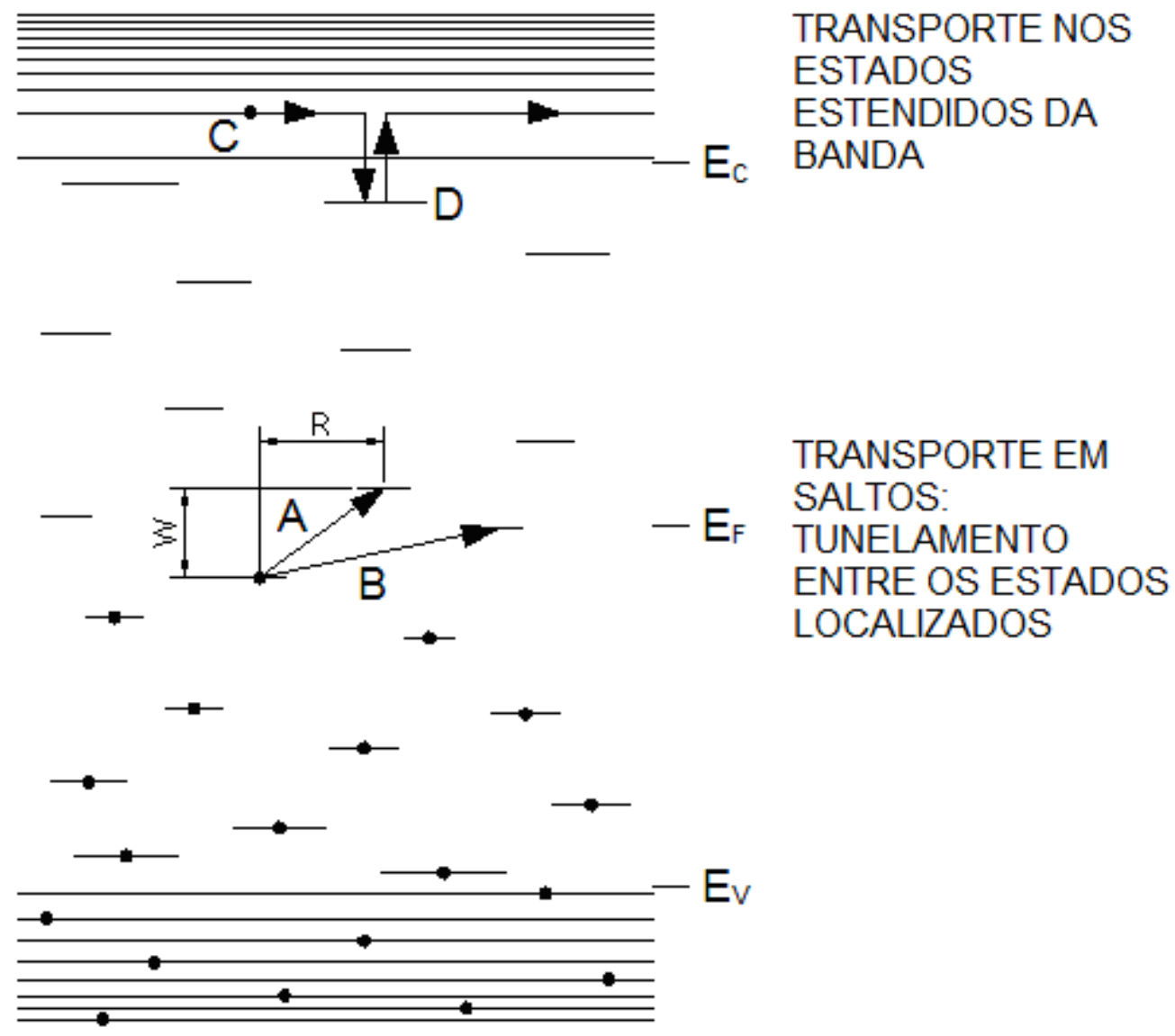

Figura 7 - Diagrama esquemático dos níveis de energia, sendo destacados os mecanismos de condução em um semicondutor amorfo. A direção vertical é o eixo da energia e a horizontal o da direção. [39].

A condução pode ocorrer tanto pelos estados estendidos da banda de condução como pelos localizados da banda proibida. Cada mecanismo ocorre preferencialmente em uma determinada faixa de temperatura. A zero grau Kelvin, em que não há condução em semicondutores monocristalinos, os portadores dos materiais amorfos conseguem saltar de um estado localizado para outro por 
mecanismos de tunelamento quântico que não envolvem fônons, quando uma tensão maior que $\mathrm{W}$ da figura 7 é aplicada. Este processo ocorre quando os estados localizados preenchidos têm o mesmo valor de posição na direção horizontal. À medida que a temperatura aumenta, a absorção e emissão de fônons passa a fazer parte do processo, fazendo com que alguns portadores consigam alcançar estados mais distantes com R maiores, como indicado na figura 7. Quando eles ganham energia suficiente ocorrem saltos para estados localizados cada vez mais próximos da banda de condução, com a probabilidade $(p)$ de ocorrer um salto para $A p(A)$ mais favorável de que para $B p(B)$. Na eq. (1) é apresentado um equacionamento desenvolvido por Mott [39] que relaciona a probabilidade de salto para um estado com uma dada distância e energia.

$$
p \sim \exp \left[-2 \alpha R-\left(\frac{W}{k T}\right)\right]
$$

Nesta equação o primeiro fator, $\exp (-2 \alpha R)$, expressa essencialmente a probabilidade de um elétron saltar ao longo da distancia $R$ a partir de um estado localizado inicial e o segundo, $\exp (-\mathrm{W} / \mathrm{kT})$, a probabilidade do elétron em superar a energia $W$ através da energia fornecida pela temperatura. Este modelo, proposto primeiro por Mott foi chamado de modelo em faixas variáveis. Nele é considerado que a densidade de estados localizados na faixa $\pm \mathrm{kT}$ em torno de $\mathrm{E}_{\mathrm{F}}$ é constante. Assim, para temperaturas baixas a condutividade varia muito pouco com a temperatura, como descrito pela eq. (2),

$$
\sigma_{s}=\sigma_{s 0} \exp -\left(\frac{\alpha_{s}}{T^{1 / 4}}\right)
$$

em que $\sigma_{\mathrm{s} 0}$ é o pré-fator da condutividade de salto e $\alpha_{\mathrm{s}}$ é uma constante. Com aumentos maiores da temperatura, os elétrons da cauda da banda de valência conseguem alcançar os estados da cauda da banda de condução. Nestas condições a temperatura passa a influenciar significativamente o mecanismo de condução, como pode ser observado na eq. (3),

$$
\sigma_{c}=\sigma_{c 0} \exp \left(\frac{E_{C c}-E_{F}}{k T}\right)
$$


em que $\mathrm{E}_{\mathrm{Cc}}$ expressa a energia média dos estados da cauda da banda de condução e $\sigma_{c 0}$ é um pré-fator. Nestas condições, os portadores passam a fluir pela banda de condução e são freqüentemente aprisionados pelos estados localizados da banda proibida próximos da borda de mobilidade, como indicado em $\mathrm{C}$ da figura 7. Depois de um certo tempo os portadores aprisionados em $D$ são liberados com uma taxa que cai exponencialmente com a diminuição da energia dos estados localizados envolvidos. Como o tempo durante o qual os portadores permanecem em movimento na banda de condução é muito menor que o tempo em que eles ficam aprisionados, a mobilidade de deriva dos portadores não consegue ser muito grande.

A condução por saltos entre os estados localizados da banda proibida dominam a condutividade dos semicondutores amorfos em uma faixa de temperatura muito ampla, competindo com a condução entre bandas dos estados estendidos em temperaturas que vão até a temperatura ambiente [39]. Como seria de imaginar a condutividade dos filmes de a-Si:H é muito baixa $\left(\sim 10^{-8} \Omega^{-1} \mathrm{~m}^{-1}\right)$, já que há 0 aprisionamento freqüente de portadores durante o transporte eletrônico. Todavia com a incidência de luz, com energia do fóton maior que a da banda proibida (banda de mobilidade), há a geração de pares elétron-lacuna nos estados estendidos, tal como ocorre no material monocristalino, e, portanto, um aumento drástico na condutividade nestas condições. Assim um bom material de a-Si:H, com uma baixa densidade de estados localizados na banda proibida, que servem como centro de recombinação e armadilhamento de cargas, consegue ter uma fotosensibilidade (razão entre fotocondutividade e condutividade de escuro) maior que $10^{6}$ quando a intensidade luminosa é AM1.5 (1500 $\mathrm{W} \mathrm{m}^{-2}$ ) [19], já que mais portadores conseguem alcançar a banda de condução e assim obter uma mobilidade maior que a dos portadores que conduzem pelos estados localizados da banda proibida. 


\section{DEPOSIÇÃO DE a-Si:H}

\subsection{Reator sputtering}

O reator magnetron sputtering RF tipo diodo do Laboratório de Sistemas Integrados (LSI) foi utilizado para a deposição de filmes finos de a-Si:H estudados neste trabalho. Em todos os processos a pressão base atingiu o valor de aproximadamente $1 \times 10^{-6}$ Torr, produzida por uma bomba turbomolecular em série com uma bomba mecânica. $O$ alvo utilizado foi de silício policristalino, com pureza de 99.999 \% e diâmetro de 6 polegadas. A distância entre o substrato e o alvo em todos os processos permaneceu em $10 \mathrm{~cm}$. Nas figuras 8 e 9 são apresentados, respectivamente, um esquema da câmara de deposição e uma foto do sistema magnetron sputtering RF utilizado. Neste sistema, para a deposição dos filmes, os gases foram injetados na câmara através de controladores de fluxo de massa e a pureza tanto do gás argônio como do hidrogênio utilizados foi 99,999 \%.

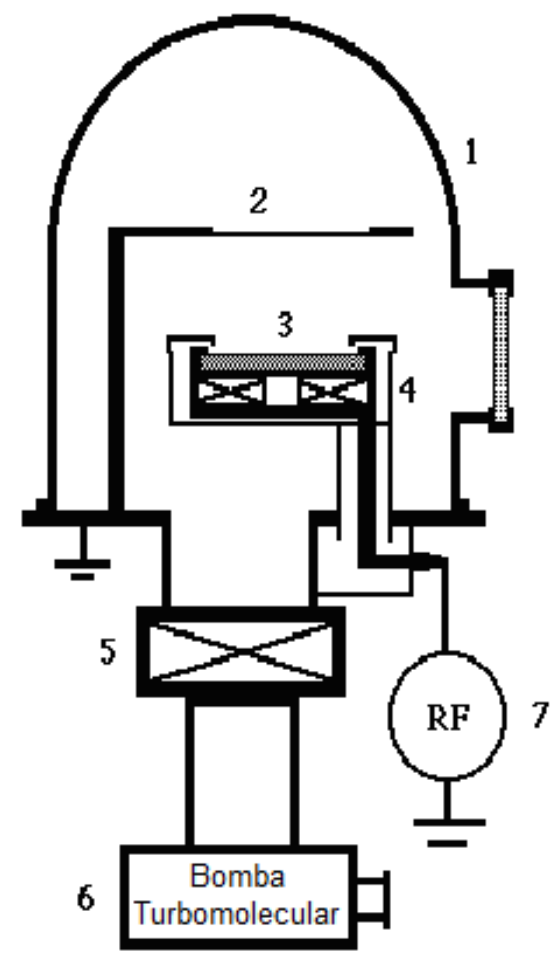

Figura 8 - Sistema de magnetron sputtering reativo: (1) Campânula de aço inoxidável, (2) porta amostra, (3) alvo, (4) eletrodo, (5) válvula gaveta, (6) bomba turbo molecular, (7) sistema de RF composto de malha de acoplamento e gerador de RF. 


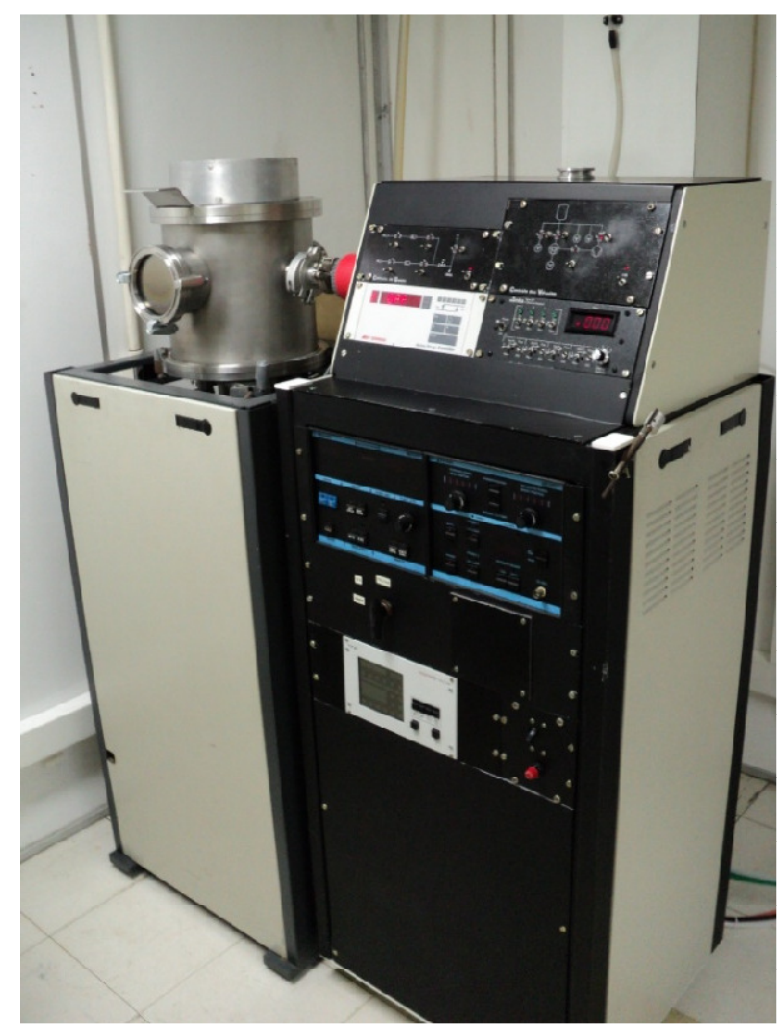

Figura 9 - Sistema magnetron sputtering reativo utilizado neste trabalho.

As etapas de deposição compreendem o posicinamento das amostras no portaamostra e do alvo no anodo; injeção de $\operatorname{Ar}$ e $\mathrm{H}_{2}$ nas devidas proporções para $\mathrm{O}$ alcance da pressão total desejada; e acionamento da fonte RF, com a potência previamente ajustada, para o início da deposição. Com o término do tempo estipulado, as deposições foram interrompidas pelo desligamento da fonte RF. Vale apena destacar que para a limpeza do alvo, toda a vez que o alvo foi montado, um plasma de argônio foi obtido por uma hora.

Para se tentar obter reprodutibilidade e baixa contaminação nos filmes depositados, antes de todos os conjuntos de deposições, a câmara do reator sputtering passou por um processo de limpeza. Neste processo a câmara foi limpa com um banho de água destilada e lixada com lixa d'água de granulação 600. A limpeza final foi feita com álcool isopropílico. Após esta etapas, titânio foi depositado por sputtering nas paredes para a absorção de partículas gasosas como vapores remanescentes da limpeza. 


\subsection{Parâmetros de deposição}

Filmes finos de a-Si:H foram depositados pelo sistema magnetron sputtering RF do LSI sobre substratos de carbono vítreo, placas de vidro para microscópio e lâminas de silício monocristalino ((100), $\phi=75 \mathrm{~mm}$, tipo $p, 1-10 \Omega . \mathrm{cm})$, polida em apenas um dos dados, oxidadas termicamente a $1150{ }^{\circ} \mathrm{C}$ com um fluxo de $2,5 \mathrm{~L} / \mathrm{min}$ de oxigênio por 2 horas. As temperaturas de deposição, estabelecidas pela temperatura do próprio plasma, foram menores que $100{ }^{\circ} \mathrm{C}$. Os substratos de carbono foram utilizados para que os filmes pudessem ser analisados por RBS e assim caracterizados em termos de contaminantes incorporados e densidade em peso volumétrica, os de vidro para a caracterização óptica pela extração dos valores da energia do "gap" óptico e os de silício monocristalino oxidados, para a extração dos espectros FTIR e condutividade elétrica a temperatura ambiente. Os espetros FTIR foram utilizados para a quantificação dos átomos de hidrogênio incorporados aos filmes e a condutividade foi obtida pela medida I-V dos filmes.

Os parâmetros de potência de RF, densidade de potência (razão entre a potência RF e a área do alvo) pressão total, tempo de deposição e concentração de hidrogênio nos gases de descarga $\left(\mathrm{Ar}+\mathrm{H}_{2}\right)$ são mostrados nas tabelas 1, 2 e 3 para o conjunto de amostras depositados na primeira $(A)$, segunda $(B)$ e terceira vez $(C)$.

Tabela 1 - Parâmetros de potência de RF (Pot.) densidade de potência (Dens. Pot.), pressão e concentração de hidrogênio nos gases de descarga $\left[\mathrm{H}_{2}\right]$ utilizados na deposição de a-Si:H sputtering reativo para as amostras do conjunto $(A)$ depositadas na primeira vez .

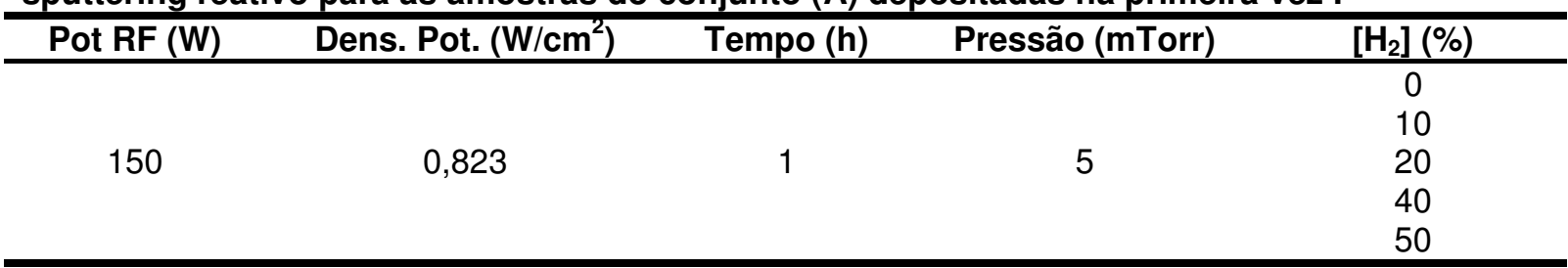

Tabela 2 - Parâmetros de potência de RF (Pot.) densidade de potência (Dens. Pot.), pressão e concentração de hidrogênio nos gases de descarga $\left[\mathrm{H}_{2}\right]$ utilizados na deposição de a-Si:H sputtering reativo para as amostras do conjunto $(B)$ depositadas na segunda vez .

\begin{tabular}{|c|c|c|c|c|}
\hline Pot RF (W) & Dens. Pot. $\left(\mathrm{W} / \mathrm{cm}^{2}\right)$ & Tempo (h) & Pressão (mTorr) & {$\left[\mathrm{H}_{2}\right](\%)$} \\
\hline 250 & 1,371 & 1 & 5 & $\begin{array}{c}0 \\
20 \\
40 \\
60 \\
\end{array}$ \\
\hline 250 & 1,371 & 1 & 10 & $\begin{array}{c}0 \\
20 \\
30 \\
50\end{array}$ \\
\hline
\end{tabular}


Tabela 3 - Parâmetros de de potência de RF (Pot.) densidade de potência (Dens. Pot.), pressão e concentração de hidrogênio nos gases de descarga $\left[\mathrm{H}_{2}\right]$ utilizados na deposição de a-Si:H sputtering reativo para as amostras do conjunto (C) depositadas na terceira vez .

\begin{tabular}{|c|c|c|c|c|}
\hline Pot RF (W) & Dens. Pot. $\left(\mathrm{W} / \mathrm{cm}^{2}\right)$ & Tempo (h) & Pressão (mTorr) & {$\left[\mathrm{H}_{2}\right](\%)$} \\
\hline 200 & 1,097 & 1 & 5 & $\begin{array}{l}20 \\
50\end{array}$ \\
\hline 200 & 1,097 & 1 & 10 & $\begin{array}{l}20 \\
40 \\
50\end{array}$ \\
\hline 250 & 1,371 & 1 & 5 & 50 \\
\hline 250 & 1,371 & 1 & 10 & $\begin{array}{l}20 \\
40 \\
50\end{array}$ \\
\hline 300 & 1,645 & 1 & 5 & 50 \\
\hline 300 & 1,645 & 1 & 10 & $\begin{array}{l}20 \\
40 \\
50\end{array}$ \\
\hline
\end{tabular}

\section{MEDIDAS}

A seguir será apresentada a metodologia de análise dos filmes de a-Si:H depositados pelo sistema magnetron sputtering RF. Apesar de as discussões dos resultados serem efetivamente apresentadas no capítulo 5, alguns resultados são mostrados aqui.

\subsection{Espessura dos filmes de a-Si:H}

O parâmetro de espessura é empregado para o tratamento dos dados das técnicas de caracterização, devendo, desta forma, ser precisamente determinado. 0 método escolhido para a obtenção deste parâmetro foi o de perfilometria em que medem-se os degraus feitos através de processos de litografia e de corrosão por plasma de $\mathrm{SF}_{6}$. Os valores obtidos de espessura média e taxa de deposição são mostrados nas tabelas 4, 5 e 6, sendo os gráficos das respectivas taxas de deposição mostrados nos gráficos (a) e (b) da figura 26 do capítulo 6 .

Tabela 4 - Valores de espessura e taxa de deposição (T. D.) dos filmes de a-Si:H depositados na primeira vez $(A)$.

\begin{tabular}{ccccc}
\hline Pot RF $(\mathbf{W})$ & $\mathbf{P}$ (mTorr) & {$\left[\mathbf{H}_{2}\right](\%)$} & Espessura $(\mathbf{n m})$ & T. D. $(\mathbf{n m} / \mathbf{s})$ \\
\hline \multirow{4}{*}{150} & 0 & 259 & 0,072 \\
& & 10 & 303 & 0,084 \\
& \multirow{2}{*}{5} & 20 & 245 & 0,068 \\
& & 40 & 271 & 0,075 \\
& 50 & 267 & 0,074 \\
\hline
\end{tabular}


Tabela 5 - Valores de espessura e taxa de deposição (T. D.) dos filmes de a-Si:H depositados na segunda vez (B).

\begin{tabular}{ccccc}
\hline Pot RF $(\mathbf{W})$ & $\mathbf{P}$ (mTorr) & {$\left[\mathbf{H}_{\mathbf{2}}\right](\%)$} & Espessura $(\mathbf{n m})$ & T. D. $\mathbf{( n m} / \mathbf{s})$ \\
\hline \multirow{3}{*}{250} & & 0 & 604 & 0,168 \\
& \multirow{2}{*}{5} & 20 & 679 & 0,189 \\
& & 40 & 687 & 0,191 \\
& 60 & 570 & 0,158 \\
\hline \multirow{3}{*}{250} & \multirow{3}{*}{10} & 0 & 563 & 0,156 \\
& & 20 & 698 & 0,194 \\
& & 30 & 666 & 0,185 \\
& 50 & 597 & 0,166 \\
\hline
\end{tabular}

Tabela 6 - Valores de espessura e taxa de deposição (T. D.) dos filmes de a-Si:H depositados na terceira vez (C).

\begin{tabular}{ccccc}
\hline Pot RF $(\mathbf{W})$ & $\mathbf{P}$ (mTorr) & {$\left[\mathbf{H}_{\mathbf{2}}\right](\%)$} & Espessura $(\mathbf{n m})$ & T. D. $(\mathbf{n m} / \mathbf{s})$ \\
\hline \multirow{2}{*}{200} & \multirow{2}{*}{5} & 20 & 360 & 0,100 \\
& & 50 & 384 & 0,107 \\
\hline \multirow{2}{*}{200} & \multirow{2}{*}{10} & 20 & 344 & 0,117 \\
& & 40 & 375 & 0,104 \\
250 & 5 & 50 & 412 & 0,114 \\
\hline \multirow{2}{*}{250} & \multirow{2}{*}{10} & 50 & 519 & 0,144 \\
& & 20 & 595 & 0,153 \\
& & 40 & 576 & 0,155 \\
300 & 5 & 50 & 522 & 0,145 \\
\hline \multirow{2}{*}{300} & \multirow{2}{*}{10} & 50 & 692 & 0,192 \\
& & 40 & 601 & 0,167 \\
& & 50 & 736 & 0,204 \\
& & & 698 & 0,194 \\
\hline
\end{tabular}

\subsection{RBS}

Os filmes de a-Si:H depositados sobre lâminas de carbono vítreo a $150 \mathrm{~W}$ e 5 mTorr na primeira vez (A) foram analisados por RBS do LAMFI (laboratório de análise de materiais por feixe iônico) do IF-USP com um feixe de $\mathrm{H}^{+}$. Seus espectros foram obtidos e simulados pelo programa SIMNRA. Os espectros e simulação SIMNRA são mostrados nas figuras 10,11, 12 e 13 e os parâmetros de ajuste da simulação para cada gráfico são mostrados nas tabelas 7, 8, 9 e 10. Nestas tabelas a densidade superficial simulada é referenciada como Dens. Sup. e as camadas são as que compõe os filmes simulados a partir da superfície (camada 1) até o substrato. 


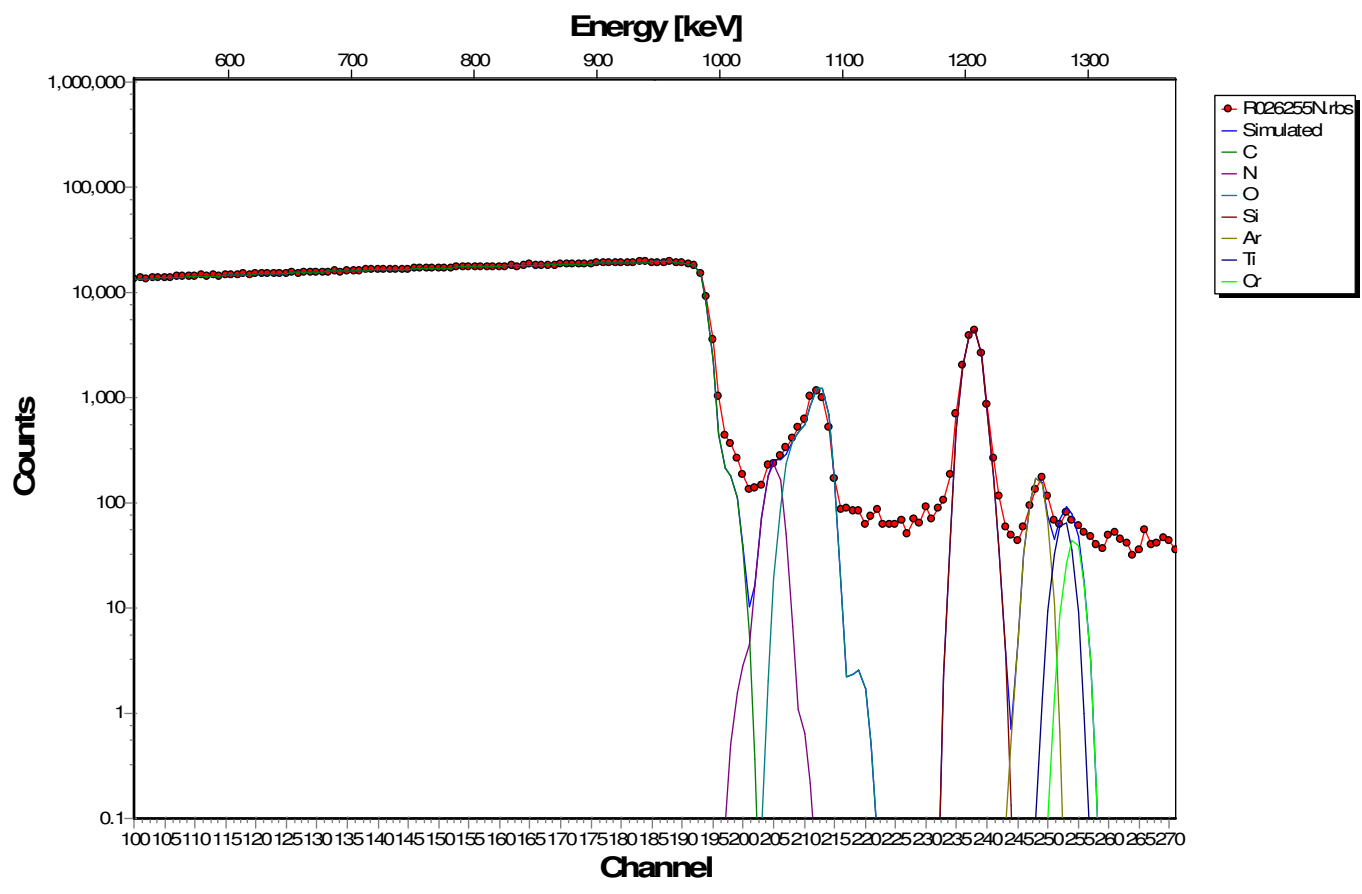

Figura 10 - a-Si:H depositado a 150 W, 5 mTorr e $0 \%$ de $\mathrm{H}_{2}$.

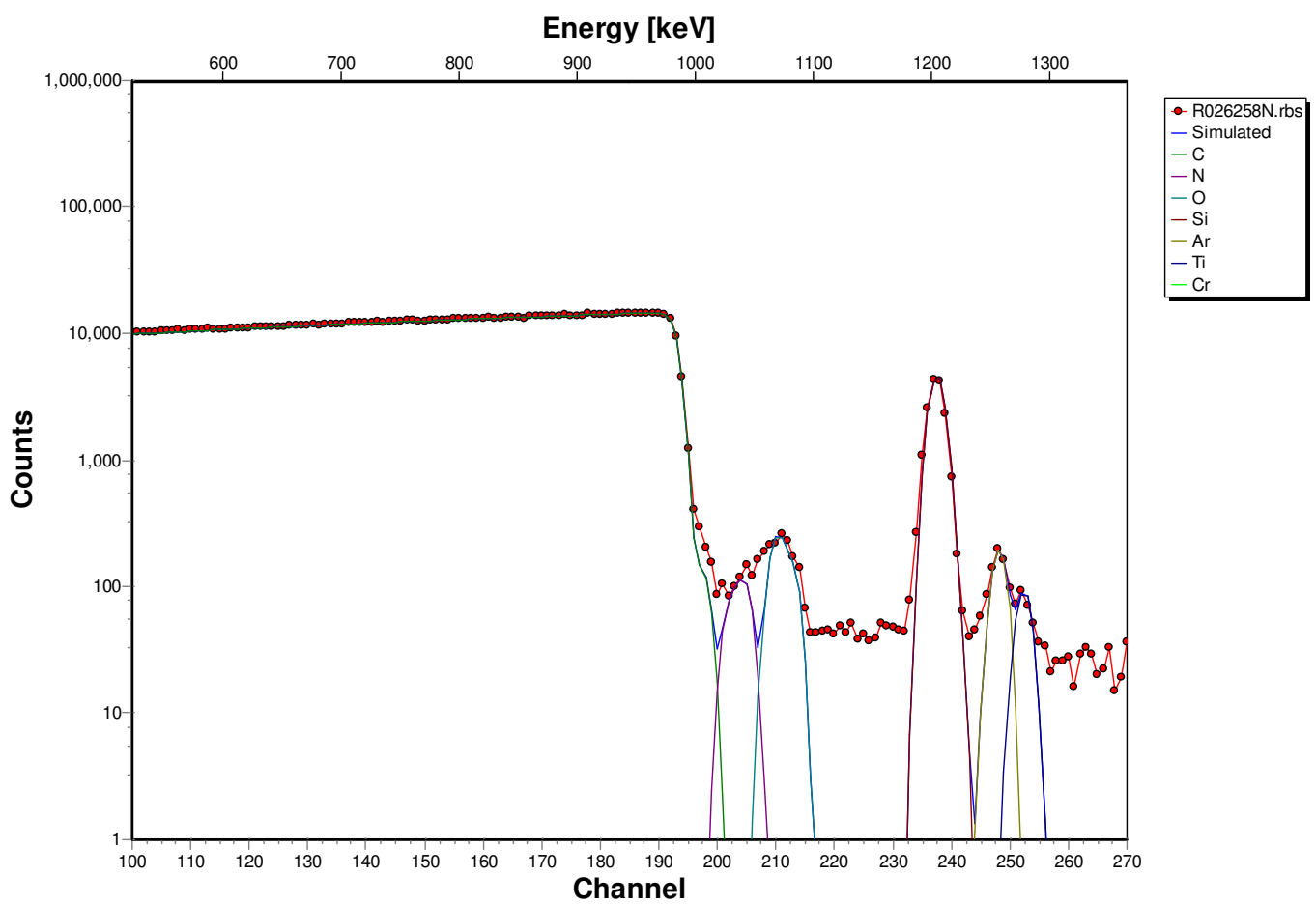

Figura 11 - a-Si:H depositado a $150 \mathrm{~W}, 5$ mTorr e $10 \%$ de $\mathrm{H}_{2}$. 


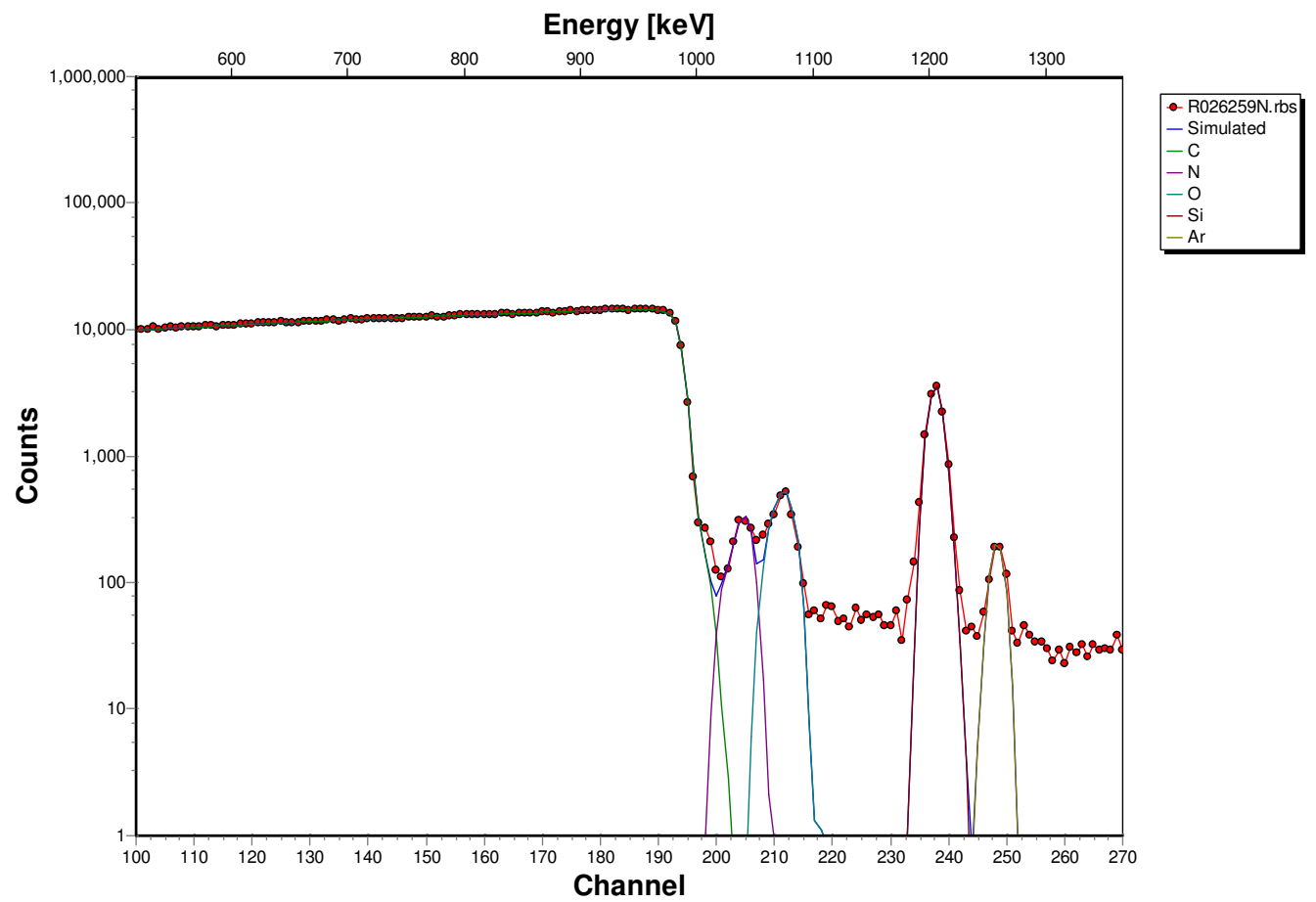

Figura 12 - a-Si:H depositado a $150 \mathrm{~W}, 5$ mTorr e $20 \%$ de $\mathrm{H}_{2}$.

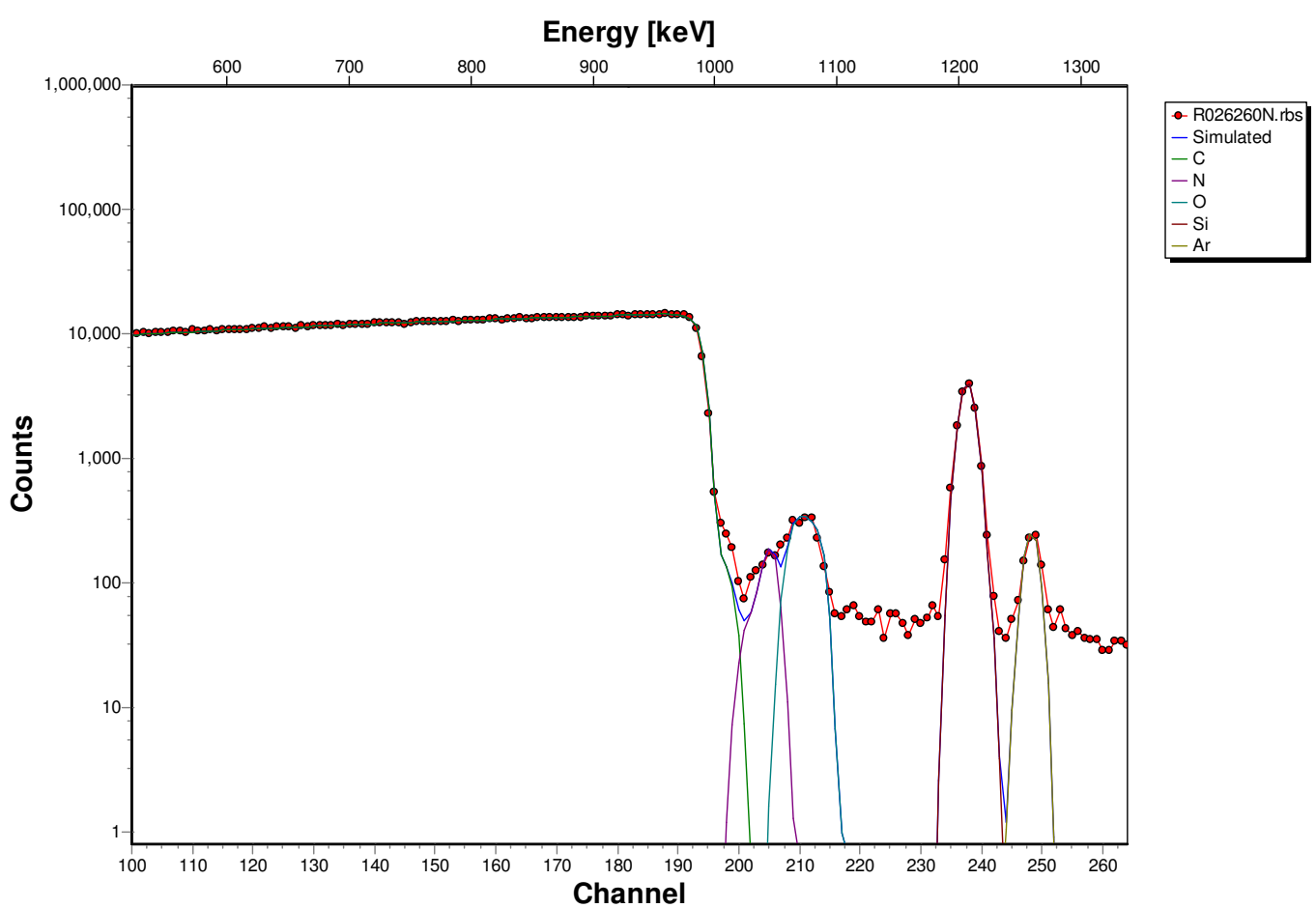

Figura 13 - a-Si:H depositado a $150 \mathrm{~W}, 5$ mTorr e $40 \%$ de $\mathrm{H}_{2}$.

Tabela 7 - Simulação SIMNRA do a-Si:H depositados a $150 \mathrm{~W}, 5 \mathrm{mTorr}$ e $0 \%$ de $\mathrm{H}_{2}$.

\begin{tabular}{ccccccccc}
\hline Camada & $\begin{array}{c}\text { Dens. Sup. } \\
\left(\mathbf{c m}^{-2}\right)\end{array}$ & $\mathbf{0}$ & $\mathbf{T i}$ & $\mathbf{A r}$ & $\mathbf{S i}$ & $\mathbf{C r}$ & $\mathbf{C}$ & $\mathbf{N}$ \\
\hline 1 & $1000 \times 10^{15}$ & 0,2451 & 0,0037 & 0,0139 & 0,6127 & 0,0020 & & \\
2 & $2900 \times 10^{15}$ & 0,0450 & & & & & 0,9500 & 0,0010 \\
3 & Substrato & & & & & & 1 & \\
\hline
\end{tabular}


Tabela 8 - Simulação SIMNRA do a-Si:H depositado a $150 \mathrm{~W}, 5 \mathrm{mTorr}$ e $10 \%$ de $\mathrm{H}_{2}$.

\begin{tabular}{ccccccccc}
\hline Camada & $\begin{array}{c}\text { Dens. Sup. } \\
\left(\mathbf{c m}^{-2}\right)\end{array}$ & $\mathbf{O}$ & $\mathbf{T i}$ & $\mathbf{A r}$ & $\begin{array}{c}\text { Composição } \\
\mathbf{S i}\end{array}$ & $\mathbf{C r}$ & $\mathbf{C}$ & $\mathbf{N}$ \\
\hline 1 & $50 \times 10^{15}$ & 0,08 & & & 0,92 & & & \\
2 & $1000 \times 10^{15}$ & 0,03923 & 0,00711 & 0,02206 & 0,85805 & & 0,07355 \\
3 & $1500 \times 0^{15}$ & 0,043 & & & & & 0,922 & 0,035 \\
4 & Substrato & & & & & & 1 & \\
\hline
\end{tabular}

Tabela 9 - Simulação SIMNRA do a-Si:H depositado a $150 \mathrm{~W}, 5 \mathrm{mTorr}$ e $20 \%$ de $\mathrm{H}_{2}$.

\begin{tabular}{ccccccccc}
\hline \multirow{2}{*}{ Camada } & $\begin{array}{c}\text { Dens. Sup. } \\
\left(\mathbf{c m}^{-2}\right)\end{array}$ & $\mathbf{O}$ & $\mathbf{T i}$ & $\mathbf{A r}$ & $\mathbf{S i}$ & $\mathbf{C r}$ & $\mathbf{C}$ & $\mathbf{N}$ \\
\hline 1 & $1000 \times 10^{15}$ & 0,07528 & & 0,02237 & 0,65 & & 0,05225 & 0,2 \\
2 & $90 \times 10^{15}$ & 0,5 & & & & 0,1 & 0,4 \\
3 & $2100 \times 10^{15}$ & 0,05 & & & & 0,9 & 0,05 \\
4 & Substrato & & & & & 1 & \\
\hline
\end{tabular}

Tabela 10 - Simulação SIMNRA do a-Si:H depositado a $150 \mathrm{~W}, 5 \mathrm{mTorr} \mathrm{e} 40 \%$ de $\mathrm{H}_{2}$.

\begin{tabular}{ccccccccc}
\hline Camada & $\begin{array}{c}\text { Dens. Sup. } \\
\left(\mathbf{c m}^{-2}\right)\end{array}$ & $\mathbf{0}$ & $\mathbf{T i}$ & $\mathbf{A r}$ & $\mathbf{S i}$ & $\mathbf{C r}$ & $\mathbf{C}$ & $\mathbf{N}$ \\
& $1000 \times 10^{15}$ & 0,065 & & 0,028 & 0,775 & & & 0,1321 \\
2 & $2100 \times 10^{15}$ & 0,05 & & & & & 0,93 & 0,02 \\
3 & Substrato & & & & & 1 & \\
\hline
\end{tabular}

\subsection{Coeficiente de absorção $(\alpha)$}

O coeficiente de absorção é utilizado tanto o tratamento numérico dos espectros de absorção óptica ou transmissão dos filmes de a-Si:H analisados tanto pela técnica FTIR como pela de absorção óptica no ultra-violeta até o visível. Desta forma aqui é apresentado um breve levantamento bibliográfico das principais metodologias de obtenção deste parâmetro assim como a efetivamente utilizada neste trabalho obtida por simplificações.

Para um feixe de luz que incide normalmente em uma superfície de silício polida nos dois lados, em que não há absorção ou reflexão associada à rugosidade superficial, danos ou anomalias, a transmitância pode ser determinada pela eq. (4),

$$
T \approx\left(1-R_{1}\right) e^{-\alpha t}-\left(1-R_{1}\right) R_{1} e^{-\alpha t}+\left(1-R_{1}\right) R_{1}^{2} e^{-\alpha 3 t}-\left(1-R_{1}\right) R_{1}^{3} e^{-\alpha 3 t}+\ldots
$$

em que t é a espessura da lâmina de silício, $R_{1}$ é a luz refletida na interface ar-silício, com as camadas de ar e silício sendo consideradas infinitamente espessas. Cada termo da série infinita da eq. (4) é associado com reflexões sucessivas da luz entre superfícies da lâmina de silício. 
A partir desta equação muitas outras surgiram para se tentar determinar o coeficiente de absorção. Brodsky [40], por exemplo, desconsiderou a interferência entre as refletâncias e aproximou a eq. (4) para a eq. (5),

$$
T=(1-R)^{2} e^{-\alpha d} /\left(1-R^{2} e^{-2 \alpha d}\right)
$$

em que $d$ é a espessura do filme e $R$ a reflexão em múltiplas interfaces determinada empiricamente. Fazendo com que $\mathrm{T}_{0}$ correspondesse à transmissão do substrato para $\alpha=0$, Brodsky obteve a partir da eq. (5) a eq. (6) que pode ser resolvida para $\alpha$ em termos da medida da transmitância $\mathrm{T}$.

$$
T=\frac{4 T_{0}^{2} e^{-\alpha d}}{\left(1+T_{0}\right)^{2}-\left(1-T_{0}\right)^{2} e^{-2 \alpha d}}
$$

Este método de análise é chamado de BCC já que foi desenvolvido Brodsky, Cardona e Cuomo, sendo bastante utilizado inclusive por Langford [41], uma vez que ele fornece uma boa aproximação de $\alpha$.

Outros autores como Connell e Lewis desenvolveram outros métodos tão bons quanto o BCC para a aproximação do coeficiente de absorção. Em sua aproximação o coeficiente de absorção pode ser obtido, conforme descrito por Freeman [42] pela eq. (7),

$$
\alpha=-\left(\frac{1}{t}\right) \ln \mid\left(\frac{1}{B}\right)\left\{A+\left[A^{2}+2 B T\left(1-R_{2} R_{3}\right)^{1 / 2}\right]\right\}
$$

em que $A=-\left(1-R_{1}\right)\left(1-R_{2}\right)\left(1-R_{3}\right), B=2 T\left(R_{1} R_{2}+R_{1} R_{3}-2 R_{1} R_{2} R_{3}\right)$, T é a transmitância e $R_{1}, R_{2}$ e $R_{3}$ são as refletâncias das interfaces entre ar-filme, filme substrato, e substrato-ar respectivamente.

Uma vez que a parte imaginária do índice de refração é sempre menor que 0,1, é válido calcular a refletância de uma superfície entre os meios a e b, usando os índices de refração $n_{a}$ e $n_{b}$, pela eq. (8). Assim os valores de $R_{1}, R_{2}$ e $R_{3}$ podem ser encontrados.

$$
R_{a b}=\left(\frac{n_{b}-n_{a}}{n_{b}+n_{a}}\right)^{2}
$$

Apesar da utilização destes dois métodos um tanto elaborados para a obtenção do coeficiente de absorção, uma abordagem mais simples pode utilizada, como 
sugerido por Harame [43] e Smith [44], utilizando-se a lei de Beer-Lambert mostrada na eq. (9), que além de desconsiderar as interferências entre as interfaces da eq. (4), desconsiderou também a luz refletida na interface ar-silício.

$$
\frac{T}{T_{0}}=e^{-\alpha(\omega) d}
$$

Na eq (9) T e $T_{0}$ são, respectivamente, a transmitância do filme e do substrato e d a espessura do filme. Neste trabalho este ultimo método foi o utilizado assim como a relação indicada na eq. (10) para a conversão aproximada da transmitância para absorbância [44].

$$
A=-\log _{10} T
$$

\subsection{FTIR}

Para a extração dos espectros FTIR, tanto o LME da POLI-USP como o LEM (laboratório de espectroscopia molecular) do IQ-USP foram utilizados. Os espectros de absorção no infravermelho com transformada de Fourier foram obtidos para todas as amostras, sendo utilizadas como substrato de referência, lâminas oxidadas na parte polida, em alguns casos correspondentes às próprias lâminas as quais foram depositados os respectivos filmes. Estes espectros extraídos são mostrados nas figuras 15-22 para cada condição de potência e pressão nas diversas concentrações de hidrogênio nos gases de descarga. Neles o eixo y se refere à razão entre o coeficiente de absorção $\alpha(\omega)$, calculado conforme descrito no item 5.3, e o número de onda $\omega$, para a melhor comparação entre amostras de diferentes espessuras e para a melhor observação de como é feito o cálculo da concentração das ligações conforme descrito a seguir. Ainda nestes gráficos os picos encontrados foram associados com modos vibracionais de possíveis moléculas. Para uma melhor compreensão, estes modos vibracionais são indicados na figura 14. 


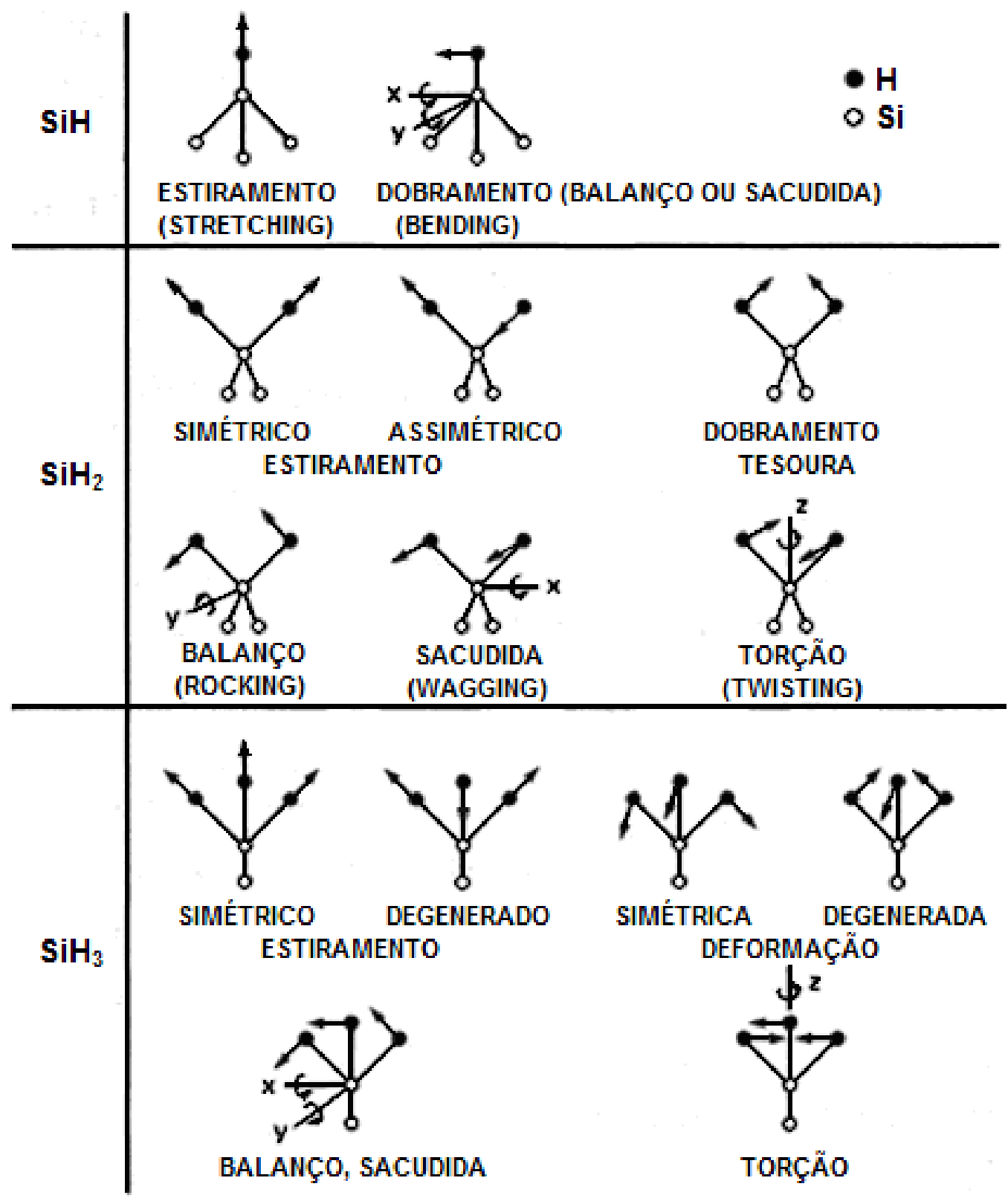

Figura 14 - llustração da referência [45] indicando as vibrações SiH locais para os grupos SiH, $\mathrm{SiH}_{2}$ e $\mathrm{SiH}_{3}$.

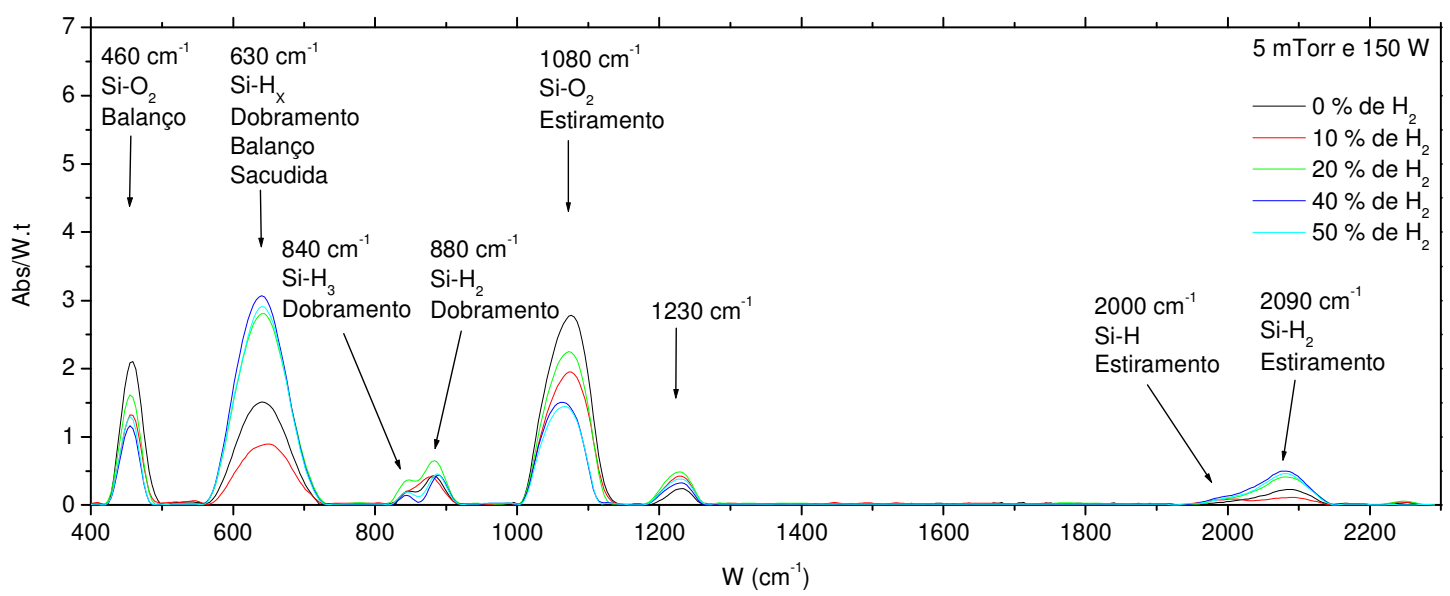

Figura 15 - Espectro de infravermelho dos filmes depositados a 5 mTorr e 150 W. 


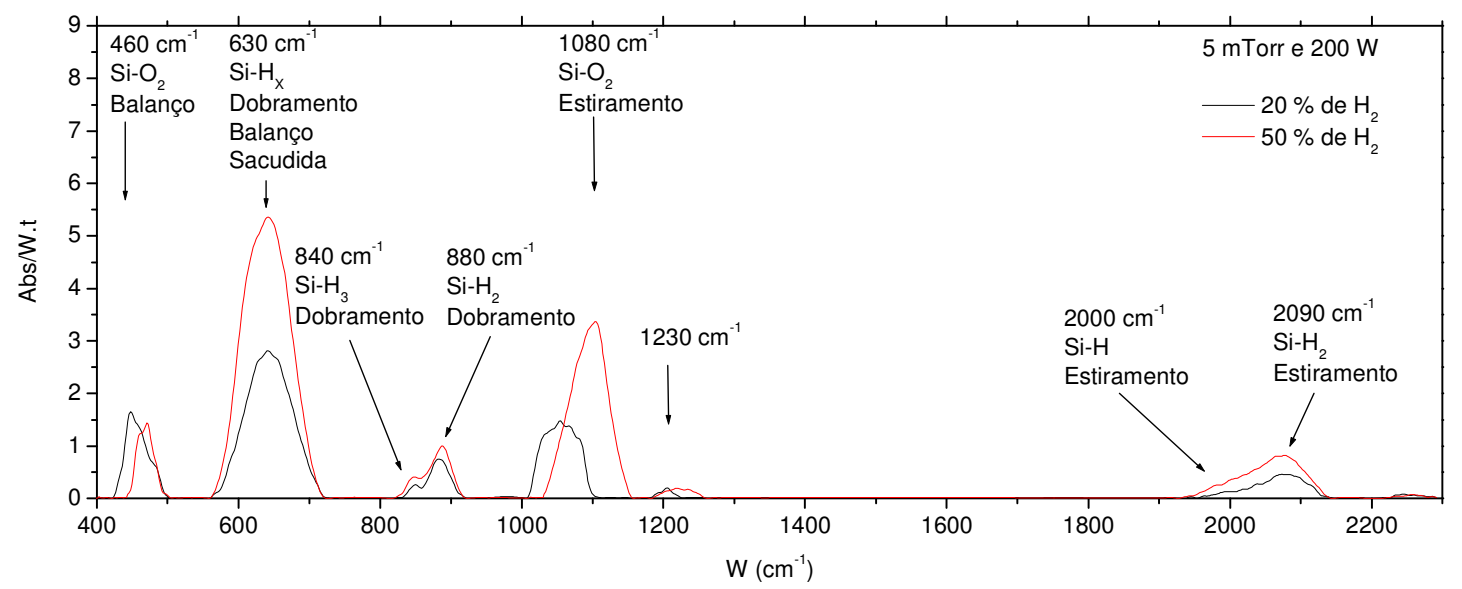

Figura 16 - Espectro de infravermelho dos filmes depositados a 5 mTorr e 200 W.

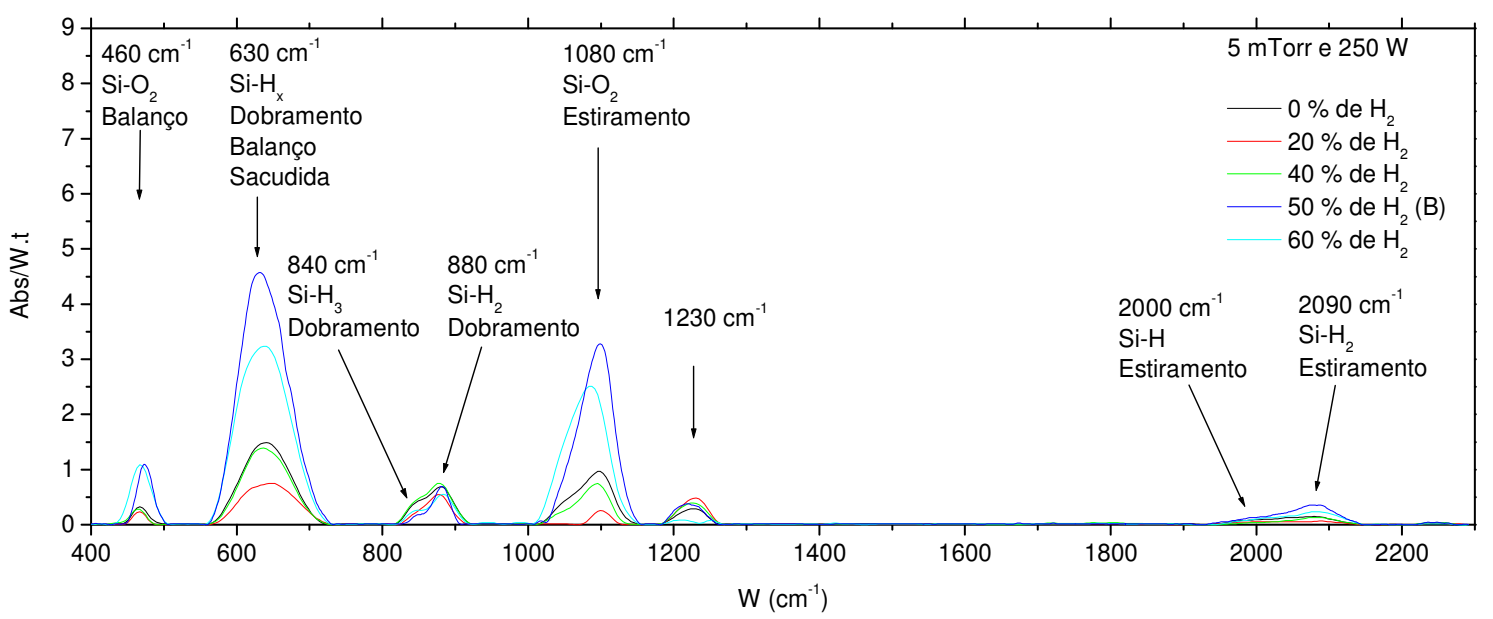

Figura 17 - Espectro de infravermelho dos filmes depositados a 5 mTorr e $250 \mathrm{~W}$.

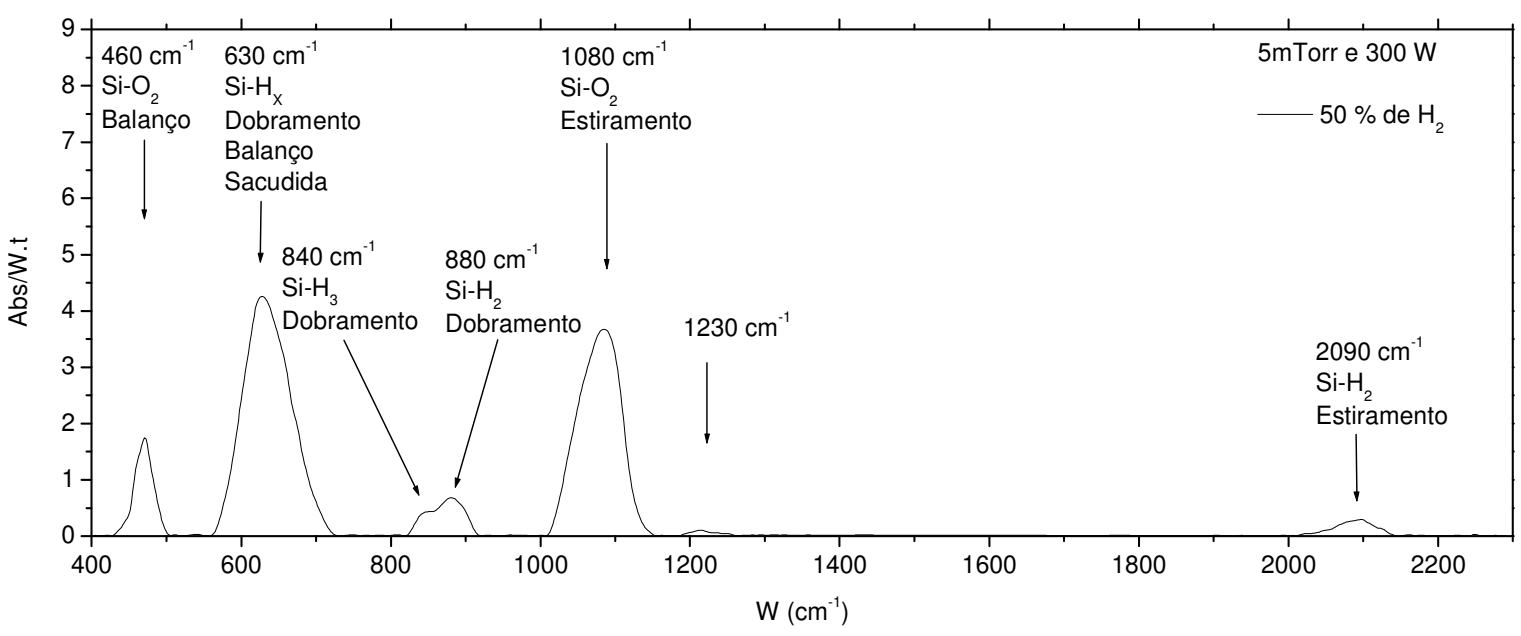

Figura 18 - Espectro de infravermelho dos filmes depositados a 5 mTorr e 300 W. 


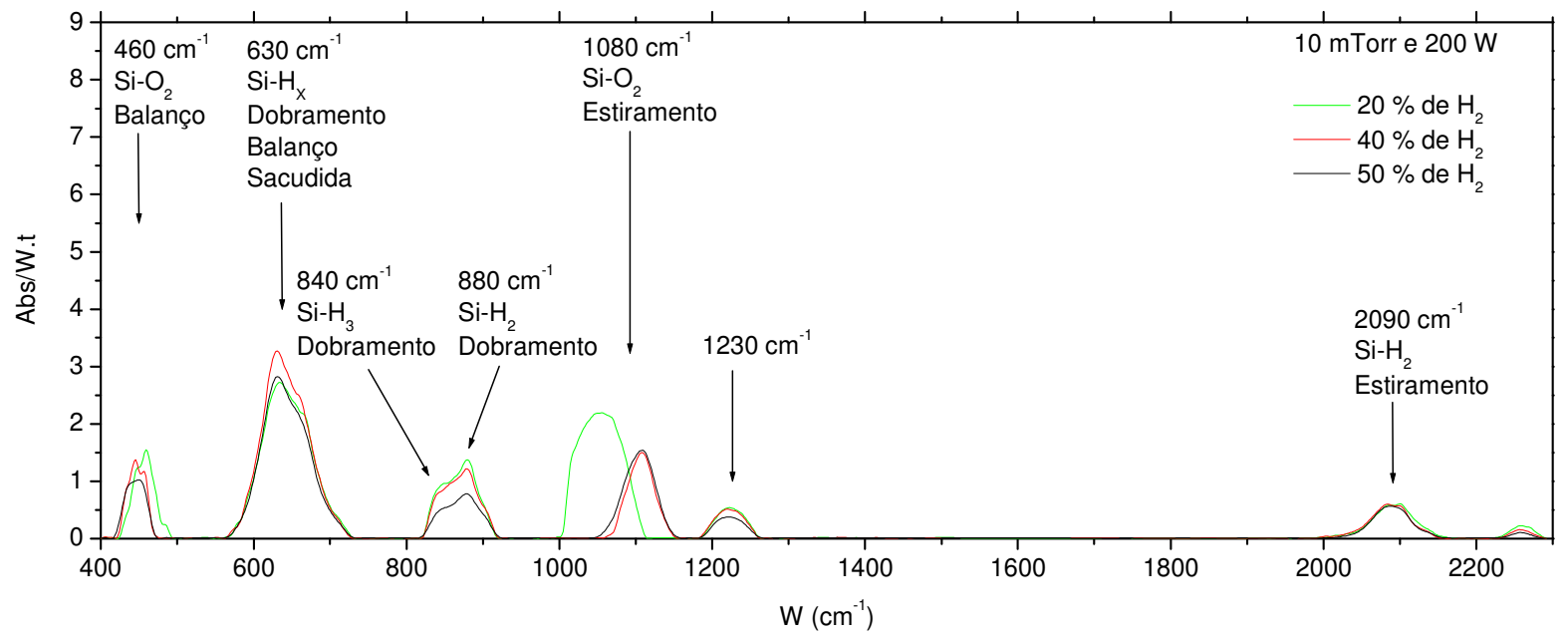

Figura 19 - Espectro de infravermelho dos filmes depositados a 10 mTorr e 200 W.

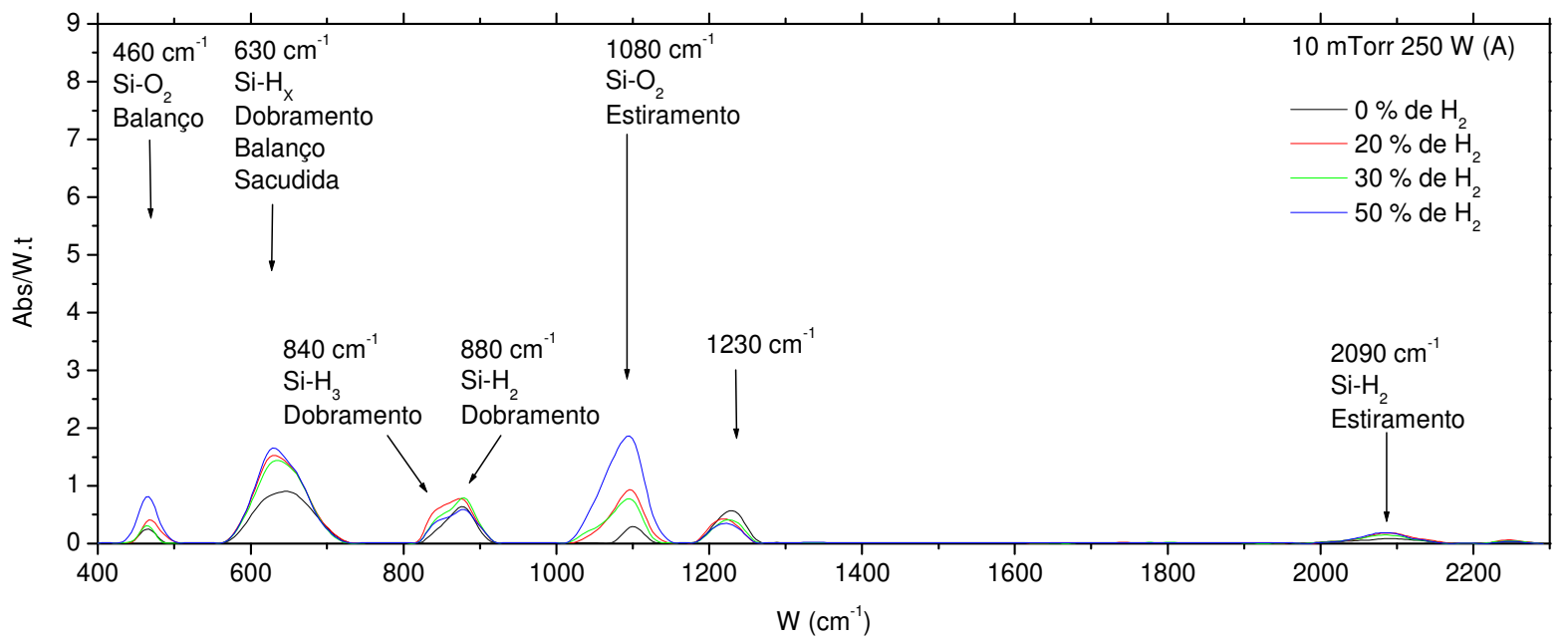

Figura 20 - Espectro de infravermelho dos filmes depositados a 10 mTorr e 250 W (A).

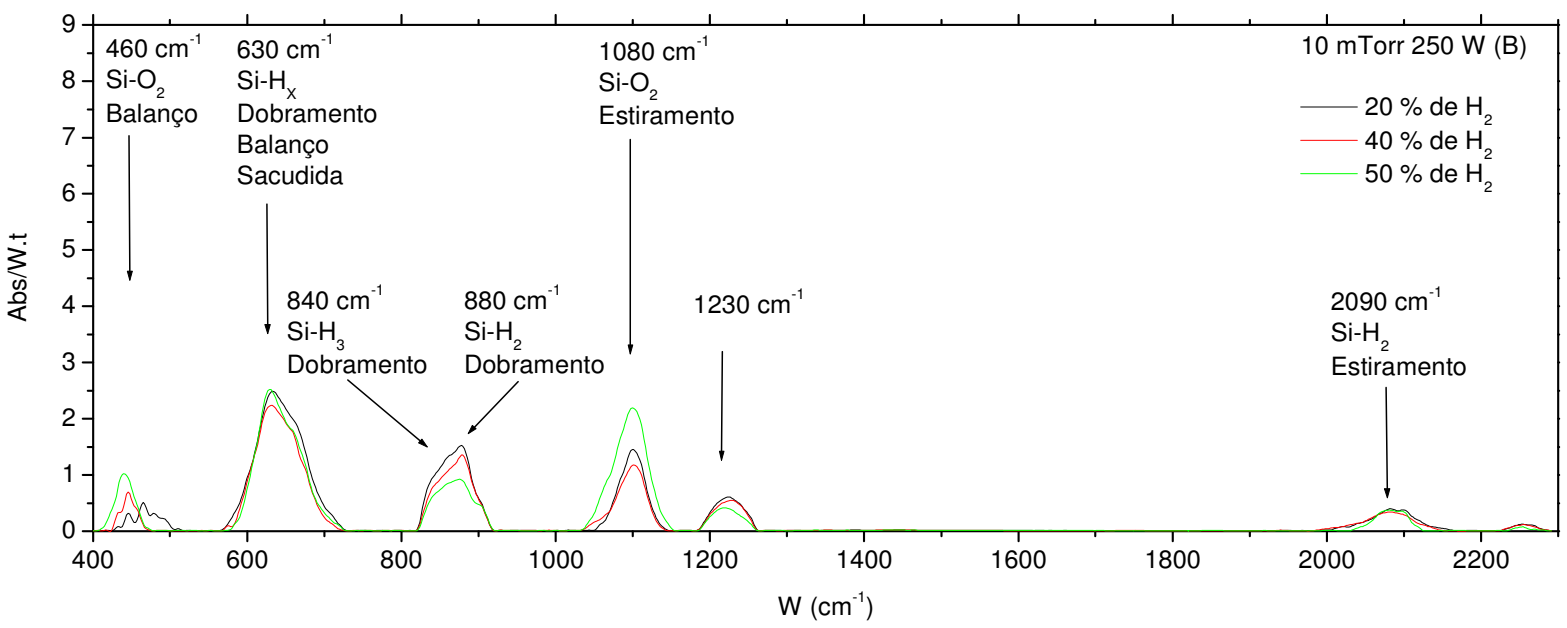

Figura 21 - Espectro de infravermelho dos filmes depositados a 10 mTorr e 250 W (B). 


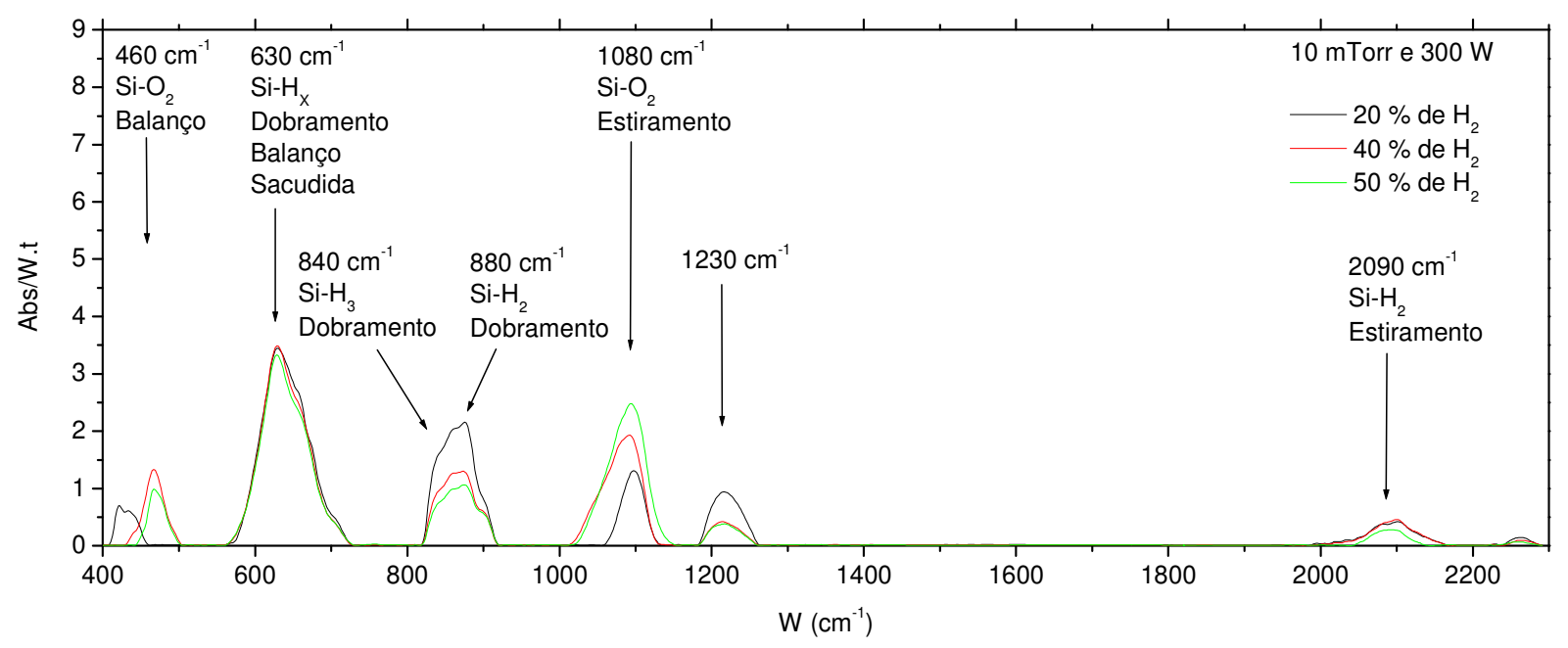

Figura 22 - Espectro de infravermelho dos filmes depositados a 10 mTorr e 300 W.

Para a quantificação da concentração de ligações, principalmente entre os átomos de silício e hidrogênio de interesse neste trabalho, são utilizadas equações que relacionam a força de oscilação $I$ com a constante de proporcionalidade $A$ de cada banda de absorção através da utilização da eq. (11) [41]. Assim, com as devidas constantes de proporcionalidades é possível obter a contração de cada tipo de ligação dos gráficos 15-22 pela integração das áreas de cada banda e multiplicação com seus respectivos valores de $A$.

$$
N_{H}=A I, \quad \text { em que } \quad I=\int(\alpha(\omega) / \omega) d \omega
$$

\subsection{Espectroscopia de absorção no ultravioleta-visível}

A espectroscopia de ultravioleta foi realizada no LACIFID (laboratório de cristais iônicos, filmes finos e datação) do IF-USP para a obtenção do espectro de absorção óptica das amostras depositadas sobre placas de vidro. A partir destes espectros tanto os valores de energia do "gap" óptico $E_{g}$ como os de $B$, que dá informações sobre a distribuição de estados no "gap" pertos das bandas, puderam ser obtidos. Para tanto a relação da eq. (12) foi considerada [42],

$$
(\alpha h v)^{1 / 2}=B\left(h v-E_{0}\right)
$$

em que $h$ é a constante de Planck e $v$ a freqüência da radiação. Este valor de $B$ é inversamente proporcional à largura das caudas das bandas de energia que surgem devido às ligações fracas de grande tensão mecânica no a-Si:H, diretamente 
relacionadas com a densidade de defeitos. Ele pode ser determinado pela inclinação de $\sqrt{\alpha h v} \times h v$ e $\mathrm{Eg}_{\mathrm{opt}}\left(\mathrm{E}_{0}\right)$ através da interseção da curva com a abscissa [46], embora o método seja menos sensível que o CPM (método de fotocorrente constante) e o PDS (espectroscopia de deflexão fototérmica) [19]. Nas tabelas 11 e 12 estão contidos os valores de $\mathrm{Eg}$ e parâmetros $B$ obtidos para as amostras depositadas na primeira $(A)$ e terceira vez $(C)$. No apêndice $B$ estão os gráficos $A$ partir dos quais foram extraídos estes valores. Estes resultados são efetivamente analisados no item 6.4 do capítulo 6.

Tabela 11 - Valores de Eg e parâmetro B das amostras depositadas pela primeira vez (A).

\begin{tabular}{ccccc}
\hline Pot RF $(\mathbf{W})$ & $\mathbf{P}$ (mTorr) & {$\left[\mathbf{H}_{2}\right](\%)$} & $\mathbf{B}(\mathbf{e V} . \mathbf{c m})^{-1 / 2}$ & $\mathbf{E g}(\mathbf{e V})$ \\
\hline & & 0 & 592 & 2,02 \\
\multirow{2}{*}{150} & 10 & 543 & 1,99 \\
& \multirow{2}{*}{5} & 20 & 641 & 1,99 \\
& & 40 & 662 & 2,06 \\
& & 50 & 575 & 1,99 \\
\hline
\end{tabular}

Tabela 12 - Valores de Eg e parâmetro B das amostras depositadas pela terceira vez (C).

\begin{tabular}{ccccc}
\hline Pot RF $(\mathbf{W})$ & $\mathbf{P}$ (mTorr) & {$\left[\mathbf{H}_{\mathbf{2}}\right](\%)$} & $\mathbf{B}(\mathbf{e V} . \mathbf{c m})^{-1 / 2}$ & $\mathbf{E g}(\mathbf{e V})$ \\
\hline \multirow{2}{*}{200} & \multirow{2}{*}{5} & 20 & 680 & 1,66 \\
& & 50 & 417 & 1,88 \\
\hline \multirow{2}{*}{200} & \multirow{2}{*}{10} & 20 & 690 & 2,48 \\
& & 40 & 719 & 2,43 \\
250 & 5 & 50 & 714 & 2,50 \\
\hline \multirow{2}{*}{250} & \multirow{2}{*}{10} & 20 & 559 & 2,05 \\
& & 40 & 472 & 2,22 \\
\multirow{2}{*}{300} & 5 & 50 & 559 & 2,28 \\
\multirow{2}{*}{300} & \multirow{2}{*}{10} & 20 & 637 & 2,40 \\
& & 40 & 476 & 1,97 \\
& & 50 & 565 & 2,14 \\
& & & 508 & 2,16 \\
\end{tabular}

\subsection{Condutividade}

A condutividade de escuro e a fotocondutividade das amostras de a-Si:H foram obtidas pelo levantamento de curvas de corrente-tensão (I-V) nas amostras sobre as quais foram evaporados dois contatos de alumínio através de uma máscara mecânica com aberturas para a deposição de alumínio na forma de tiras paralelas. $\mathrm{Na}$ figura 23 está representada a amostra com seus contatos, estando também indicadas as dimensões dos contatos. 


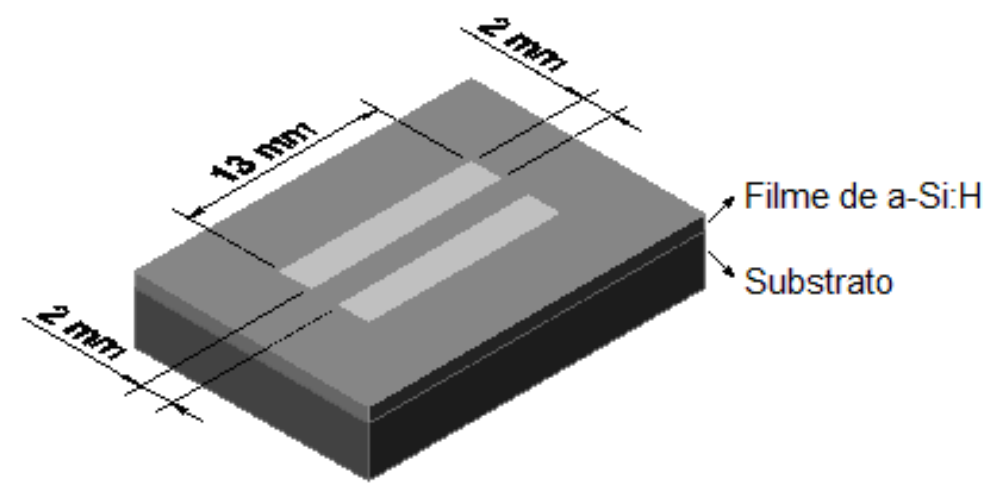

Figura 23 - Representação dos contatos de alumínio com suas dimensões.

Em todas as medidas foram levantadas curvas I-V com a tensão aplicada variando de 0 a $10 \mathrm{~V}$ e computados os valores de corrente. As medidas de amostras que não apresentaram contato ôhmico foram desconsideradas.

As amostras foram medidas na condição de escuro e de claro, esta última com uma lâmpada halógena dicróica de $50 \mathrm{~W}$ calibrada com uma foto-célula padrão para a intensidade luminosa AM1 $\left(100 \mathrm{~mW} / \mathrm{cm}^{2}\right)$ em termos de inclinação e posição conforme mostrado na figura 24 (a). Nesta calibração a tensão elétrica da fotocélula tinha que atingir o valor correspondente à intensidade luminosa AM1 com a aproximação da lâmpada. Estando a lâmpada calibrada, ela foi posicionada no Agilent 4156C (Precision Semiconductor Parameter Analyzer) do LSI conforme indicado na figura 24 (b).

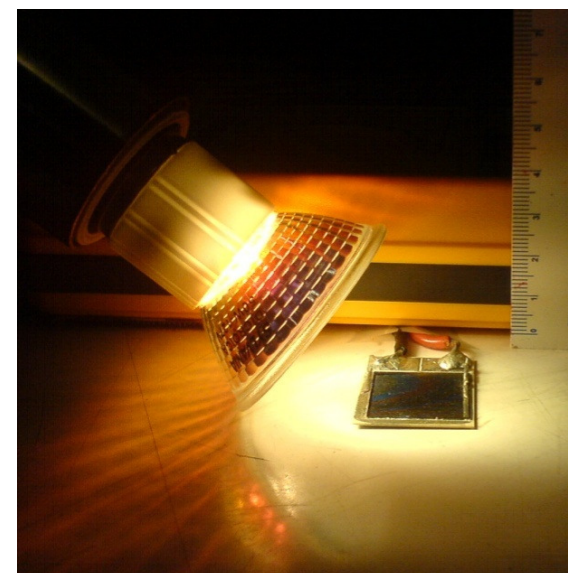

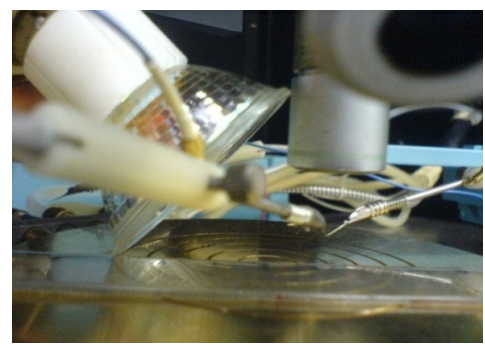

(b)

(a)

Figura 24 - Foto de calibação da lâmpada halógena dicróica em termos de inclinação e posição para a intensidade AM1 medida pela fotocélula (a) e posicionamento da lâmpada no equipamento de medida I-V para a medida de I-V no claro com a intensidade AM1 (b). 
Para cada condição de deposição foram medidas de 2 a 4 amostras para a obtenção de um valor médio de condutividade, conforme descrito abaixo. Em cada medida a curva I-V no escuro foi medida uma vez e a curva no claro foi medida de 5 a 7 vezes. Como exemplo na figura 25 são mostradas as curvas I-V extraídas da amostra depositada pela segunda vez (B) a $250 \mathrm{~W}, 10$ mTorr e $30 \%$ de hidrogênio nos gases de descarga. Neste gráfico pode ser observado que são obtidos valores positivos e negativos de fotocorrente o que se deve a utilização de uma lâmpada que irradia a $60 \mathrm{~Hz}$ que alterna ciclicamente a tensão aplicada em seus terminais. Assim, como houve simetria entre os valores positivos e negativos de fotocorrente, poderiam ser consideradas tanto a parte positiva como a negativa das curvas.

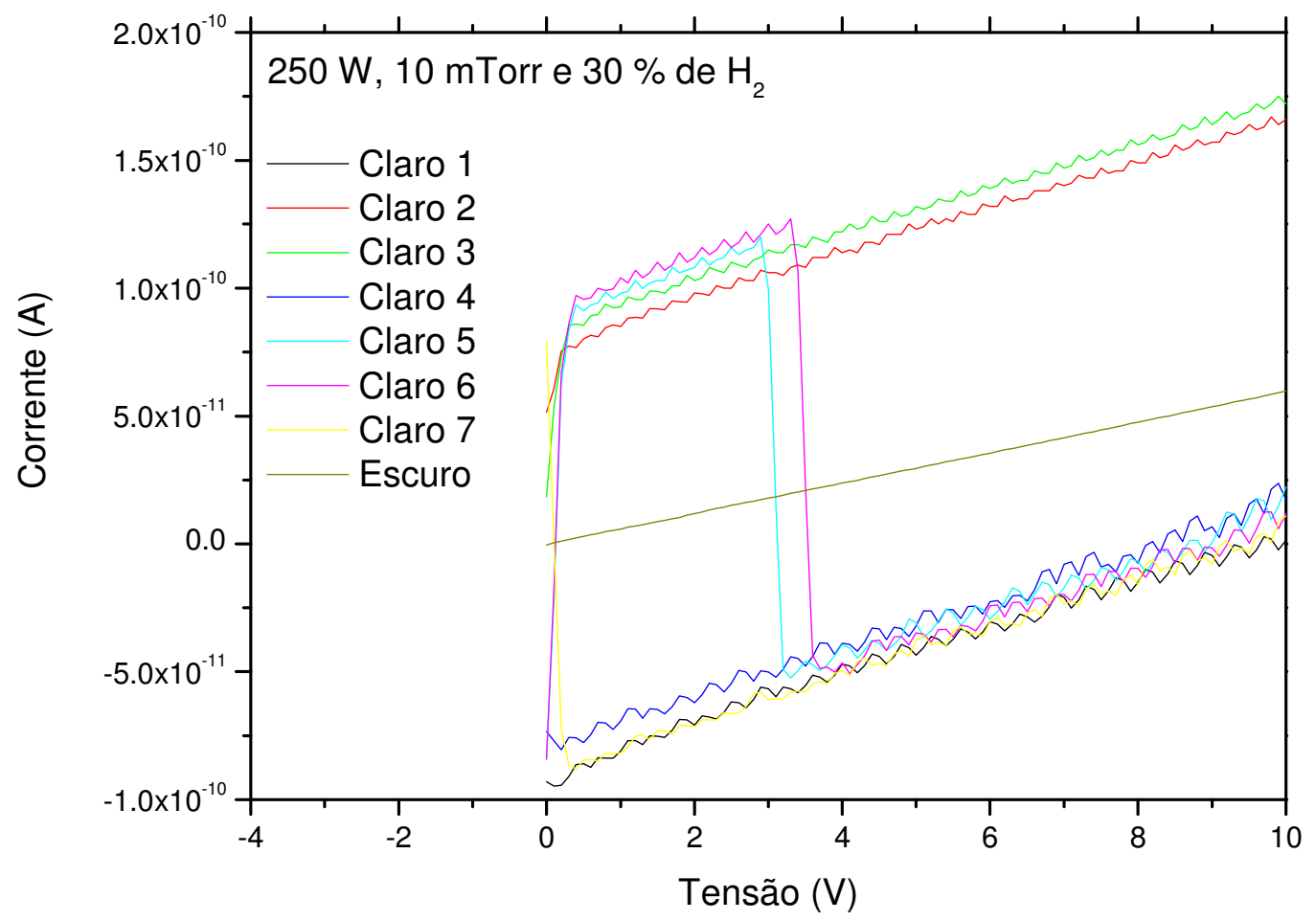

Figura 25 - Curva I-V no escuro e no claro esta ultima com a lâmpada halógena ajustada para a intensidade AM1. Esta amostra foi a depositada da segunda vez (B) a $250 \mathrm{~W}, 10 \mathrm{mTorr}$ e $30 \%$ de $\mathrm{H}_{2}$ nos gases de descarga.

Os valores de condutividade de escuro de fotocondutividade foram obtidos, respectivamente, pelas eq. (13) e (14)

$$
\sigma_{\text {escuro }}=\frac{L}{W . t} \cdot \frac{i_{\text {escuro }}}{V}
$$




$$
\sigma_{\text {foto }}=\frac{L}{W . t} \cdot \frac{i_{\text {foto }}}{V}
$$

em que $L$ é a distância entre os contatos, $W$ o comprimento e $i_{\text {foto }}$ a diferença entre a corrente com iluminação e sem iluminação. Os resultados obtidos são mostrados nas tabelas 13, 14 e 15 para as amostras depositadas pela primeira (A), segunda (B) e terceira vez $(C)$.

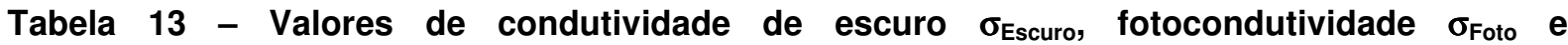
Fotosensibilidade das amostras de a-Si:H depositadas pela primeira vez (A).

\begin{tabular}{cccccc}
\hline Pot RF $(\mathrm{W})$ & $\mathbf{P}$ (mTorr) & {$\left[\mathrm{H}_{\mathbf{2}}\right](\%)$} & $\sigma_{\text {Escuro }}(\boldsymbol{\Omega} . \mathbf{c m})^{-1}$ & $\boldsymbol{\sigma}_{\text {Foto }}(\boldsymbol{\Omega} . \mathbf{c m})^{-1}$ & Fotosensibilidade \\
\hline \multirow{4}{*}{150} & & 0 & $3,07 \times 10^{-5}$ & $3,00 \times 10^{-4}$ & 10 \\
& & 10 & $1,85 \times 10^{-5}$ & $4,35 \times 10^{-4}$ & 23 \\
& 5 & 20 & $1,86 \times 10^{-6}$ & $3,80 \times 10^{-4}$ & 204 \\
& & 40 & $3,12 \times 10^{-7}$ & $3,19 \times 10^{-4}$ & 1025 \\
& & 50 & $1,43 \times 10^{-5}$ & $3,04 \times 10^{-4}$ & 21 \\
\hline
\end{tabular}

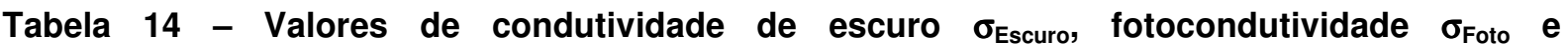
Fotosensibilidade das amostras de a-Si:H depositadas pela segunda vez (B).

\begin{tabular}{cccccc}
\hline Pot RF $(\mathbf{W})$ & $\mathbf{P}$ (mTorr) & {$\left[\mathrm{H}_{2}\right](\%)$} & $\sigma_{\text {Escuro }}(\Omega . \mathbf{c m})^{-1}$ & $\sigma_{\text {Foto }}(\Omega . c m)^{-1}$ & Fotosensibilidade \\
\hline \multirow{4}{*}{250} & & 0 & $1,85 \times 10^{-6}$ & $3,79 \times 10^{-4}$ & 205 \\
& \multirow{2}{*}{5} & 20 & $1,12 \times 10^{-6}$ & $2,22 \times 10^{-4}$ & 197 \\
& & 40 & $3,87 \times 10^{-6}$ & $3,41 \times 10^{-4}$ & 88 \\
& & 60 & $5,84 \times 10^{-7}$ & $2,88 \times 10^{-4}$ & 566 \\
\hline \multirow{4}{*}{250} & \multirow{2}{*}{10} & 0 & $2,89 \times 10^{-7}$ & $7,61 \times 10^{-3}$ & 545 \\
& & 20 & $1,43 \times 10^{-7}$ & $2,25 \times 10^{-4}$ & 2865 \\
& & 30 & $8,99 \times 10^{-8}$ & $2,82 \times 10^{-4}$ & 3140 \\
\hline
\end{tabular}

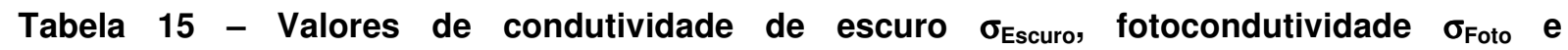
Fotosensibilidade (Fotosensib.) das amostras de a-Si:H depositadas pela terceira vez (C).

\begin{tabular}{|c|c|c|c|c|c|}
\hline Pot RF (W) & $\mathbf{P}$ (mTorr) & {$\left[\mathrm{H}_{2}\right](\%)$} & $\sigma_{\text {Escuro }}(\Omega . c m)^{-1}$ & $\sigma_{\text {Foto }}(\Omega . \mathrm{cm})^{-1}$ & Fotosensibilidade \\
\hline \multirow[b]{2}{*}{200} & \multirow[b]{2}{*}{5} & 20 & $1,26 \times 10^{-6}$ & $5,72 \times 10^{-4}$ & 455 \\
\hline & & 50 & $1,44 \times 10^{-6}$ & $1,41 \times 10^{-3}$ & 982 \\
\hline \multirow{3}{*}{200} & \multirow{3}{*}{10} & 20 & $1,13 \times 10^{-6}$ & $2,65 \times 10^{-4}$ & 235 \\
\hline & & 40 & $3,88 \times 10^{-6}$ & $7,61 \times 10^{-3}$ & 1960 \\
\hline & & 50 & $2,51 \times 10^{-7}$ & $2,25 \times 10^{-4}$ & 896 \\
\hline 250 & 5 & 50 & $3,66 \times 10^{-6}$ & $1,11 \times 10^{-4}$ & 30 \\
\hline \multirow{3}{*}{250} & \multirow{3}{*}{10} & 20 & $1,29 \times 10^{-6}$ & $1,72 \times 10^{-4}$ & 133 \\
\hline & & 40 & $4,44 \times 10^{-6}$ & $5,17 \times 10^{-4}$ & 116 \\
\hline & & 50 & $7,23 \times 10^{-8}$ & $1,41 \times 10^{-4}$ & 1954 \\
\hline 300 & 5 & 50 & $1,09 \times 10^{-5}$ & $3,59 \times 10^{-4}$ & 33 \\
\hline \multirow{3}{*}{300} & \multirow{3}{*}{10} & 20 & $1,61 \times 10^{-7}$ & $1,19 \times 10^{-4}$ & 736 \\
\hline & & 40 & $4,25 \times 10^{-7}$ & $9,31 \times 10^{-4}$ & 2190 \\
\hline & & 50 & $1,79 \times 10^{-7}$ & $4,30 \times 10^{-4}$ & 2398 \\
\hline
\end{tabular}




\section{ANÁLISE DOS RESULTADOS E DISCUSSÃO}

\subsection{Taxa de deposição}

Nos gráficos (a) e (b) da figura 26 são mostrados os valores de taxa de deposição obtidos a partir dos dados das tabelas 4,5 e 6 para as amostras depositadas respectivamente a 5 e 10 mTorr.

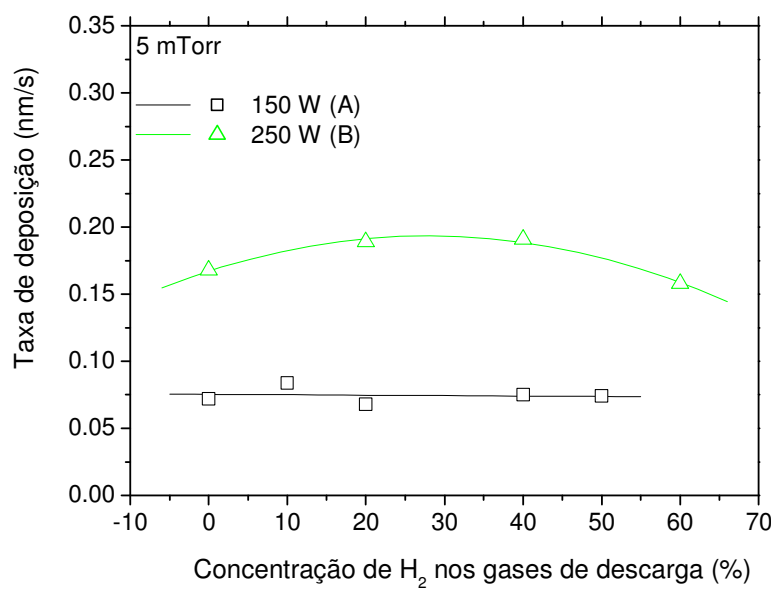

(a)

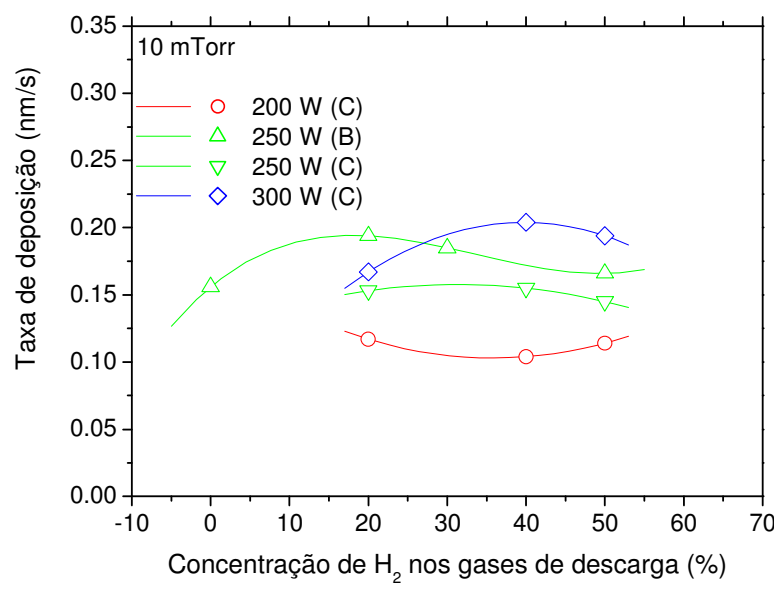

(b)

Figura 26 - Taxa de deposição dos filmes depositados a 5 (a) e 10 (b) mTorr.

A partir destes gráficos pode-se dizer que a taxa de deposição não variou muito nem com o aumento da concentração de hidrogênio dos gases de descarga e nem com a pressão total, como pode ser observado para este ultimo a partir das taxas de deposição das amostras depositadas a $250 \mathrm{~W}$ pela segunda vez (B).

Analisando separadamente a influência que a quantidade de hidrogênio no plasma e pressão total poderiam ter na taxa de deposição, podemos dizer que, no caso da concentração de hidrogênio nos gases de descarga, tanto o efeito corrosivo do substrato durante a deposição para a formação de compostos voláteis, como a menor concentração de argônio no sistema para a liberação de mais átomos de silício do alvo no processo de desbaste devem ser considerados [1]. Assim, considerando apenas a concentração de hidrogênio, seu aumento produziria uma diminuição da taxa de deposição. Já com relação à concentração de argônio, seu aumento também produziria uma diminuição da taxa de deposição já que menos 
silício seria liberado no sistema pelo processo de desbaste. Como para os filmes estudados neste trabalho a taxa de deposição não variou muito, estes efeitos não foram dominantes, estando outros mecanismos envolvidos. Hossain [47] propõe que o excesso de hidrogênio poderia promover um aumento da ionização do argônio pela formação de espécies $\mathrm{ArH}^{+}$, em seu estado metaestável, resultando em uma não alteração da taxa de deposição, já que o rendimento de desbaste do $\mathrm{Ar}^{+}$e $\mathrm{ArH}^{+}$ são praticamente iguais e que a quebra deste estado metaestável fornece mais íons de Ar. Na eq. (15) é mostrada esta reação.

$$
\begin{gathered}
A r \rightarrow A r^{+}+e \\
A r+e \rightarrow A r H^{+}+e \\
A r H^{+} \rightarrow A r^{+}+H
\end{gathered}
$$

Por outro lado o aumento da pressão total proporcionaria às espécies gasosas, principalmente as $\mathrm{SiH}_{\mathrm{x}}$, uma maior perda de energia o que acarretaria em uma formação de ligações fracas, com grande tensão mecânica, que reagiriam mais facilmente com o hidrogênio do plasma para a formação de compostos voláteis, pelo efeito corrosivo do hidrogênio, resultando assim em uma diminuição da taxa de deposição com o aumento da pressão. Todavia este efeito favoreceria o aumento da ordem de pequeno alcance, já que a corrosão seletiva do hidrogênio tende a reagir apenas com ligações fracas, deixando as fortes, com pouca tensão mecânica, intactas. Como o aumento da pressão não acarretou na diminuição da taxa de deposição, outros mecanismos estariam envolvidos. Outro efeito do aumento da pressão seria a diminuição do rendimento de desbaste do alvo, pelas espécies com menor energia, balanceada por uma certa quantidade de aumento, já que existiria uma maior quantidade de argônio no sistema.

Hossain ainda cita, a partir da literatura disponível, que a taxa de deposição depende de muitos fatores e que varia de sistema para sistema, já que ela pode mudar com pequenas variações na pressão total da câmara, pressão parcial de Ar, potência RF, temperatura do substrato, corrente de descarga, etc, sendo difícil identificar um único parâmetro que tenha um impacto isolado na taxa de deposição [47].

Mirza [48] obteve valores de taxa de deposição de filmes depositados por um sistema magnetron sputtering de $0,194 \mathrm{~nm} / \mathrm{s}$ compatíveis com as taxas obtidas 
neste trabalho. Mirza utilizou uma densidade de potência entre 0,32 a 0,56 W/ $/ \mathrm{cm}^{2}$, uma pressão total de 5 mTorr e uma temperatura de $240{ }^{\circ} \mathrm{C}$. Os valores de densidade de potência utilizados neste trabalho são indicados nas tabelas 1, 2 e 3.

Como esperado, a taxa de deposição aumentou com o aumento da potência [47], já que nestas condições houve um aumento da energia do argônio para a remoção de uma maior quantidade de silício pelo ataque iônico, tanto a 5 como a 10 mTorr.

Apesar das condições de deposição serem reproduzidas para as amostras depositadas a $250 \mathrm{~W}$ e 10 mTorr, sua taxa de deposição diminuiu um pouco do valor esperado, o que atribui uma certa reprodutibilidade. Esta pequena diferença pode ter ocorrido devido à possibilidade de ocorrência de pequenas variações do fluxo dos gases, controlados pelo controlador do fluxo de massa, ou diferenças na potência refletida relacionada com o acoplamento de malha do sistema de deposição.

\subsection{RBS}

Os valores de densidade volumétricas dos filmes de a-Si:H depositados pela primeira vez a $150 \mathrm{~W}$ e 5 mTorr, mostrados na tabela 16, foram obtidos pela razão entre a densidade superficial dos espectros RBS, transformada de átomos $/ \mathrm{cm}^{2}$ para $\mathrm{g} / \mathrm{cm}^{2}$, e espessuras de cada filme obtidas por perfilometria mostradas nas tabelas 4 , 5 e 6. Na tabela 16 ainda são mostrados os valores de densidade superficial e espessura integrada de silício resultante da integração da área dos espectros RBS, referentes ao silício.

Tabela 16 - Resultado da análise RBS dos filmes de a-Si:H, estando indicados os valores de densidade superficial de Si (Dens. Sup. Si), espessura integrada (Esp. de integração) e densidade volumétrica calculada $(\rho)$.

\begin{tabular}{cccc}
\hline$\left[\mathrm{H}_{2}\right](\%)$ & Dens. Sup. Si $\left(\times 10^{15} \mathrm{~cm}^{-2}\right)$ & Esp. de Integração $(\mathrm{nm})$ & $\rho\left(\mathrm{g} \cdot \mathrm{cm}^{-3}\right)$ \\
\hline 0 & 633 & 127 & 1,14 \\
10 & 895 & 180 & 1,38 \\
20 & 674 & 135 & 1,28 \\
40 & 770 & 155 & 1,33 \\
50 & 707 & 142 & 1,24 \\
\hline
\end{tabular}

Freeman [49] obteve valores de densidade volumétrica um pouco maiores na faixa de 1,90 a 2,10 g/cm³ , para seus filmes depositados de 5 a 10 mTorr de pressão total, já que ele utilizou uma temperatura do substrato maior de deposição, de 200 a 
$250{ }^{\circ} \mathrm{C}$. Sua taxa de deposição foi de $0,1 \mathrm{~nm} / \mathrm{s}$. Assim os valores obtidos neste trabalho estão mais próximos do obtido por Brodsky [40], de 1,40 g/ $\mathrm{cm}^{3}$, que utilizou uma pressão total de $2 \times 10^{-2}$ Torr, temperatura do substrato de $200{ }^{\circ} \mathrm{C}$ e obteve taxa de deposição de $0,27 \mathrm{~nm} / \mathrm{s}$.

Em geral há uma tendência de diminuição da densidade do filme com o aumento da pressão total, já que em pressões maiores, a corrente iônica resultante se torna maior, assim como a probabilidade de encontro de partículas, o que provoca uma diminuição da energia dos íons e, conseqüentemente, da densidade do filme [50].

Com relação aos elementos incorporados aos filmes de a-Si:H, depositados a 150 W e 5 mTorr e quantificados nas tabelas 7-10, foi encontrado argônio em todos os filmes em uma concentração que variou de 1,4 a 2,8 at. \%, assim como nos filmes de a-Si depositado na fase inicial deste trabalho descrita no item 2. Este elemento é comumente encontrado em filmes depositados pelo sistema magnetron sputtering, sendo aprisionado durante a deposição do filme nas microlacunas formadas [49], já que o argônio também bombardeia a superfície do filme em crescimento, além das espécies $\mathrm{SiH}_{\mathrm{x}}$ [8]. Os valores quantificados nas amostras estão na faixa dos comumente encontrados para filmes de a-Si:H depositados por sistemas magnetron sputtering [42], embora Liang [50] tenha dito que esta concentração usual seria menor do que 1 at. \%.

Conforme destacado por Liang [50] a concentração de argônio no filme diminui com o aumento tanto da temperatura como da pressão total. Isso pode ser explicado em termos da relação entre a energia das partículas de argônio e a das partículas do filme em crescimento, de modo que quando esta relação é alta, a energia do argônio é maior, assim como sua probabilidade de ser aprisionado por processos de colisão. Desta forma, o principal mecanismo de incorporação de argônio se deve à incidência deste gás com alta energia cinética, de modo que, neste trabalho, os filmes de aSi:H depositados a 10 mTorr teriam uma concentração de argônio menor que a dos filmes depositados a 5 mTorr.

Já os outros elementos contaminantes como o oxigênio, carbono, nitrogênio e alguns metais também são comumente encontrados em filmes depositados por sputtering. Pinarbasi [24] obteve, em seus filmes de boa qualidade, 50 ppm de oxigênio $\left(1,88 \times 10^{18}\right.$ átomos $\left./ \mathrm{cm}^{3}\right), 15 \mathrm{ppm}$ de carbono $\left(7,53 \times 10^{17}\right.$ átomos $\left./ \mathrm{cm}^{3}\right)$ e 5 ppm de nitrogênio $\left(2,15 \times 10^{17}\right.$ átomos $\left./ \mathrm{cm}^{3}\right)$, por espectroscopia de massa neutra 
secundária. Sua detecção de impurezas metálicas foi menor que 10 ppm que é suficiente para se fazer dispositivos de alto desempenho. Os valores de densidade atômica deste trabalho, obtidos através da multiplicação da densidade atômica volumétrica (razão entre a densidade superficial e a espessura do filme) pela porcentagem de cada elemento das tabelas 7-10 para os contaminantes das amostras obtidas a 150 W e 5 mTorr, são apresentados na tabela 17.

Tabela 17 - Densidade atômica dos elementos dos filmes obtidos a $150 \mathrm{~W}$ e $5 \mathrm{mTorr}$

\begin{tabular}{|c|c|c|c|c|c|c|c|c|}
\hline \multirow{2}{*}{$\begin{array}{l}{[\mathrm{H}]} \\
(\%)\end{array}$} & \multirow{2}{*}{ Camada } & \multicolumn{7}{|c|}{ Densidade Atômica (átomo/cm³) } \\
\hline & & $\mathrm{O}$ & $\mathrm{Ti}$ & $\mathrm{Ar}$ & $\mathrm{Si}$ & $\mathrm{Cr}$ & C & $\mathrm{N}$ \\
\hline 0 & 1 & $9,5 \times 10^{21}$ & $1,4 \times 10^{20}$ & $5,4 \times 10^{20}$ & $2,4 \times 10^{22}$ & $7,7 \times 10^{19}$ & - & - \\
\hline 10 & 1 & $2,8 \times 10^{21}$ & - & - & $3,2 \times 10^{22}$ & - & - & - \\
\hline 10 & 2 & $1,4 \times 10^{21}$ & $2,5 \times 10^{20}$ & $7,6 \times 10^{20}$ & $3,0 \times 10^{22}$ & - & - & $2,5 \times 10^{21}$ \\
\hline 20 & 1 & $3,1 \times 10^{21}$ & - & $9,1 \times 10^{20}$ & $2,7 \times 10^{22}$ & - & $2,1 \times 10^{21}$ & $8,2 \times 10^{21}$ \\
\hline 40 & 1 & $2,4 \times 10^{21}$ & - & $1,0 \times 10^{21}$ & $2,9 \times 10^{22}$ & - & - & $4,9 \times 10^{21}$ \\
\hline
\end{tabular}

Como pode ser observado nesta tabela, os valores de densidade para 0 oxigênio, carbono e nitrogênio são comparativamente muito grandes, já que níveis destas impurezas tão baixos quanto $3 \times 10^{19} \mathrm{~cm}^{-3}$ são necessários para a produção de dispositivos com boa qualidade [51]. No caso destes contaminantes acredita-se que tenham origem no próprio sistema de vácuo. Assim, em condições de ultra-alto vácuo Shimizu [52] obteve $2 \times 10^{17} \mathrm{~cm}^{-3}$ de carbono, $2 \times 10^{16} \mathrm{~cm}^{-3}$ de nitrogênio e $3 \times 10^{18} \mathrm{~cm}^{-3}$ de oxigênio. Morimoto [53], apesar de ter usado uma pressão base da ordem de $10^{-6}$ Torr, como neste trabalho, conseguiu reduzir o nível de contaminantes aquecendo as paredes do sistema "glow discharge" a $400{ }^{\circ} \mathrm{C}$ antes do processo de deposição. As concentrações de oxigênio, nitrogênio e carbono resultantes do trabalho de Morimoto foram, respectivamente, $2 \times 10^{18} \mathrm{~cm}^{-3}, 8 \times 10^{17} \mathrm{~cm}^{-3}$ e $8 \times 10^{16} \mathrm{~cm}^{-}$ 3 . Liang [50] purificou o gás argônio com uma armadilha gelada de nitrogênio líquido, antes de sua entrada no sistema, para a redução dos níveis de contaminação por oxigênio.

Os contaminantes metálicos que aparecem na amostra depositada a 0 e $10 \%$ de hidrogênio nos gases de descarga são o Ti, com 5 ppm, e o $\mathrm{Cr}$, com 3 ppm, no primeiro caso, e Ti com 9 ppm, no segundo caso. Já que eles aparecem em apenas algumas amostras, podem ter surgido do próprio sistema RBS, com a incidência de parte do feixe de próton no grampo metálico que prendia a amostra. Todavia, estando estes valores de contaminantes metálicos dentro da faixa considerada boa 
para a produção de dispositivos, deve-se preocupar em reduzir apenas os outros contaminantes.

Apesar de elementos contaminantes, como o oxigênio e o nitrogênio, poderem agir como passivadores de ligações incompletas, nas concentrações obtidas neste trabalho eles aumentam a densidade de estados na banda proibida [52], o que não ocorre para as impurezas de carbono e argônio. Todavia como a proporção de silício e oxigênio dos filmes é da ordem de 10:1, pode ter sido depositado um óxido de silício amorfo hidrogenado.

\subsection{FTIR}

As propriedades elétricas dos filmes de a-Si:H dependem da quantidade e forma de ligação dos átomos de hidrogênio [45] que, além de passivarem ligações incompletas, diminuindo assim a quantidade de defeitos, reagem quimicamente com o silício durante o processo de deposição [54].

Nos espectros FTIR das figuras 15 a 22 foram identificadas três principais regiões para os modos vibracionais de ligações entre silício e hidrogênio [41], cujos picos que estão situados a $640 \mathrm{~cm}^{-1}$, correspondem ao modo vibracional sacudida (wagging) do $\mathrm{SiH}_{3}$, balanço (rocking) do $\mathrm{SiH}_{2}$ ou dobramento (bending) do $\mathrm{SiH}$; a 840 e $890 \mathrm{~cm}^{-1}$, correspondente ao modo vibracional dobramento de polihidretos de silício; e a 2000 e $2100 \mathrm{~cm}^{-1}$, correspondente ao modo vibracional estiramento (stretching) respectivamente do $\mathrm{SiH}$ e $\mathrm{SiH}_{2}$. Estes picos têm uma tendência de aumentarem gradualmente com a concentração de hidrogênio nos gases de descarga como observado neste trabalho e no de Gekka [46] e Abelson [20].

Além destes principais picos que foram utilizados para a quantificação do hidrogênio incorporado e entendimento da forma de estruturação dos filmes, foram encontradas bandas de absorção a 460, 1080, 1230 e $2240 \mathrm{~cm}^{-1}$ que podem corresponder respectivamente ao modo vibracional balanço e estiramento do $\mathrm{SiO}_{2}$, dobramento do $\mathrm{NH}$ e estiramento do $\mathrm{SiH}_{3}$, conforme indicados nas figuras de $15 \mathrm{a}$ 22. Nestas figuras são ainda observadas bandas de absorção de hidretos de silício mesmo para $0 \%$ de hidrogênio nos gases de descarga. Como sugerido por Gekka [46] a absorção de hidrogênio pelos filmes nesta condição pode ter ocorrido devido à 
entrada de vapor de água no sistema já que absorções de $\mathrm{SiO}_{2}$ estiramento também aparecem em todos os filmes.

A seguir são discutidas tanto as três principais regiões para os modos vibracionais de ligações entre o silício o hidrogênio como as bandas a $1080 \mathrm{~cm}^{-1}$ do modo vibracional estiramento do $\mathrm{SiO}_{2}$. Para esta ultima é feita uma comparação entre as áreas integradas destes picos e a concentração de oxigênio obtida pela análise RBS para a verificação da magnitude desta contaminação em todos os filmes de a-Si:H estudados neste trabalho.

\subsubsection{Absorção a $630 \mathrm{~cm}^{-1}$}

A banda de absorção ao redor de $650 \mathrm{~cm}^{-1}$ sempre corresponde a um pico único de maior força de oscilação dentre as bandas dos modos vibracionais das ligações entre silício e hidrogênio [42]. Como ela contém as contribuições das ligações tanto de monohidretos $(\mathrm{SiH})$ como de polihidretos $\left(\mathrm{SiH}_{2}\right.$ e $\left.\mathrm{SiH}_{3}\right)$ ela pode ser relacionada com a concentração total de hidrogênio, como feito por Pibril [22], Brodsky [40] e Langford [41], utilizando a constante de proporcionalidade $A_{640}=1.6 \times 10^{19} \mathrm{~cm}^{-2}[55]$ ou $0.032 \mathrm{~cm} \%$ [19].

Pirnarbasi [24] mostrou que filmes de a-Si:H depositados por sistemas magnetron sputtering, com qualidade eletrônica tão boa quanto a do material depositado por "glow discharge", apresentam concentrações totais de hidrogênio variando de 10 a 28 at. \%. A concentração total de ligações entre silício e hidrogênio, calculada a partir das áreas das gaussianas ajustadas destes picos através da eq. (11), são mostrados na tabela do apêndice $B$ e nos gráficos da figura 27 separados em 5 mTorr (a) e 10 mTorr (b).

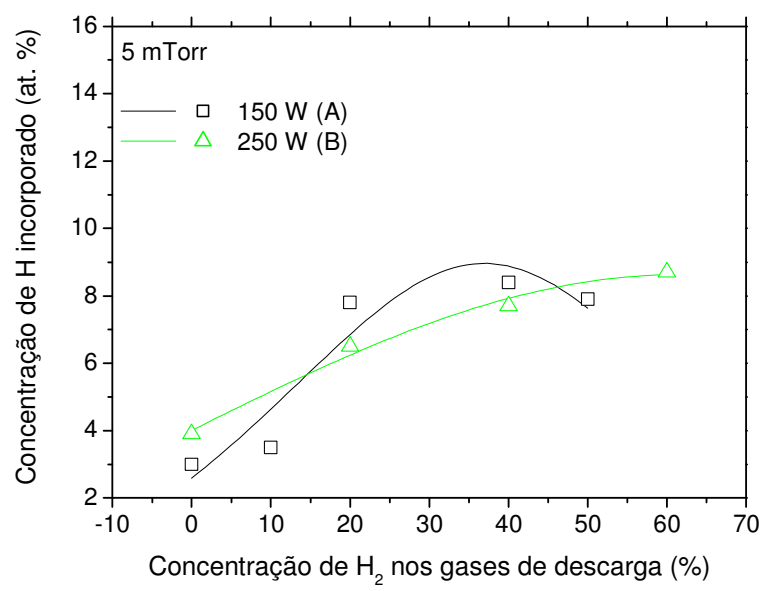

(a)

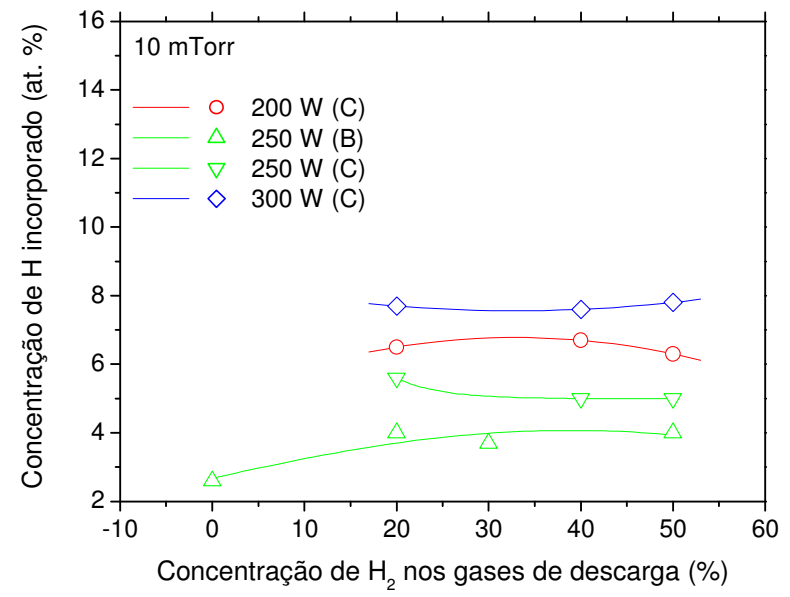

(b)

Figura 27 - Concentração total de hidrogênio ligado para 5 mTorr (a) e 10 mTorr (b). 
Com base nestes gráficos, a primeira observação a ser feita é que a concentração total de hidrogênio incorporado ao filme aumentou com o aumento da concentração de hidrogênio nos gases de descarga para as amostras depositadas a 5 mTorr, ao passo que ela se manteve praticamente constante para as amostras depositadas a 10 mTorr. Além disso, pode-se dizer que os filmes depositados a 5 mTorr incorporaram mais hidrogênio que os depositados a 10 mTorr.

Esta diminuição do conteúdo de hidrogênio nos filmes com o aumento da pressão total está relacionada com o aumento da taxa de fluxo de hidrogênio e argônio nos gases de descarga que em maior quantidade acabam extraindo hidrogênio da superfície do filme em crescimento [47], uma vez que o hidrogênio reage quimicamente com o silício durante a deposição. Este comportamento está de acordo com o trabalho de Saito [56] e [1]. Pode ter ocorrido também um aumento da taxa de remoção do hidrogênio na câmara de sputtering com relação à taxa de incorporação deste nos filmes.

Apesar de a 5 mTorr a concentração total de hidrogênio incorporado aos filmes aumentar com a concentração de hidrogênio nos gases de descarga, parece haver uma concentração de saturação, a partir da qual a concentração total de hidrogênio incorporado começa a diminuir com aumentos maiores na concentração de hidrogênio nos gases de descarga. Este comportamento foi bem observado para as amostras deste trabalho depositadas a $150 \mathrm{~W}\left(0,823 \mathrm{~W} / \mathrm{cm}^{2}\right)$ e nas de Hossain [47] que utilizou a mesma pressão total de $5 \mathrm{mTorr}$, mas um pouco mais que o dobro da densidade de potência $\left(1,91 \mathrm{~W} / \mathrm{cm}^{2}\right)$. Em seu trabalho a concentração de hidrogênio de saturação foi de aproximadamente $35 \%$, semelhante a de $40 \%$ deste trabalho.

Nos filmes de a-Si:H deste trabalho depositados a 5 mTorr as concentrações totais de hidrogênio incorporado diminuem com o aumento da potência, quando consideramos separadamente os filmes depositados na primeira - $150 \mathrm{~W}(\mathrm{~A})$ segunda - $250 \mathrm{~W}(\mathrm{~B})$ - e terceira vez - $200 \mathrm{~W}(\mathrm{C}), 250 \mathrm{~W}$ (C) e $300 \mathrm{~W}$, conforme pode ser observado na figura 27 (a) e nas tabelas do apêndice B. Este comportamento também foi observado por Hossain [47] em seus filmes depositados a 5 mTorr.

Para os filmes depositados a 10 mTorr a maior pressão da câmara não permitiu que houvesse variações significativas da concentração total de hidrogênio incorporado com o aumento da concentração de hidrogênio nos gases de descarga. Assim esta concentração variou apenas com a potência RF. 


\subsubsection{Absorção a 860 e $880 \mathrm{~cm}^{-1}$}

Filmes de a-Si:H que apresentam absorções entre 700 e $1200 \mathrm{~cm}^{-1}$ possuem muitos defeitos como espaços vazios do tipo microlacunas e altas concentrações de polihidretos de silício [45, 57]. A existência destas bandas, assim como sua magnitude, depende da pressão parcial de hidrogênio, pressão total dos gases de descarga e temperatura do substrato durante a deposição [42], de modo que não só a diminuição da temperatura de deposição como o aumento da pressão total produzem filmes com mais microlacunas [57]. Nas tabelas 18, 19 e 20 são apresentados os valores da área integrada das bandas de absorção formadas nesta região para os filmes estudados neste trabalho. No apêndice $C$ são mostradas as gaussianas ajustadas para cada uma destas bandas. Vale apena salientar que os valores das destas áreas não podem ser comparados para bandas diferentes.

Tabela 18 - Características dos picos em torno de 800 e $900 \mathrm{~cm}^{-1}$ das amostras depositadas pela primeira vez $(A)$

\begin{tabular}{|c|c|c|c|c|c|c|c|c|c|c|}
\hline $\begin{array}{l}\text { Pot RF } \\
\text { (W) }\end{array}$ & $\begin{array}{c}\mathbf{P} \\
\text { (mTorr) }\end{array}$ & $\begin{array}{c}{\left[\mathrm{H}_{2}\right]} \\
(\%)\end{array}$ & Pico & Área & Pico & Área & Pico & Área & Pico & Área \\
\hline \multirow{5}{*}{150} & \multirow[t]{5}{*}{ 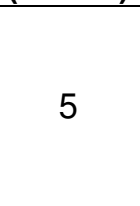 } & 0 & 848,3 & 21,8 & - & - & 880,8 & 13,2 & - & - \\
\hline & & 10 & 843,0 & 20,6 & - & - & 882,2 & 19,5 & - & - \\
\hline & & 20 & 842,6 & 22,6 & - & - & 883,5 & 32,6 & - & - \\
\hline & & 40 & 844,7 & 11,3 & - & - & 888,2 & 20,7 & - & - \\
\hline & & 50 & 843,2 & 15,5 & - & - & 886,5 & 14,0 & - & - \\
\hline
\end{tabular}

Tabela 19 - Características dos picos em torno de 800 e $900 \mathrm{~cm}^{-1}$ das amostras depositadas pela segunda vez $(B)$

\begin{tabular}{|c|c|c|c|c|c|c|c|c|c|c|}
\hline $\begin{array}{l}\text { Pot RF } \\
\text { (W) }\end{array}$ & $\begin{array}{c}\mathbf{P} \\
\text { (mTorr) }\end{array}$ & $\begin{array}{l}{\left[\mathrm{H}_{2}\right]} \\
(\%)\end{array}$ & Pico & Área & Pico & Área & Pico & Área & Pico & Área \\
\hline \multirow{4}{*}{250} & \multirow[t]{4}{*}{ (……, } & 0 & 840,3 & 6 & 862,2 & 12,6 & 884,1 & 12,2 & - & - \\
\hline & & 20 & 840,8 & 3 & 855,6 & 4,7 & 882,8 & 15,1 & - & - \\
\hline & & 40 & 840,7 & 4 & 855,6 & 2,4 & 883,5 & 17,6 & - & - \\
\hline & & 60 & 841,4 & 3 & 851,2 & 2,2 & 886,2 & 15,5 & - & - \\
\hline \multirow{4}{*}{250} & \multirow{4}{*}{10} & 0 & 838,4 & 0,6 & 850,0 & 4,1 & 877,9 & 23,3 & - & - \\
\hline & & 20 & 834,0 & 8 & 853,9 & 22,3 & 880,1 & 23,1 & 904,2 & 4,1 \\
\hline & & 30 & 836,0 & 4 & 853,3 & 15 & 880,6 & 25 & 905,0 & 5 \\
\hline & & 50 & 835,4 & 4 & 852,5 & 11,8 & 880,6 & 21,2 & 905,4 & 3,5 \\
\hline
\end{tabular}


Tabela 20 - Características dos picos em torno de 800 e $900 \mathrm{~cm}^{-1}$ das amostras depositadas pela terceira vez (C)

\begin{tabular}{|c|c|c|c|c|c|c|c|c|c|c|}
\hline $\begin{array}{l}\text { Pot RF } \\
\text { (W) }\end{array}$ & $\begin{array}{c}\mathbf{P} \\
\text { (mTorr) }\end{array}$ & $\begin{array}{l}{\left[\mathrm{H}_{2}\right]} \\
(\%) \\
\end{array}$ & Pico & Área & Pico & Área & Pico & Área & Pico & Área \\
\hline \multirow{2}{*}{200} & \multirow[t]{2}{*}{ 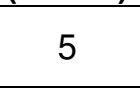 } & 20 & 850,5 & 2,1 & - & - & 889,1 & 13,6 & - & - \\
\hline & & 50 & 842,8 & 2,8 & - & - & 889,1 & 13,3 & - & - \\
\hline \multirow{3}{*}{200} & \multirow{3}{*}{10} & 20 & 837,7 & 22,6 & 862,6 & 47,0 & 881,0 & 11,7 & 895,7 & 38,6 \\
\hline & & 40 & 836,3 & 14 & 858,8 & 42 & 881,9 & 28,0 & 903,4 & 17,4 \\
\hline & & 50 & 845,3 & 29 & 861,2 & 2,8 & 878,5 & 36,1 & 904,4 & 21,7 \\
\hline \multirow[t]{2}{*}{250} & 5 & 50 & 839,6 & 16 & 863,6 & 29,4 & 883,2 & 25,4 & - & - \\
\hline & \multirow{3}{*}{10} & 20 & 831,4 & 19 & 858,7 & 58 & 880,6 & 11 & 892,3 & 56 \\
\hline \multirow[t]{2}{*}{250} & & 40 & 838,1 & 14 & 861,6 & 34,7 & 880,4 & 10,5 & 892,6 & 42 \\
\hline & & 50 & 836,2 & 12 & 859,7 & 37,1 & 881,5 & 18,8 & 903,9 & 16,5 \\
\hline 300 & 5 & 50 & 839,6 & 16 & 863,6 & 29,4 & 883,2 & 25,4 & - & - \\
\hline \multirow{3}{*}{300} & \multirow{3}{*}{10} & 20 & 834,2 & 29 & 857,3 & 90 & 880,3 & 47 & 901,9 & 23 \\
\hline & & 40 & 839,6 & 41 & 857,3 & 14,2 & 875,2 & 54,9 & 903,0 & 17,9 \\
\hline & & 50 & 835,4 & 19 & 857,7 & 41,9 & 879,3 & 30,5 & 902,0 & 22,0 \\
\hline
\end{tabular}

O pico das bandas que aparecem em todas as amostras são os que apareceram a 840 e $880 \mathrm{~cm}^{-1}$. Eles podem corresponder respectivamente à deformação simétrica do $\mathrm{SiH}_{3}$ e ao modo vibracional "scissor-bend" do $\mathrm{SiH}_{2}$, conforme proposto por Ishida [54]. Além deles, são contabilizados picos a $860 \mathrm{~cm}^{-1}$, podendo corresponder ao modo vibracional dobramento do $\mathrm{SiH}_{3}$ [19], e a $905 \mathrm{~cm}^{-1}$, considerado como a vibração degenerada do $\mathrm{SiH}_{3}$ por Ishida [54].

São analisadas a seguir, através dos gráficos da figura 28 , as áreas apenas dos picos a 840 e $880 \mathrm{~cm}^{-1}$, já que eles aparecem em todas as amostras e fornecem informações tanto do $\mathrm{SiH}_{3}$ dobramento como do $\mathrm{SiH}_{2}$ dobramento. Estas análises, além das que se seguem, são realizadas para a melhor compreensão das estruturas resultantes, nos filmes de a-Si:H, com a variação dos parâmetros de deposição e assim elas possam ser melhor correlacionadas com as características ópticas e elétricas, já que estas dependem fortemente das estruturas dos filmes de a-Si:H.

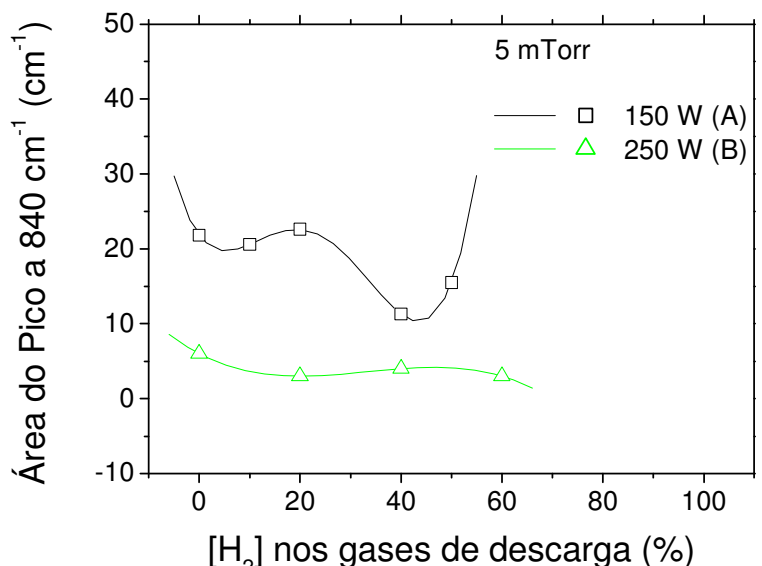

(a)

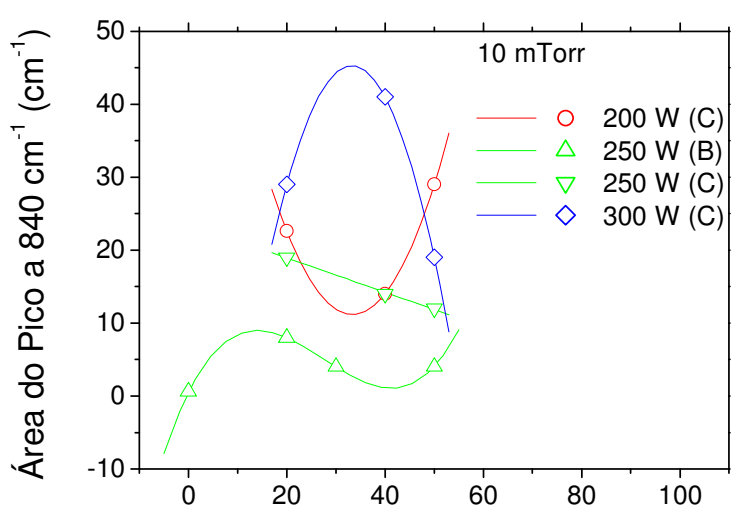

$\left[\mathrm{H}_{2}\right]$ nos gases de descarga (\%)

(b) 


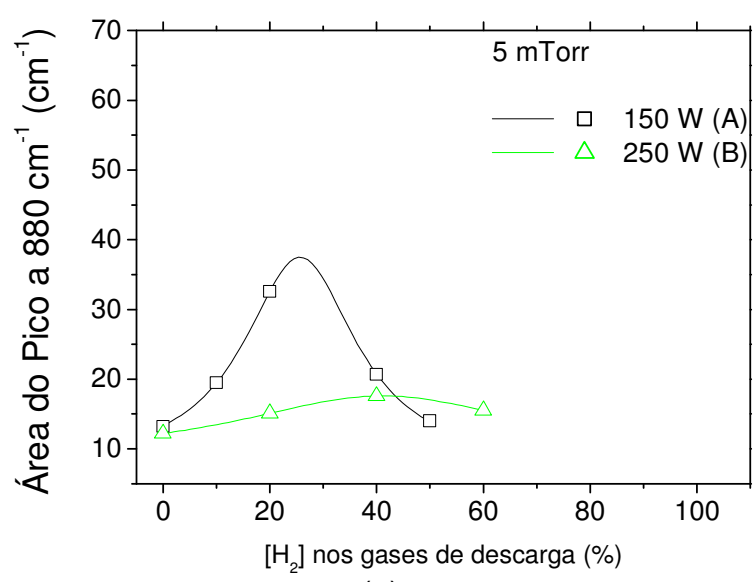

(c)

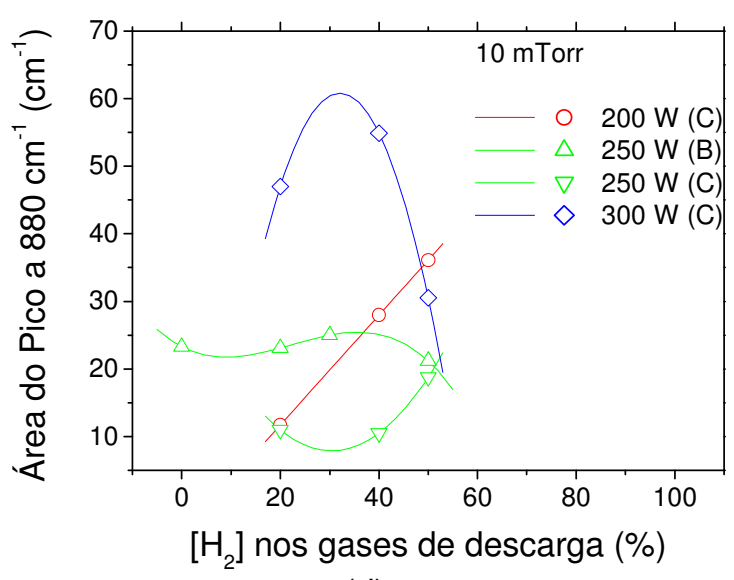

(d)

Figura 28 - Áreas dos picos a $840 \mathrm{~cm}^{-1}$ das amostras de a-Si:H depositadas a 5 mTorr (a) e 10 mTorr (b) e áreas dos picos a $880 \mathrm{~cm}^{-1}$ das amostras depositadas a $5 \mathrm{mTorr}$ (c) e $10 \mathrm{mTorr}$ (d).

A partir dos gráficos (a) e (b) da figura 28 pode ser observada, através da área das bandas a $840 \mathrm{~cm}^{-1}$, a variação da concentração de ligações $\mathrm{SiH}_{3}$ tanto com a concentração de hidrogênio nos gases de descarga como com a pressão total. Por outro lado a partir dos gráficos (c) e (d) pode ser observada, através das áreas das bandas a $880 \mathrm{~cm}^{-3}$, a variação da concentração de ligações $\mathrm{SiH}_{2}$ dobramento. Com base nestas observações pode-se dizer que houve um aumento das ligações $\mathrm{SiH}_{3} \mathrm{e}$ $\mathrm{SiH}_{2}$ dobramento com o aumento da pressão total de deposição. Contudo para os filmes depositados pela terceira vez a 250 W (C) e 10 mTorr a concentração de ligações $\mathrm{SiH}_{2}$ dobramento seguiu uma ordem inversa, diminuindo com o aumento da pressão.

Como pode ser observado pela comparação dos gráficos (b) da figura 28 e (b) da figura 27, as amostras depositadas a 10 mTorr têm uma tendência semelhante de aumento tanto da concentração de ligações $\mathrm{SiH}_{3}$ dobramento como da concentração total de hidrogênio incorporado com o aumento da potência. Assim, o aumento da potência de RF de $200 \mathrm{~W}$ para $250 \mathrm{~W}$ produziu uma diminuição da concentração total de hidrogênio refletindo na diminuição da concentração de ligações $\mathrm{SiH}_{3}$. Com relação às amostras depositadas a $200 \mathrm{~W}$ e 10 mTorr, a concentração de ligações $\mathrm{SiH}_{2}$ dobramento, para este aumento de potência, diminuiu apenas nas concentrações de hidrogênio nos gases de descarga superiores a 40 \% para as amostras do primeiro conjunto, mas em toda a faixa para as amostras do segundo conjunto. Desta forma as amostras de a-Si:H depositadas a $250 \mathrm{~W}$ e 10 mTorr na terceira vez têm mais ligações $\mathrm{SiH}_{3}$ e menos $\mathrm{SiH}_{2}$ dobramento que as depositadas na segunda vez. Nesta mesma condição de pressão total de 10 mTorr, o aumento 
da potência RF de $250 \mathrm{~W}$ para $300 \mathrm{~W}$ produziu filmes com máximas concentrações tanto de ligações $\mathrm{SiH}_{3}$ como de $\mathrm{SiH}_{2}$ dobramento, como pode ser observado respectivamente nos gráficos (b) e (d) da figura 28 , refletindo nas maiores concentrações de hidrogênio incorporado da figura 27 (b).

Para as amostras depositadas a 5 mTorr a concentração de ligações $\mathrm{SiH}_{3}$ aumentou com o aumento da potência de $200 \mathrm{~W}$ para $250 \mathrm{~W}$. Embora as amostras depositadas a $150 \mathrm{~W}$ e 5 mTorr tenham apresentado as maiores concentrações de ligações $\mathrm{SiH}_{3}$ e $\mathrm{SiH}_{2}$ dobramento e as depositadas a $200 \mathrm{~W}$ nesta mesma pressão tenham apresentado as menores concentrações destas ligações, as amostras depositadas a $200 \mathrm{~W}$ apresentam a maior concentração de hidrogênio total, conforme pode ser observado no gráfico (a) da figura 27 , o que implicaria em uma grande concentração de monohidretos de silício.

Já para as amostras depositadas pela primeira vez a $150 \mathrm{~W}$ e $5 \mathrm{mTorr}$, houve um máximo de concentração total de hidrogênio incorporado a 40 \% hidrogênio nos gases de descarga e um mínimo na concentração de ligações $\mathrm{SiH}_{3}$. Como nesta mesma região a concentração de ligações $\mathrm{SiH}_{2}$ dobramento foi relativamente baixa para o conjunto de amostras depositadas nesta potência e pressão, dá para concluir que haveria uma alta concentração de monohidretos de silício. Nesta mesma amostra uma região de máximo de ligações $\mathrm{SiH}_{2}$ dobramento, a $20 \%$ de hidrogênio nos gases de descarga, corresponde a uma região também de máximo, mas de ligações $\mathrm{SiH}_{3}$ e portanto uma alta concentração de hidrogênio incorporado, de modo que o comportamento de formação de ligações $\mathrm{SiH}_{2}$ dobramento com a variação da concentração de hidrogênio no gás segue o de formação de ligações $\mathrm{SiH}_{3}$ para esta condição de potência e pressão.

\subsubsection{Absorção a 2000 e $2090 \mathrm{~cm}^{-1}$}

As absorções a 2000 e $2090 \mathrm{~cm}^{-1}$ correspondem aos modos vibracionais estiramento das ligações $\mathrm{SiH}$ e $\mathrm{SiH}_{2}$ respectivamente [45]. Como pode ser observado nos gráficos das figuras 15 a 22, as concentrações de ligações $\mathrm{SiH}_{2}$ estiramento são quase sempre maiores que as de ligações $\mathrm{SiH}$ estiramento, o que também caracteriza filmes com grande concentrações de espaços vazios do tipo microlacunas e polihidretos de silício. Este comportamento também foi observado nos filmes de Noda [57] depositados a temperatura ambiente pelo sistema magnetron sputtering. Esta dominância de ligações $\mathrm{SiH}_{2}$ estiramento sobre $\mathrm{SiH}$ 
estiramento indica um excesso de hidrogênio incorporado nos filmes. Em temperaturas maiores de deposição como de $200{ }^{\circ} \mathrm{C}$, Noda obteve uma diminuição na concentração de espaços vazio tipo microlacunas refletindo no estabelecimento de absorções dominantes a $1994 \mathrm{~cm}^{-1}$ e a $650 \mathrm{~cm}^{-1}$. Nas tabelas do apêndice D são apresentadas as concentrações de ligações $\mathrm{SiH}$ e $\mathrm{SiH}_{2}$, dos filmes estudados neste trabalho, para o modo vibracional estiramento, correspondentes às bandas respectivamente a 2000 e $2090 \mathrm{~cm}^{-1}$. As concentrações destas ligações foram calculadas com as constantes de proporcionalidade $A_{2000}=0.26 \mathrm{~cm} \%$ e $A_{2090}=0.28$ $\mathrm{cm} \%$ tal como proposto por Kuo [19]. Os gráficos que relacionam estas concentrações com a concentração de hidrogênio nos gases de descarga, para as duas condições de pressão total e diversas condições de potência são mostrados na figura 29.

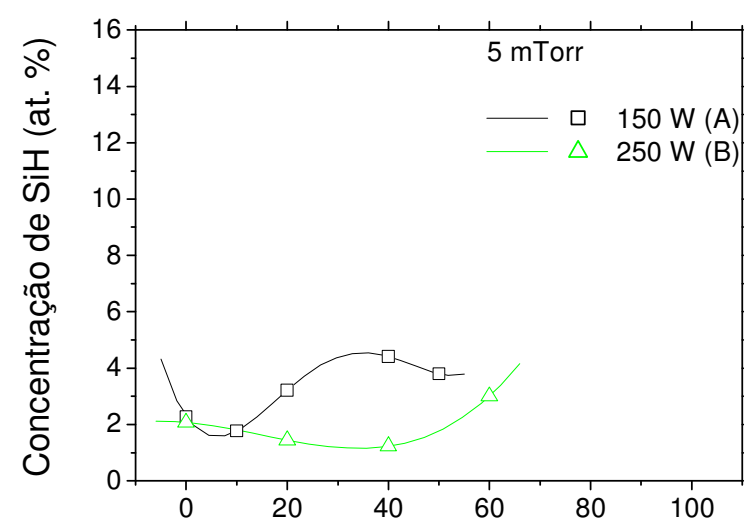

$\left[\mathrm{H}_{2}\right]$ nos gases de descarga (\%)

(a)

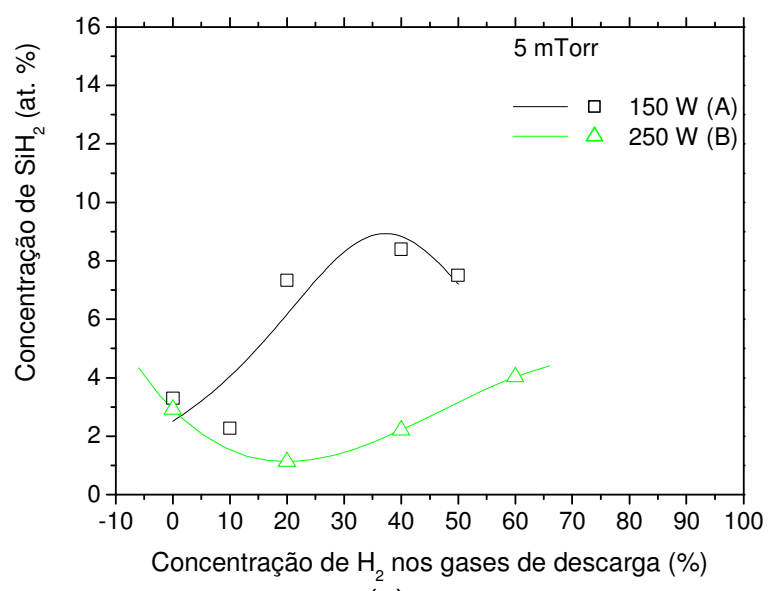

(c)

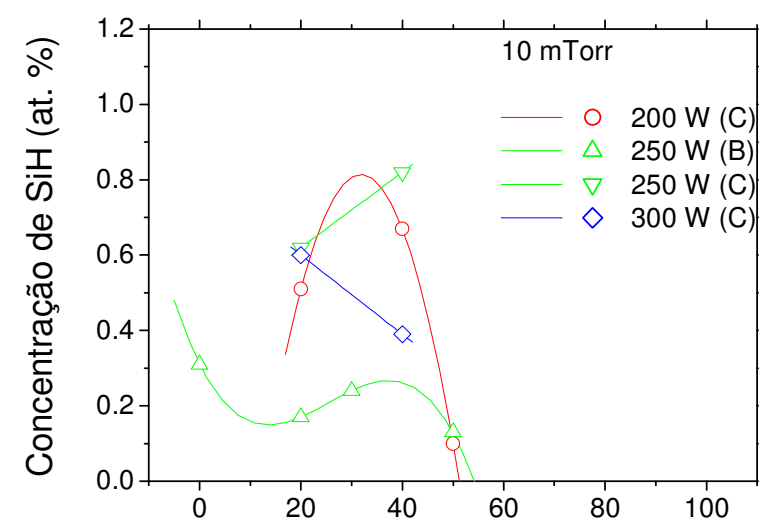

$\left[\mathrm{H}_{2}\right]$ nos gases de descarga (\%)

(b)

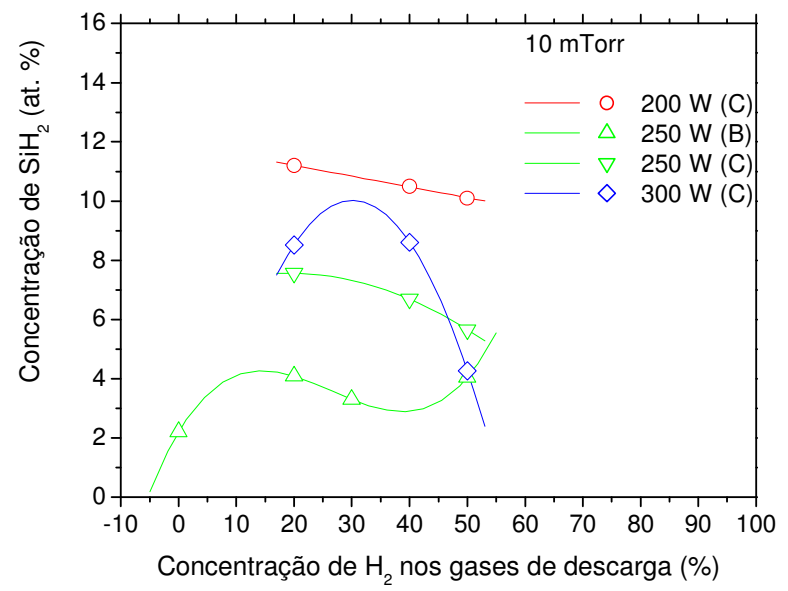

(d)

Figura 29 - Concentração de ligações SiH estiramento para 5 mTorr (a) e 10 mTorr (b) e de ligações $\mathrm{SiH}_{2}$ dobramento para $5 \mathrm{mTorr}$ (c) e $10 \mathrm{mTorr}$ (d). 
Pode ser observado a partir tanto dos gráficos (a) e (c) da figura 29 como dos gráficos (c) e (d) da figura 28 que o comportamento da concentração de ligações $\mathrm{SiH}_{2}$ estiramento se diferencia um pouco do observado para a concentração de ligações $\mathrm{SiH}_{2}$ dobramento. Como as variações nas concentrações de ligações $\mathrm{SiH}_{2}$ estiramento seguiram as de ligações $\mathrm{SiH}$ estiramento, as máximas e as mínimas concentrações de $\mathrm{SiH}$ são semelhantes às concentrações de ligações $\mathrm{SiH}_{2}$ estiramento, o que não ocorreu quando são comparadas as concentrações de ligações $\mathrm{SiH}$ com as de ligações $\mathrm{SiH}_{2}$ dobramento. Para as análises das medidas ópticas e elétricas, são considerados apenas as ligações $\mathrm{SiH}_{2}$ dobramento porque, esta parece se relacionar bem com as ligações $\mathrm{SiH}_{3}$ dobramento dos gráficos (a) e (b) da figura 28.

Através da comparação entre os gráficos da figura 29 pode-se observar um efeito de quase extinção das ligações $\mathrm{SiH}$ estiramento com o aumento da pressão de 5 mTorr em (a) para 10 mTorr em (b), mas pouca variação da concentração de $\mathrm{SiH}_{2}$ estiramento nesta mudança.

As amostras de a-Si:H depositadas a 200 W e 5 mTorr foram as que apresentaram as maiores concentrações de ligações $\mathrm{SiH}$ estiramento, como pode ser observado no gráfico (a) da figura 29, correspondendo também às amostras com menores concentrações tanto de $\mathrm{SiH}_{3}$ dobramento como de $\mathrm{SiH}_{2}$ dobramento, como pode ser observado a partir dos gráficos da figura 28.

Apesar de as amostras depositadas a 150 W e 5 mTorr apresentarem as maiores concentrações de ligações $\mathrm{SiH}_{3}$ dobramento e $\mathrm{SiH}_{2}$ dobramento, como pode ser visto respectivamente nos gráficos (a) e (c) da figura 28 , ocorre um mínimo de concentração de ligações $\mathrm{SiH}_{3}$ correspondente a baixas concentrações de ligações $\mathrm{SiH}_{2}$ dobramento em aproximadamente $40 \%$ de hidrogênio nos gases de descarga. Como nesta mesma região a concentração de ligações SiH estiramento do gráfico (a) da figura 29 é a maior entre as obtidas a $150 \mathrm{~W}$, estas ligações SiH acabam contribuindo com a concentração total de hidrogênio para produzir, tal como mostrado na figura 27 (a), uma maior que a concentração total de hidrogênio.

Apesar de os filmes depositados pela primeira vez a 150 W e 5 mTorr apresentarem um valor máximo de concentração tanto de ligações $\mathrm{SiH}_{3}$ dobramento como de $\mathrm{SiH}_{2}$ dobramento a aproximadamente 20 \% de hidrogênio nos gases de descarga, nesta região os filmes apresentaram uma grande concentração de ligações SiH estiramento, de modo que a concentração total é relativamente alta, 
apesar de não ser a máxima. Desta forma pode-se dizer que, como a concentração total de hidrogênio incorporado tanto a 20 como a 40 \% de hidrogênio nos gases de descarga praticamente não mudou, a diminuição da concentração de ligações $\mathrm{SiH}$ estiramento foi compensada pelo aumento tanto de ligações $\mathrm{SiH}_{3}$ dobramento como de $\mathrm{SiH}_{2}$ dobramento.

Assim, pode-se dizer que para os filmes depositados pela primeira vez a $150 \mathrm{~W}$ e 5 mTorr a concentração de ligações $\mathrm{SiH}_{3}$ dobramento, $\mathrm{SiH}_{2}$ dobramento e $\mathrm{SiH}$ estiramento aumenta com a concentração total de hidrogênio até aproximadamente $20 \%$ de hidrogênio nos gases de descarga. Aumentos maiores da concentração de hidrogênio nos gases de descarga produzem uma diminuição nas concentrações tanto de ligações $\mathrm{SiH}_{3}$ dobramento como de $\mathrm{SiH}_{2}$ dobramento, apesar de a concentração de ligações $\mathrm{SiH}$ estiramento continuar aumentando até ser atingida uma concentração máxima a $40 \%$ de hidrogênio nos gases de descarga. A concentração total de hidrogênio incorporado não variou muito entre 20 e 60 \%. A partir de $40 \%$, aumentos maiores na concentração de hidrogênio produziram uma ligeira diminuição da concentração total de hidrogênio e da concentração tanto de ligações $\mathrm{SiH}$ estiramento como de $\mathrm{SiH}_{2}$ dobramento, apesar de a concentração de ligações $\mathrm{SiH}_{3}$ dobramento ter aumentado.

Com estas análises será possível relacionar as concentrações de ligações SiH estiramento, $\mathrm{SiH}_{2}$ dobramento e $\mathrm{SiH}_{3}$ dobramento com as propriedades ópticas e elétricas dos filmes de a-Si:H investigados neste trabalho, já que filmes com altas concentrações de ligações $\mathrm{SiH}_{2}$ e principalmente $\mathrm{SiH}_{3}$ apresentam muitos espaços vazios do tipo microlacunas, além da predominância destes dois tipos de ligações estar relacionada com a formação de estruturas poliméricas no filme.

\subsubsection{Absorção a $1080 \mathrm{~cm}^{-1}$}

Neste trabalho foram encontradas bandas de absorção a aproximadamente $1080 \mathrm{~cm}^{-1}$ consideradas, como Gekka [46], absorções de ligações entre o silício e o oxigênio. Em seu trabalho Gekka depositou filmes de a-Si:H a $1 \times 10^{-3} \mathrm{mTorr}$ de pressão total, $250{ }^{\circ} \mathrm{C}$ de temperatura do substrato, 1.91 a $2.5 \mathrm{~W} / \mathrm{cm}^{2}$ de potência RF e de 0 a $30 \%$ de hidrogênio nos gases de descarga. Ele atribuiu a presença deste pico, que apareceu em todos os espectros FTIR deste trabalho, à entrada de uma quantidade muito pequena de vapor de água supostamente contida no gás argônio. 
A concentração de oxigênio pôde ser obtida a partir de uma relação estabelecida entre a área desta banda e a concentração de oxigênio quantificada pela análise RBS dos filmes de a-Si:H depositados a $150 \mathrm{~W}$ e $5 \mathrm{mTorr}$ (tabela 17). Um método semelhante para a obtenção da constante de proporcionalidade foi empregado por Freeman [42]. Esta relação $\left(A_{1080}\right)$ é mostrada no gráfico da figura 23.

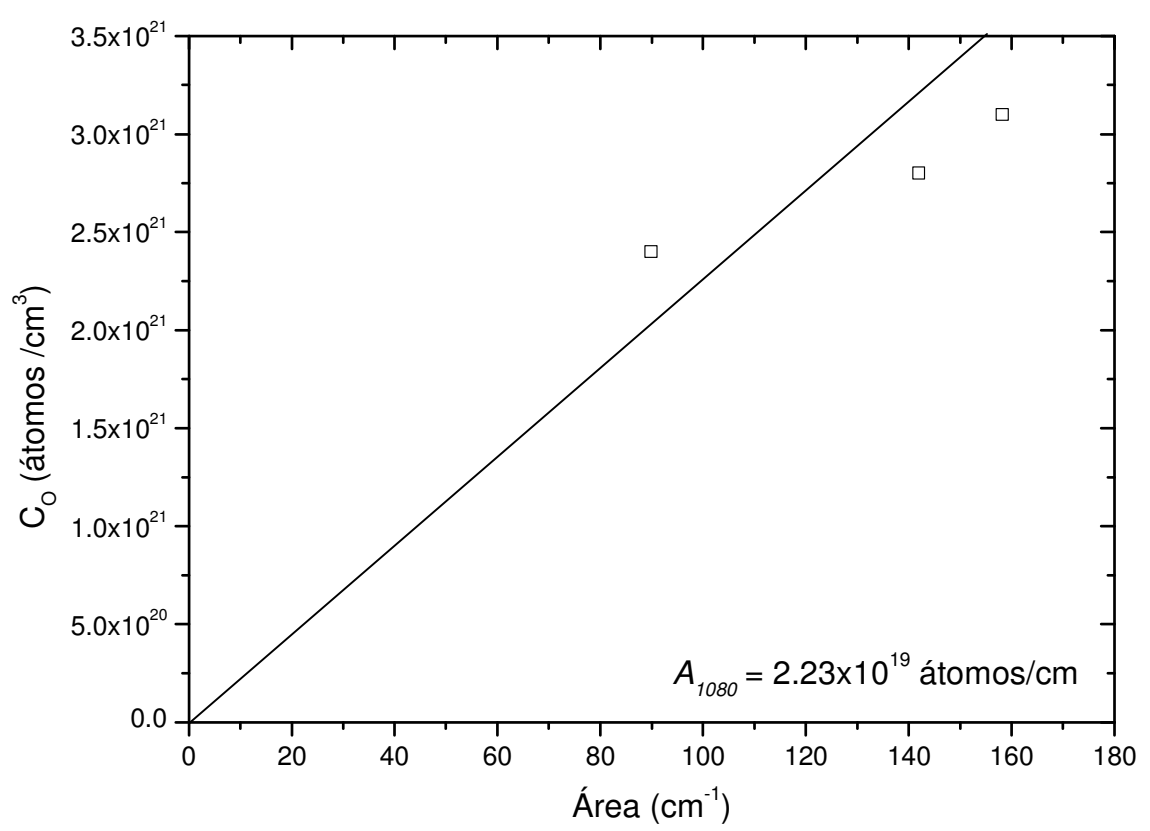

Figura 30 - Relação entre a área do pico a $1080 \mathrm{~cm}^{-1}$ e a concentração de oxigênio.

Assim, os valores das concentrações de oxigênio puderam ser calculados. Estes valores são mostrados na tabela 21 a 23.

Tabela 21 - Valores calculados da densidade atômica de oxigênio nos filmes de a-Si:H depositados pela primeira vez (A).

\begin{tabular}{cccccc}
\hline Pot RF $(\mathbf{W})$ & $\mathbf{P}$ (mTorr) & {$\left[\mathbf{H}_{2}\right](\%)$} & Área $\left(\mathbf{c m}^{-1}\right)$ & Pico $\left(\mathbf{c m}^{-1}\right)$ & {$[\mathbf{O}]\left(\mathbf{a t} / \mathbf{c m}^{3}\right)$} \\
\hline & & 0 & 199,40 & 1076,28 & $4,45 \times 10^{21}$ \\
\multirow{2}{*}{50} & 10 & 141,98 & 1072,42 & $3,17 \times 10^{21}$ \\
& \multirow{2}{*}{5} & 20 & 158,23 & 1072,42 & $3,53 \times 10^{21}$ \\
& & 40 & 89,88 & 1060,85 & $2,00 \times 10^{21}$ \\
& & 50 & 87,35 & 1068,56 & $1,95 \times 10^{21}$ \\
\hline
\end{tabular}

Tabela 22 - Valores calculados da densidade atômica de oxigênio nos filmes de a-Si:H depositados pela segunda vez (B).

\begin{tabular}{|c|c|c|c|c|c|}
\hline Pot RF (W) & P (mTorr) & {$\left[\mathrm{H}_{2}\right](\%)$} & Área $\left(\mathrm{cm}^{-1}\right)$ & $\operatorname{Pico}\left(\mathrm{cm}^{-1}\right)$ & [0] $\left(\mathrm{at} / \mathrm{cm}^{3}\right)$ \\
\hline \multirow{4}{*}{250} & \multirow{4}{*}{5} & 0 & 63,20 & 1099,42 & $1,41 \times 10^{21}$ \\
\hline & & 20 & 7,67 & 1099,42 & $1,71 \times 10^{20}$ \\
\hline & & 40 & 42.75 & 1095,56 & $9.53 \times 10^{20}$ \\
\hline & & 60 & 176,10 & 1087,85 & $3.93 \times 10^{21}$ \\
\hline \multirow{4}{*}{250} & \multirow{4}{*}{10} & 0 & 9,32 & 1099,42 & $2,08 \times 10^{20}$ \\
\hline & & 20 & 49,03 & 1099,42 & $1,09 \times 10^{21}$ \\
\hline & & 30 & 44,10 & 1095,56 & $9,83 \times 10^{20}$ \\
\hline & & 50 & 119,27 & 1095,56 & $2,66 \times 10^{21}$ \\
\hline
\end{tabular}


Tabela 23 - Valores calculados da densidade atômica de oxigênio nos filmes de a-Si:H depositados pela terceira vez (C).

\begin{tabular}{|c|c|c|c|c|c|}
\hline Pot RF (W) & $\mathbf{P}$ (mTorr) & {$\left[\mathrm{H}_{2}\right](\%)$} & Área $\left(\mathrm{cm}^{-1}\right)$ & Pico $\left(\mathrm{cm}^{-1}\right)$ & {$[0]\left(\mathrm{at} / \mathrm{cm}^{3}\right)$} \\
\hline \multirow[b]{2}{*}{200} & \multirow[b]{2}{*}{5} & 20 & 99,01 & 1066,50 & $2,21 \times 10^{21}$ \\
\hline & & 50 & 215,83 & 1105,10 & $4,81 \times 10^{21}$ \\
\hline \multirow{3}{*}{200} & \multirow{3}{*}{10} & 20 & 181,87 & 1047,20 & $4,06 \times 10^{21}$ \\
\hline & & 40 & 66,73 & 1108,90 & $1,49 \times 10^{21}$ \\
\hline & & 50 & 79,29 & 1107,00 & $1,77 \times 10^{21}$ \\
\hline \multirow[t]{2}{*}{250} & 5 & 50 & 196,10 & 1099,30 & $4,37 \times 10^{21}$ \\
\hline & \multirow{3}{*}{10} & 20 & 60,67 & 1099,30 & $1,35 \times 10^{21}$ \\
\hline \multirow[t]{2}{*}{250} & & 40 & 54,56 & 1099,30 & $1,22 \times 10^{21}$ \\
\hline & & 50 & 117,72 & 1103,20 & $2,63 \times 10^{21}$ \\
\hline 300 & 5 & 50 & 258,25 & 1081,90 & $5,76 \times 10^{21}$ \\
\hline \multirow{3}{*}{300} & \multirow{3}{*}{10} & 20 & 47,51 & 1095,40 & $1,06 \times 10^{21}$ \\
\hline & & 40 & 114,56 & 1093,50 & $2,55 \times 10^{21}$ \\
\hline & & 50 & 148,02 & 1093,50 & $3,30 \times 10^{21}$ \\
\hline
\end{tabular}

Apesar de os substratos destes filmes serem lâminas de silício oxidadas, os espectros FTIR foram obtidos utilizando-se as próprias lâminas oxidadas como referência. Tendo em vista que a influência das ligações $\mathrm{SiO}$ dos filmes de $\mathrm{SiO}_{2}$ foi considerada constante entre todas as lâminas, a variação observada nas ligações $\mathrm{SiO}$, portanto, deve-se às ligações $\mathrm{SiO}$ presentes no filme de a-Si:H.

Assim, já que a concentração de oxigênio incorporado nos filmes foi maior que $10^{19} \mathrm{~cm}^{-3}$, como explicado no item 6.2, pode ser observado a partir dos valores das concentrações de oxigênio da tabela 13 que todos os filmes apresentam uma grande densidade de defeitos, associados com este elemento.

\subsection{Absorção óptica}

Os valores de Eg obtidos a partir dos espectros de absorção óptica variam tanto com os parâmetros de deposição como com o sistema utilizado [47]. Assim Hossain [47] obteve um valor de Eg em torno de $1.86 \mathrm{eV}$, para seus filmes depositados pela técnica PECVD, mas valores que variaram em torno de $2.04 \mathrm{eV}$, para seus filmes depositados pelo sistema magnetron sputtering. Hossain ainda propõe que a diferença entre estes valores típicos se deve às diferentes formas de incorporação do hidrogênio na matriz amorfa de silício. Todavia, para os filmes de boa qualidade obtidos por Pibril [22] seus valores de Eg variaram de 1.8 a 1.9 eV. Na figura 31 são mostrados os gráficos tanto dos valores de Eg como do parâmetro B da eq. (12) obtidos a partir das amostras depositadas a 5 e 10 mTorr. Como mencionado no 
item 5.5 o valor do parâmetro B é inversamente proporcional à largura de cauda das bordas das bandas.

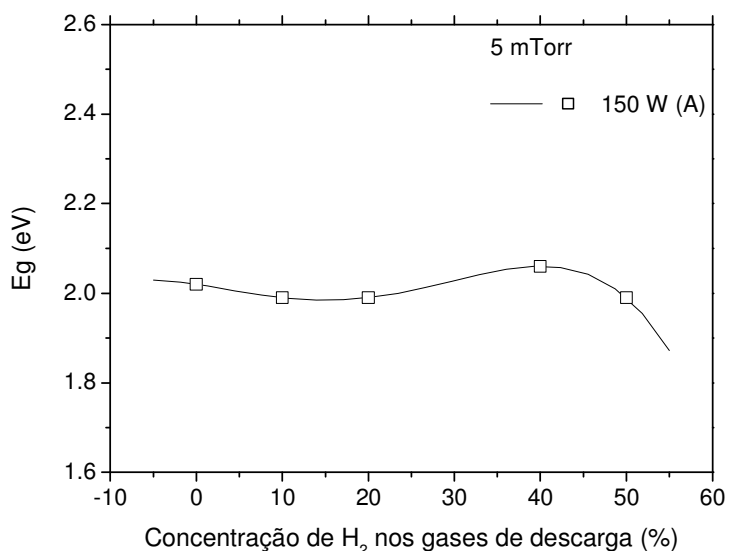

(a)

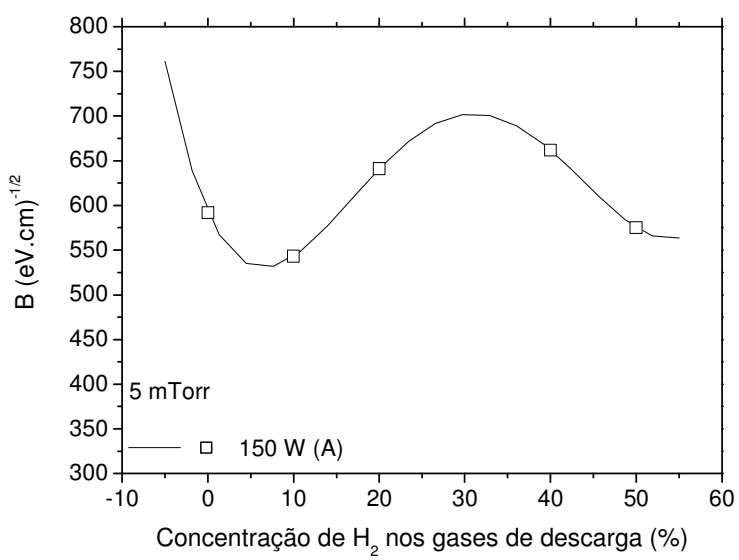

(c)

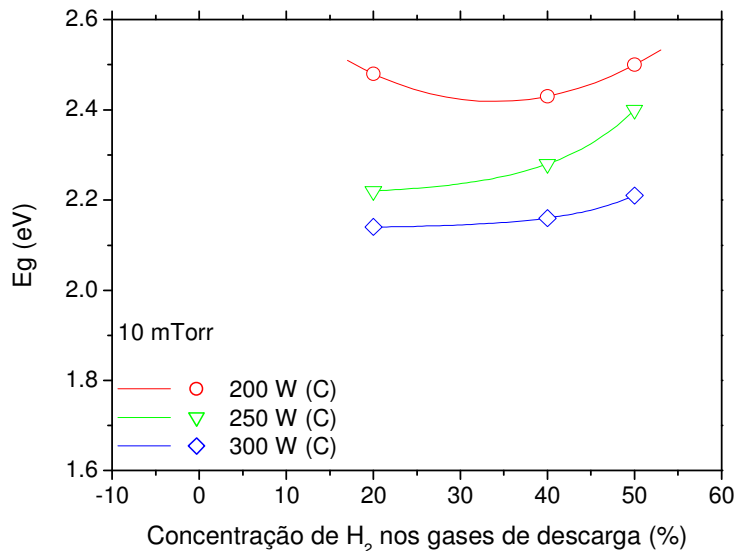

(b)

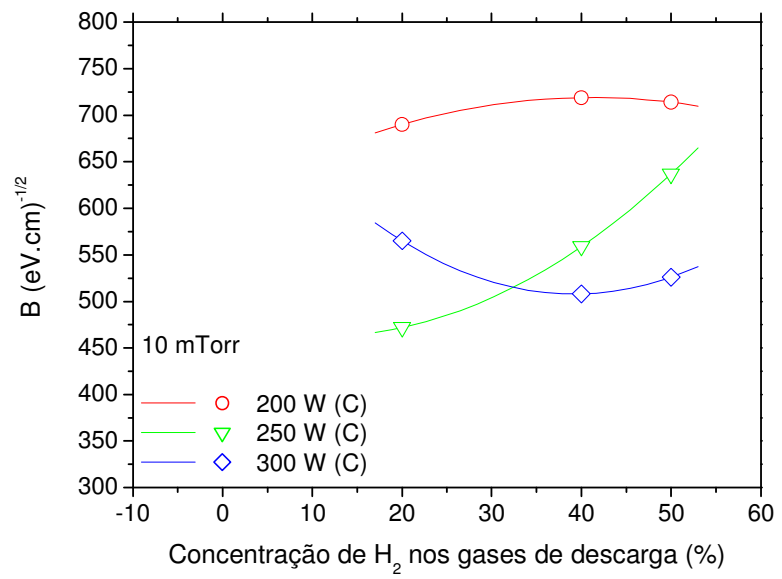

(d)

Figura 31 - Gráficos dos valores de Eg para 5 (a) e 10 mTorr (b) e de B para 5 (c) e 10 mTorr (d)

A seguir os valores de Eg e do parâmetro B são relacionados com as concentrações de ligações $\mathrm{SiH}$ estiramento, $\mathrm{SiH}_{2}$ dobramento e $\mathrm{SiH}_{3}$ dobramento como uma tentativa de explicação do efeito de aumento tanto dos valores de Eg como do parâmetro B com a compensação das ligações incompletas com átomos de hidrogênio, já que estes valores aumentam com a diminuição de defeitos na rede, como explicado no item 3.4.

A partir dos gráficos (a) e (b) da figura 31 pode ser observado que o aumento da pressão de 5 para 10 mTorr produziu aumentos dos valores de Eg, assim como no trabalho de Ishida [54] que utilizou apenas hidrogênio para o gás de descarga de seu reator magnetron sputtering. O aumento da potência produziu filmes com menores valores de Eg para a maioria das condições de deposição, principalmente para as amostras depositadas a 10 mTorr. Cuniot [58] também observou este efeito. 
Aqui e em vários outros trabalhos [18, 22, 24] houve um aumento dos valores de $\mathrm{Eg}$ com o aumento da concentração de hidrogênio nos gases de descarga. Todavia aqui isto aconteceu a partir de uma certa concentração. Pirnarbasi [24] sugeriu que este efeito se devia à eliminação de estados no topo da banda de valência, como pode ser visualizado a partir da figura 5.

Nos gráficos (a) e (c) da figura 31, o aumento da concentração de hidrogênio nos gases de descarga de 0 a $10 \%$, para os filmes depositadas pela primeira vez a 150 W e 5 mTorr, produziu uma diminuição tanto dos valores de Eg como do parâmetro B que assume seu valor mínimo. Nesta região dos gráficos (a) e (c) da figura 28 e do gráfico (a) da figura 29 pode ser observada uma redução da concentração tanto de ligações $\mathrm{SiH}_{3}$ dobramento, como de $\mathrm{SiH}$ estiramento, mas um aumento da concentração de ligações $\mathrm{SiH}_{2}$ dobramento, de modo que estes filmes com concentrações crescentes de ligações $\mathrm{SiH}_{2}$ dobramento, em detrimento da concentração de ligações $\mathrm{SiH}_{3}$ dobramento e $\mathrm{SiH}$ estiramento, apresentam uma grande desordem.

O aumento da concentração de hidrogênio nos gases de descarga de 10 a 20 $\%$, para os filmes depositados a $150 \mathrm{~W}$ e $5 \mathrm{mTorr}$, não proporcionou uma mudança significativa em seus valores de Eg, apesar de o parâmetro B ter aumentado. Nesta faixa houve um aumento da concentração de ligações $\mathrm{SiH}$ estiramento, $\mathrm{SiH}_{2}$ dobramento e $\mathrm{SiH}_{3}$ dobramento, de modo que a diminuição da desordem destes filmes se deveu ao relaxamento da rede da matriz amorfa pelo aumento da concentração de ligações $\mathrm{SiH}$ estiramento, $\mathrm{SiH}_{2}$ dobramento e $\mathrm{SiH}_{3}$ dobramento.

Para aumentos da concentração de hidrogênio nos gases de descarga de 20 a 40 \%, tanto os valores de Eg, como o parâmetro B aumentaram em decorrência da diminuição da concentração tanto de ligações $\mathrm{SiH}_{3}$ dobramento como de $\mathrm{SiH}_{2}$ dobramento assim como do aumento da concentração de ligações SiH estiramento. Desta forma a desordem da rede diminuiu com o aumento da concentração de ligações $\mathrm{SiH}$ estiramento em detrimento das de $\mathrm{SiH}_{3}$ dobramento e $\mathrm{SiH}_{2}$ dobramento.

Já para o aumento da concentração de hidrogênio nos gases de descarga de 40 a 50 \%, houve uma diminuição tanto dos valores de Eg, como do parâmetro B, já que as concentrações de ligações $\mathrm{SiH}$ estiramento e $\mathrm{SiH}_{2}$ dobramento diminuíram e as de $\mathrm{SiH}_{3}$ dobramento aumentaram. Desta forma, para estes filmes, a desordem da 
rede aumentou devido ao aumento da concentração de ligações $\mathrm{SiH}_{3}$ dobramento em detrimento das de $\mathrm{SiH}_{2}$ dobramento e $\mathrm{SiH}$ estiramento.

Ressalta-se que em cada caso o efeito dos diferentes tipos de ligação entre silício e hidrogênio na tesão mecânica da rede é diferente e que considera-se aqui a magnitude do parâmetro $\mathrm{B}$ como indicador do grau de desordem da rede.

Já os filmes depositados pela terceira vez a $200 \mathrm{~W}$ (C) e 10 mTorr foram os que apresentaram os maiores valores tanto de Eg como do parâmetro B de todas as amostras, apresar de apresentarem concentrações de SiH estiramento muito baixas. Assim o aumento da concentração de hidrogênio nos gases de descarga de 20 para $40 \%$ produziu um aumento no valor de B apesar da diminuição no valore de Eg. O relaxamento da rede se deve ao aumento da concentração tanto de ligações SiH estiramento como de $\mathrm{SiH}_{2}$ dobramento em detrimento da de $\mathrm{SiH}_{3}$ dobramento que diminuiu.

Para o aumento da concentração de hidrogênio nos gases de descarga de 40 para 50 \% houve uma diminuição do parâmetro B, apesar de o valor de Eg ter aumentado. Este aumento da tensão da rede se deve ao aumento das concentrações tanto de ligações $\mathrm{SiH}_{3}$ dobramento como de $\mathrm{SiH}_{2}$ dobramento em detrimento da de SiH estiramento que diminuiu.

O aumento da potência de 200 para $250 \mathrm{~W}$, ainda considerando as amostras depositadas pela terceira vez a 10 mTorr, produziu amostras com valores de B e Eg que cresceram com a concentração de hidrogênio nos gases de descarga. Este relaxamento da rede em toda a faixa ocorreu devido à diminuição da concentração de ligações $\mathrm{SiH}_{3}$ dobramento também em toda faixa e aumento da concentração de ligações $\mathrm{SiH}$ estiramento de 20 a $40 \%$, para valores quase inalterados de concentração de ligações $\mathrm{SiH}_{2}$ dobramento, e extinção de ligações $\mathrm{SiH}$ estiramento de 40 a 50 \%, para o aumento da concentração de ligações $\mathrm{SiH}_{2}$ dobramento.

Por fim, as amostras depositadas pela terceira vez a $300 \mathrm{~W}$ e 10 mTorr apresentaram os menores valores de Eg entre as amostras depositadas a 10 mTorr. O aumento da concentração de hidrogênio nos gases de descarga de 20 para 40 \% produziu um aumento do valor de Eg apesar de uma diminuição do valor de B. Este aumento da desordem na rede se deveu ao aumento das concentrações tanto de $\mathrm{SiH}_{3}$ dobramento como de $\mathrm{SiH}_{2}$ dobramento em detrimento da concentração de ligações $\mathrm{SiH}$ estiramento que diminuiu. 
O aumento da concentração de hidrogênio nos gases de descarga de 40 para 50 \% produziu um aumento tanto do valor de Eg como do parâmetro B. Esta pequena diminuição da desordem do filme de a-Si:H se deveu à diminuição tanto de ligações $\mathrm{SiH}_{3}$ dobramento como de $\mathrm{SiH}_{2}$ dobramento, apesar de as ligações $\mathrm{SiH}$ estiramento terem se extinguido.

Para efeito de comparação, as amostras de a-Si sem hidrogênio não apresentam variações de Eg e B com as condições de preparação [22], de modo que estes valores se mantém, respectivamente, em 1.4 eV e 385 (eV.cm) ${ }^{-1 / 2}$ aproximadamente.

Os valores de B obtidos por Freeman [49] em seus filmes depositados entre 200 e $250{ }^{\circ} \mathrm{C}$ estão entre 690 e 760 (eV.cm) ${ }^{-1 / 2}$, ficando próximos dos valores obtidos para algumas amostras estudadas neste trabalho. No trabalho de Shirafuji [59] os valores de $\mathrm{Eg}$ de seus filmes não foram afetados pela presença de oxigênio em concentrações de $10^{21} \mathrm{~cm}^{-3}$, semelhantes às obtidas neste trabalho, conforme pode ser observado nos itens 6.2 e 6.3.4. Todavia Shimizu [52] alerta que contaminantes podem alterar Eg.

\subsection{Condutividade}

A fotocondutividade e a condutividade de escuro são muito sensíveis tanto aos parâmetros deposição quanto ao tipo e ao conteúdo de impurezas [53]. Desta forma, no trabalho de Morimoto [53] o aumento da concentração de nitrogênio e oxigênio proporcionou um aumento da condutividade de escuro devido ao aumento da densidade de estados de aprisionamento de elétrons quando as impurezas presentes estão em grandes concentrações.

A fotocontutividade aumenta em ordens de grandeza em altas concentrações de oxigênio e nitrogênio, como observado por Jiranapakul [59]. Nestas condições a condução em saltos entre estados localizados da banda proibida, definida no item 3.5, é grande, o que compromete a condução entre bandas. Com o aumento da condução em saltos as propriedades semicondutoras, em especial a fotosensibilidade (razão entre fotodondutividade e condutividade de escuro), passa a não ser tão alta quanto a que poderiam ser obtidas, caso os filmes apresentassem densidades de contaminantes tão baixas quanto $10^{19} \mathrm{~cm}^{3}$. 
$\mathrm{Na}$ figura 32 são mostrados os gráficos de condutividade de escuro e da fotosensibilidade para os filmes depositados tanto a 5 como a 10 mTorr e no apêndice E são mostrados os gráficos de condutividade de escuro juntamente com os da fotocondutividade dos filmes depositados em mais de uma concentração de hidrogênio nos gases de descarga.

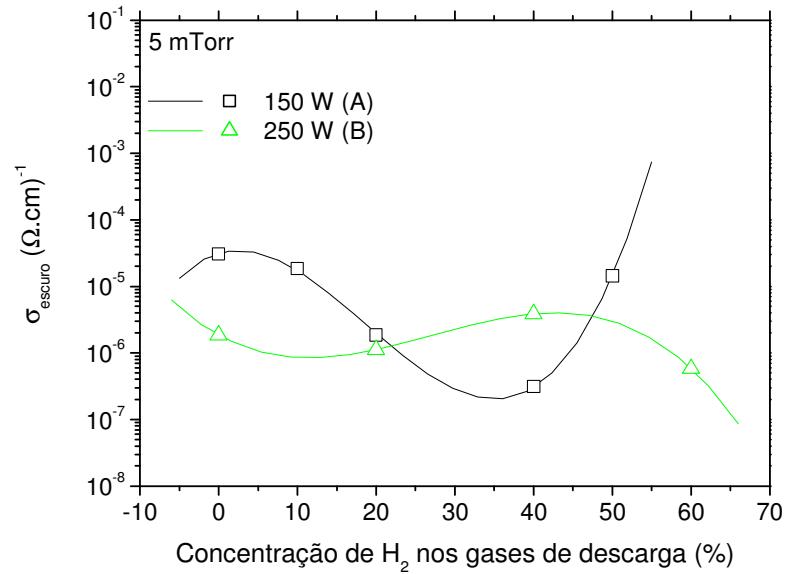

(a)

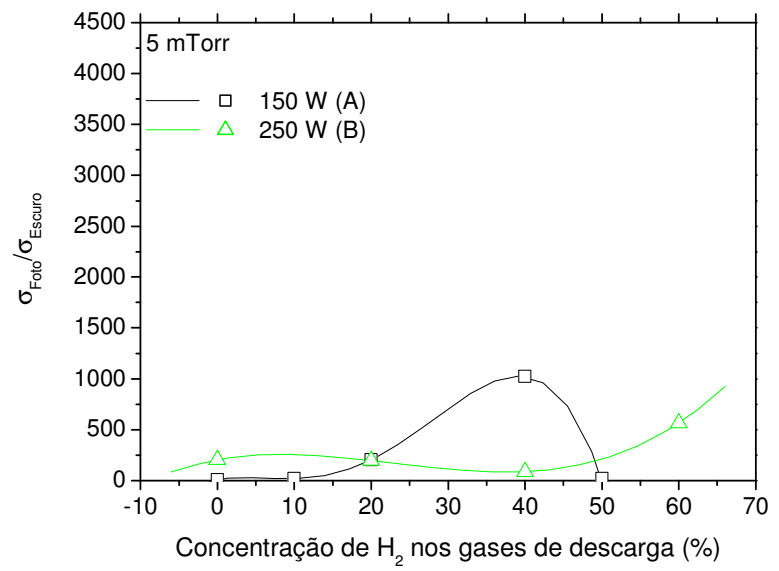

(c)

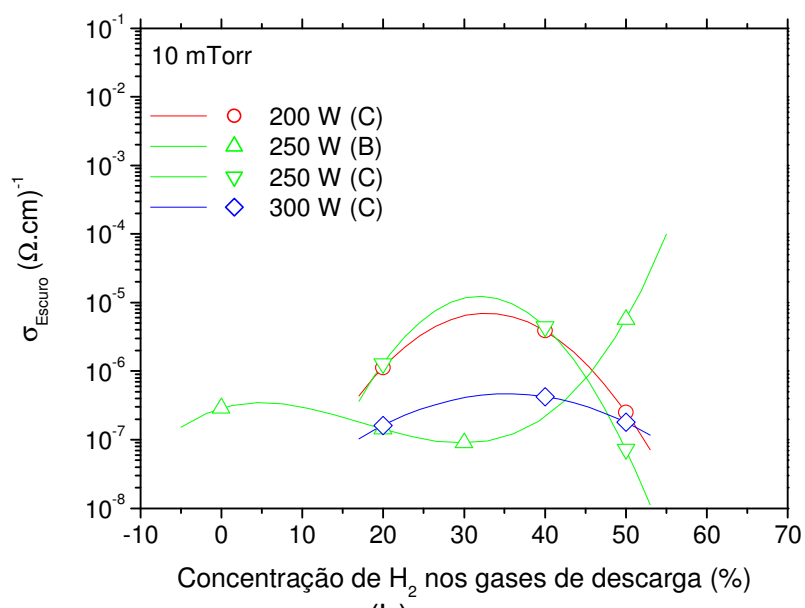

(b)

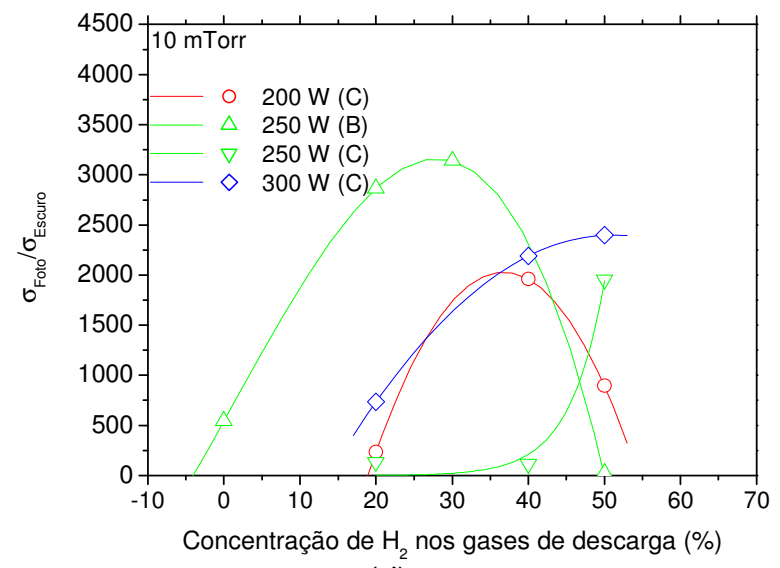

(d)

Figura 32 - Condutividade de escuro para as amostras depositadas a 5 mTorr (a) e 10 mTorr (b) e razão entre fotocondutividade e condutividade de escuro para 5 mTorr (c) e 10 mTorr (d).

Sabe-se a partir da literatura que tanto a condutividade de escuro como a fotocondutividade dependem dos parâmetros de deposição e do sistema de deposição pelo sistema magnetron sputtering. Assim, os parâmetros como densidade de potência, pressão total e concentração de hidrogênio nos gases de descarga devem ser otimizados para cada sistema, já que as condições de operação dos trabalhos encontrados na literatura variaram de sistema para sistema, como pode ser observado ao longo deste trabalho quando são feitas comparações com as condições de operação de outros trabalhos. Esta variação das condições de operação destes sistemas tipo diodo descritos na literatura ocorre devido à utilização 
de diferentes distâncias entre os eletrodos. Desta forma, o comportamento da condutividade dos filmes de a-Si:H em função da ampla faixa de parâmetros de deposição estudada ajuda a elucidar o comportamento dos filmes pela correlação entre os resultados de condutividade obtidos pelas outras técnicas de análise e assim poder ser elegidos os melhores parâmetros de deposição, como é feito a seguir.

Para os filmes de a-Si:H depositados pela primeira vez a $150 \mathrm{~W}$, 5 mTorr e $0 \%$ de hidrogênio nos gases de descarga a condutividade de escuro, cujo valor é de $3 \times 10^{-5}(\Omega . \mathrm{cm})^{-1}$, é a maior dentre todas as amostras investigadas, apresentando, portanto, a menor fotosensibilidade, igual a 10, como observado na figura 32. Nos gráficos (a) e (c) da figura 31, para esta concentração de hidrogênio nos gases de descarga o parâmetro $B$ apresentou um valor não muito baixo de $592(\mathrm{eV} . \mathrm{cm})^{-1 / 2}$, mas o segundo maior valor de Eg de $2.02 \mathrm{eV}$. Como nos gráficos (a) e (c) da figura 28 e (a) da figura 29 são apresentados, respectivamente, a maior concentração de ligações $\mathrm{SiH}_{3}$ entre as amostras depositadas a 5 mTorr para uma das menores concentrações tanto de $\mathrm{SiH}_{2}$ dobramento, como de $\mathrm{SiH}$ dentre as amostras depositadas a 5 mTorr, estes filmes apresentam uma grande densidade de defeitos, predominando a condução por saltos entre estados da banda proibidaque reflete tanto no valor muito baixo da fotosensibilidade como no valor muito alto de condutividade de escuro.

Com o aumento da concentração de hidrogênio nos gases de descarga de 0 para $10 \%$ a condutividade de escuro começa a diminuir, passando de $3 \times 10^{-5}$ a $2 \times 10^{-5}(\Omega . \mathrm{cm})^{-1}$, da mesma forma que a fotosensibilidade começa a aumentar, passando de 10 para 23. Apesar da ligeira melhora na condutividade, o parâmetro $B$ atingiu um valor mínimo, diminuindo de 592 a $543(\mathrm{eV} . \mathrm{cm})^{-1 / 2}$, sendo que o valor de Eg diminui de 2.02 para $1.99 \mathrm{eV}$. Como as concentrações tanto de ligações $\mathrm{SiH}_{3}$ dobramento como de $\mathrm{SiH}$ estiramento diminuíram um pouco e as de $\mathrm{SiH}_{2}$ dobramento começaram a aumentar, a matriz amorfa de silício começa a se alterar para acomodar mais ligações $\mathrm{SiH}_{2}$ em detrimento das de $\mathrm{SiH}_{3}$ e $\mathrm{SiH}$, de modo que a concentração total de hidrogênio nos filmes depositados pela primeira vez a $150 \mathrm{~W}$ e 5 mTorr aumentou como mostrado no gráfico (a) da figura 27. Esta incorporação de mais ligações $\mathrm{SiH}_{2}$ dobramento favoreceu a diminuição da condutividade de escuro 
e aumento da fotocondutividade, apesar de a tensão na rede ter aumentado um pouco.

O aumento da concentração total de hidrogênio nos gases de descarga de 10 para 20 \% produziu uma diminuição ainda maior da condutividade de escuro, que passou de $2 \times 10^{-5}$ a $2 \times 10^{-6}(\Omega . \mathrm{cm})^{-1}$, assim como da fotosensibilidade que passou de 23 para 204. Desta forma o parâmetro B aumentou de 543 a 641 (eV.cm) ${ }^{-1 / 2}$, apesar de o valor de Eg ter permanecido em $1.99 \mathrm{eV}$. Nesta mesma faixa as concentrações de ligações $\mathrm{SiH}_{3}, \mathrm{SiH}_{2}$ dobramento e $\mathrm{SiH}$ aumentaram atingindo os valores máximos para as duas primeiras, apesar de a concentração de ligações SiH estiramento continuar aumentando. Desta forma, nesta região, o filme incorporou bastante hidrogênio nas formas das três ligações, o que produziu uma redução na densidade de defeitos pela compensação de ligações incompletas de todas as formas.

Para o aumento da concentração de hidrogênio nos gases de descarga de 20 para $40 \%$ tanto a condutividade de escuro assume seu valor mínimo, passando de $2 \times 10^{-6}$ a $3 \times 10^{-7}(\Omega . \mathrm{cm})^{-1}$, como a fotosensibilidade atinge seu valor máximo, passando de 204 a 1025. Desta forma, tanto o parâmetro $B$, que passou de 641 a $662(\mathrm{eV} . \mathrm{cm})^{-1 / 2}$, como Eg, que passou de 1.99 a $2.06 \mathrm{eV}$, atingem seus valores máximos, estando estes valores entre os maiores obtidos para os filmes depositados a 5 mTorr. Com este aumento a concentração de ligações $\mathrm{SiH}_{3}$ atinge um valor mínimo, a de ligações $\mathrm{SiH}_{2}$ dobramento passou a diminuir e a de $\mathrm{SiH}$ atinge um máximo. Estes resultados obtidos a $40 \%$ de hidrogênio nos gases de descarga são bem coerentes, já que a predominância de ligações $\mathrm{SiH}$ em detrimento das de $\mathrm{SiH}_{3}$ e $\mathrm{SiH}_{2}$ dobramento produziu filmes com os mínimos valores de condutividade de escuro e máximos de fotosensibilidade entre os filmes depositados a 5 mTorr.

Com o aumento da concentração de hidrogênio nos gases de descarga de 40 a $50 \%$ a condutividade de escuro passa a aumentar de $3 \times 10^{-7}$ a $1 \times 10^{-5}(\Omega . \mathrm{cm})^{-1}$ e a fotosensibilidade a diminuir de 1025 a 21. Desta forma, assim como o parâmetro $B$ diminuiu passando de 662 a 575 (eV.cm) $)^{-1 / 2}$, Eg também diminuiu passando de 2.06 a $1.99 \mathrm{eV}$, já que a concentração de ligações $\mathrm{SiH}_{3}$ dobramento começa a aumentar prevalecendo sobre as de $\mathrm{SiH}$ estiramento e $\mathrm{SiH}_{2}$ dobramento que começam a diminuir.

Para as amostras depositadas a pela segunda vez a 250 W e 5 mTorr, a condutividade de escuro não variou em uma faixa tão ampla como a das amostras 
depositadas a $150 \mathrm{~W}$. Assim, com este aumento de potência a condutividade de escuro diminuiu de $2 \times 10^{-6}$ para $1 \times 10^{-6}(\Omega . \mathrm{cm})^{-1}$ para o aumento da concentração de hidrogênio nos gases de descarga de 0 para $20 \%$, o que produziu valores muito semelhantes para a fotosensibilidade que variou de 205 a 195. Apesar dos valores de $\mathrm{B}$ e Eg não serem obtidos para as amostras depositadas pela segunda vez a depositadas a $250 \mathrm{~W}$ e 5 mTorr, o comportamento da condutividade pode ser entendido em termos das ligações entre silício e hidrogênio, como está sendo feito neste trabalho. Assim nesta faixa de concentração de hidrogênio nos gases de descarga houve um pequeno aumento da concentração de ligações $\mathrm{SiH}_{2}$ dobramento para uma pequena diminuição tanto da concentração de ligações SiH estiramento como da de $\mathrm{SiH}_{3}$ dobramento. Desta forma a amostra que apresenta a menor condutividade tem um pequeno predomínio de ligações $\mathrm{SiH}_{2}$ dobramento em detrimento das de $\mathrm{SiH}$ estiramento e $\mathrm{SiH}_{3}$ dobramento.

O aumento da concentração de hidrogênio nos gases de descarga de 20 para $40 \%$ produziu filmes de a-Si:H depositados pela segunda vez a $250 \mathrm{~W}$ e 5 mTorr com os maiores valores de condutividade de escuro desta potência e pressão, que aumentou de $1 \times 10^{-6}$ para $4 \times 10^{-6}(\Omega . \mathrm{cm})^{-1}$, e menores valores de fotosensibilidade, que diminuiu de 197 para 88. Este comportamento da condutividade está coerente com a ligeira diminuição da concentração de ligações SiH estiramento assim como com os ligeiros aumentos tanto da concentração de ligações $\mathrm{SiH}_{3}$ dobramento como da de $\mathrm{SiH}_{2}$ dobramento, que por sua vez aumentou um pouco mais.

Já o aumento da concentração de hidrogênio nos gases de descarga de 40 para $60 \%$ produziu uma diminuição da condutividade de escuro de $4 \times 10^{-6}$ para $6 \times 10^{-7}$ $(\Omega . \mathrm{cm})^{-1}$ e um aumento da fotosensibilidade de 88 para 566. Esta melhora no comportamento elétrico se deveu ao aumento da concentração de ligações $\mathrm{SiH}$ estiramento, que assumiu o maior valor dentre os obtidos para os filmes depositados a $250 \mathrm{~W}$ e 5 mTorr, e à ligeira diminuição tanto da concentração de ligações $\mathrm{SiH}_{3}$ como a de $\mathrm{SiH}_{2}$.

O aumento da pressão para 10 mTorr produziu alguns filmes com os menores valores de condutividade de escuro e maiores fotosensibilidades dentre os obtidos neste trabalho, apesar de serem obtidas as menores concentrações de ligações $\mathrm{SiH}$ destes filmes. Assim para os filmes depositados pela terceira vez a $200 \mathrm{~W}$ e 10 mTorr, o aumento da concentração de hidrogênio nos gases de descarga de 20 para 
$40 \%$ produziu um aumento da condutividade de escuro de $1 \times 10^{-6}$ a $4 \times 10^{-6}(\Omega . \mathrm{cm})^{-1}$, apesar de a fotosensibilidade ter aumentado de 235 para 1960, como pode ser observado nos gráficos (b) e (d) da figura 32. Desta forma, a partir dos gráficos (b) e (d) da figura 31 pode ser observado que houve um aumento de B de 472 para 559 $(\mathrm{eV} . \mathrm{cm})^{-1 / 2}$, apesar de o valor de Eg ter diminuído de 2.48 para $2.43 \mathrm{eV}$. Assim, a partir dos gráficos (b) e (d) da figura 28 e (b) da figura 29, constata-se que a diminuição da concentração de ligações $\mathrm{SiH}_{3}$, e o aumento tanto da concentração de ligação $\mathrm{SiH}_{2}$ dobramento como de $\mathrm{SiH}$ foram suficientes para produzir filmes com maiores fotosensibilidade.

Já para o aumento da concentração de hidrogênio nos gases de descarga de 40 para $50 \%$, houve uma diminuição tanto da condutividade de escuro, que passou de $4 \times 10^{-6}$ para $3 \times 10^{-7}(\Omega . \mathrm{cm})^{-1}$, como da fotosensibilidade, que passou de 1960 para 896, o que pode estar relacionado com a pequena diminuição do parâmetro $B$, que passou de 719 para $714(\mathrm{eV} . \mathrm{cm})^{-1 / 2}$, apesar de Eg ter aumentado de 2.45 para 2.50 eV. Assim, como as concentrações de ligações $\mathrm{SiH}_{3}$ e de $\mathrm{SiH}_{2}$ dobramento aumentaram e a de SiH diminuiu, estes filmes depositados a 50 \% de hidrogênio têm uma maior densidade de defeitos.

O aumento da potência de $200 \mathrm{~W}$ para $250 \mathrm{~W}$ produziu filmes de a-Si:H pela segunda vez com menores valores de condutividade de escuro, assim como maiores de fotosensibilidades em uma ampla faixa de concentração de hidrogênio nos gases de descarga. Desta forma o aumento da concentração de hidrogênio de 0 para $20 \%$ proporcionou uma diminuição da condutividade de escuro de $3 \times 10^{-7}$ para $1 \times 10^{-7}$ $(\Omega . \mathrm{cm})^{-1}$ e um aumento da fotosensibilidade de 545 para 2865. Para estas amostras não foram obtidos os espectros de absorção óptica. Todavia apesar da diminuição da condutividade de escuro e aumento da fotosensibilidade, a concentração de ligações $\mathrm{SiH}_{3}$ aumentou, a de $\mathrm{SiH}$ diminuiu e a de $\mathrm{SiH}_{2}$ praticamente não variou.

Já o aumento da concentração de hidrogênio nos gases de descarga de 20 para $30 \%$ produziu amostras com os menores valores de condutividade de escuro dentre as amostras depositadas pela segunda vez, que diminuindo de $1 \times 10^{-7}$ para $9 \times 10^{-8}$ $(\Omega . \mathrm{cm})^{-1}$, e com os maiores valores de fotosensibilidade, que aumentou de 2865 para 3140. Este bom comportamento da condutividade se reflete na diminuição da concentração de ligações $\mathrm{SiH}_{3}$ dobramento e aumento das concentrações tanto de $\mathrm{SiH}$ estiramento como de $\mathrm{SiH}_{2}$ dobramento. 
Todavia as amostras depositadas pela terceira vez a $250 \mathrm{~W}$ e 10 mTorr apresentaram um comportamento diferente. Com os valores de condutividade de escuro semelhantes aos obtidos para os filmes depositados a $200 \mathrm{~W}$, na faixa de 20 a $40 \%$ de hidrogênio nos gases de descarga há um aumento da condutividade de escuro de $1 \times 10^{-6}$ para $4 \times 10^{-6}(\Omega . \mathrm{cm})^{-1}$. Este aumento da condutividade de escuro produziu uma pequena diminuição da fotosensibilidade de 133 para 116, apesar do aumento tanto de $B$, que passou de 472 para 559 (eV.cm $)^{-1 / 2}$, como de Eg, que passou de 2.22 para $2.28 \mathrm{eV}$. Como a concentração de ligações $\mathrm{SiH}_{3}$ diminuiu e a de $\mathrm{SiH}$ aumentou, ficando a concentração de ligações $\mathrm{SiH}_{2}$ praticamente inalterada, o filme com maior condutividade de escuro teria uma menor densidade de defeitos.

Com o aumento da concentração de hidrogênio nos gases de descarga de 40 para $50 \%$ houve uma diminuição da condutividade de escuro de $4 \times 10^{-6}$ para $7 \times 10^{-8}$ $(\Omega . \mathrm{cm})^{-1}$, sendo este o menor valor de condutividade de escuro obtido para os filmes estudados neste trabalho. Desta forma a fatosensibilidade, apesar de não ter sido a maior, aumentou de 116 para 1954. Assim houve um aumento tanto do valor de Eg, que passou de 2.28 para $2.4 \mathrm{eV}$, como dos valores de $\mathrm{B}$, que passaram de 559 a $637(\mathrm{eV} . \mathrm{cm})^{-1 / 2}$, já que a concentração de ligações $\mathrm{SiH}_{3}$ dobramento atingiu um valor mínimo e a de $\mathrm{SiH}_{2}$ dobramento um valor máximo, apesar de não serem encontradas ligações SiH estiramento.

Por fim o aumento da potência de $250 \mathrm{~W}$ para $300 \mathrm{~W}$ proporcionou uma diminuição da condutividade de escuro quando comparada com a dos filmes do segundo conjunto. Assim o aumento da concentração de hidrogênio nos gases de descarga de 20 para $40 \%$ produziu um aumento da condutividade de escuro de $2 \times 10^{-7}$ para $4 \times 10^{-7}(\Omega . \mathrm{cm})^{-1}$, mas um aumento da razão fotosensibilidade de 736 a 2190. Desta forma, apesar de os valores de B terem diminuído de 565 a 508 $(\mathrm{eV} . \mathrm{cm})^{-1 / 2}$, os valores de Eg aumentaram de 2.14 para $2.16 \mathrm{eV}$. Esta redução dos valores de $B$, que ocorreu devido ao aumento da concentração tanto de ligações $\mathrm{SiH}_{3}$ dobramento como de $\mathrm{SiH}_{2}$ dobramento e diminuição da concentração de ligações $\mathrm{SiH}$ estiramento, não foi suficiente para a diminuição da razão fotosensibilidade.

Com o aumento da concentração de hidrogênio nos gases de descarga de 40 para $50 \%$ a condutividade de escuro diminuiu de $4 \times 10^{-7}$ para $2 \times 10^{-7}(\Omega . \mathrm{cm})^{-1} \mathrm{e}$ fotosensibilidade aumentou de 2190 para 2398 . Como houve um aumento tanto do 
valor de Eg, que passou de 2.16 para $2.21 \mathrm{eV}$, como do parâmetro $\mathrm{B}$, que passou de 508 a $526(\mathrm{eV} . \mathrm{cm})^{-1 / 2}$, houve uma diminuição tanto da concentração de ligações $\mathrm{SiH}_{3}$ dobramento como da de ligações $\mathrm{SiH}_{2}$ dobramento, apesar de não serem encontradas ligações $\mathrm{SiH}$ estiramento. 


\section{FILMES MAIS FOTOSENSÍVIES}

Sendo a fotosensibilidade um parâmetro muito importante para dispositivos de filme fino, principalmente células solares, os filmes mais fotosensíveis de cada série de potência são mostrados nas tabelas 24 e 25, para os filmes depositados, respectivamente, a $5 \mathrm{mTorr}$ e $10 \mathrm{mTorr}$. Nestas tabelas são apresentados também os parâmetros de caracterização de cada filme, de modo que $\left[\mathrm{H}_{\text {Total }}\right]$ se refere à concentração total de hidrogênio, $[\mathrm{SiH}]$ à concentração de ligações SiH estiramento e tanto $\left[\mathrm{SiH}_{2}\right]$ como $\left[\mathrm{SiH}_{3}\right]$ às áreas integradas destas ligações obtidas a partir dos espectros FTIR. Estas áreas são proporcionais às concentrações de ligações $\mathrm{SiH}_{2}$ dobramento e $\mathrm{SiH}_{3}$ dobramento.

Tabela 24 - Características dos filmes de a-Si:H obtidos a 5 mTorr que obtiveram as maiores razões $\sigma_{\mathrm{Foto}} / \sigma_{\mathrm{Escuro}}$ do conjunto de cada série de potência de $R F$ investigada.

\begin{tabular}{|c|c|c|c|c|c|c|c|c|c|}
\hline $\begin{array}{l}\text { Pot } \\
\text { (W) }\end{array}$ & $\begin{array}{l}{\left[\mathrm{H}_{2}\right]} \\
(\%)\end{array}$ & $\begin{array}{l}\sigma_{\text {Escuro }} \\
(\Omega . c m)^{-1}\end{array}$ & $\begin{array}{l}\sigma_{\text {Foto }} \\
\sigma_{\text {Esc }}\end{array}$ & $\begin{array}{c}\mathrm{Eg} \\
(\mathrm{eV})\end{array}$ & $\begin{array}{c}\text { B } \\
(\mathrm{eV} \cdot \mathrm{cm})^{-1 / 2} \\
\end{array}$ & $\begin{array}{l}{\left[\mathrm{H}_{\text {Total }}\right]} \\
(\text { at. \%) }\end{array}$ & $\begin{array}{c}{[\mathrm{SiH}]} \\
\text { (at. \%) }\end{array}$ & $\begin{array}{l}{\left[\mathrm{SiH}_{2}\right]} \\
\left(\mathrm{cm}^{-1}\right) \\
\end{array}$ & $\begin{array}{l}{\left[\mathrm{SiH}_{3}\right]} \\
\left(\mathrm{cm}^{-1}\right)\end{array}$ \\
\hline $150(A)$ & 40 & $3 \times 10^{-7}$ & 1025 & 2,05 & 662 & 8,4 & 4,41 & 20,7 & 11,3 \\
\hline $250(B)$ & 60 & $6 \times 10^{-7}$ & 566 & - & - & 8,7 & 3 & 15,5 & 3 \\
\hline
\end{tabular}

Tabela 25 - Características dos filmes de a-Si:H obtidos a $10 \mathrm{mTorr}$ que obtiveram as maiores razões $\sigma_{\text {Foto }} / \sigma_{\text {Escuro }}$ do conjunto de cada série de potência de RF investigada.

\begin{tabular}{|c|c|c|c|c|c|c|c|c|c|}
\hline $\begin{array}{l}\text { Pot } \\
\text { (W) }\end{array}$ & $\begin{array}{l}{\left[\mathrm{H}_{2}\right]} \\
(\%)\end{array}$ & $\begin{array}{c}\sigma_{\text {Escuro }} \\
(\Omega . \mathrm{cm})^{-1}\end{array}$ & $\begin{array}{l}\sigma_{\text {Foto }} \\
\sigma_{\text {Esc }}\end{array}$ & $\begin{array}{l}\mathrm{Eg} \\
(\mathrm{eV})\end{array}$ & $\begin{array}{c}\text { B } \\
(\mathrm{eV} \cdot \mathrm{cm})^{-1 / 2}\end{array}$ & $\begin{array}{l}{\left[\mathrm{H}_{\text {Total }}\right]} \\
(\text { at. \%) }\end{array}$ & $\begin{array}{c}\text { [SiH] } \\
\text { (at. \%) }\end{array}$ & $\begin{array}{l}{\left[\mathrm{SiH}_{2}\right]} \\
\left(\mathrm{cm}^{-1}\right)\end{array}$ & $\begin{array}{l}{\left[\mathrm{SiH}_{3}\right]} \\
\left(\mathrm{cm}^{-1}\right)\end{array}$ \\
\hline $250(\mathrm{~B})$ & 30 & $9 \times 10^{-8}$ & 3140 & - & - & 3,7 & 0,24 & 25 & 4 \\
\hline $300(\mathrm{C})$ & 50 & $2 \times 10^{-7}$ & 2398 & 2,21 & 526 & 7,8 & - & 30,5 & 19 \\
\hline 200 (C) & 40 & $4 \times 10^{-6}$ & 1960 & 2,43 & 719 & 6,7 & 0,67 & 28 & 14 \\
\hline 250 (C) & 50 & $7 \times 10^{-8}$ & 1954 & 2,40 & 637 & 5 & - & 18,8 & 12 \\
\hline
\end{tabular}

A partir dos dados das tabelas 24 e 25 pode-se dizer que neste trabalho, assim como em trabalhos recentes como o de Kim [1] que utilizaram sistemas magnetron sputtering, as maiores fotosensibilidade foram da ordem de $10^{3}$. Por outro lado Oyama [14] obteve filmes finos de $\mu \mathrm{c}-\mathrm{Si} \mathrm{H}$ também com a técnica magnetron sputtering RF obtendo filmes a $200{ }^{\circ} \mathrm{C}$ com uma fotosensibilidade de $10^{2}$, sendo chamados por ele de filmes com alta qualidade. Como Phuong [60] obteve seus filmes de a-Si:H com uma fotosensibilidade da ordem de $10^{2}$ por um sistema magnetron sputtering DC a temperatura ambiente e uma pressão base de $2 \times 10^{-6}$ Torr e sendo seus filmes considerados apropriados para aplicações de sensores fotocondutores, os filmes mais fotosensíveis obtidos neste trabalho poderiam igualmente ser usados para esta aplicação. 
O parâmetro microestrutural $\left(\mathrm{Si}-\mathrm{H}_{2} /\left(\mathrm{Si}-\mathrm{H}_{2}+\mathrm{Si}-\mathrm{H}\right)\right)$ destes filmes foi maior que 60 $\%$, chegando até $100 \%$, para todos os filmes, indicando que estes filmes devem apresentar muitas micro-lacunas ou muitos contornos de grão. Vale a pena mencionar que a utilização de altas pressões totais pode levar ao crescimento de filmes porosos [11]. Todavia, como os filmes que apresentaram as maiores fotosensibilidades foram os depositados a 10 mTorr e, já que foi constatado que em altas pressões há o favorecimento da formação de nano ou micro cristais [13], os maiores parâmetros microestruturais dos filmes depositados a 10 mTorr poderiam estar associados a contornos de grãos, justificando assim as maiores fotosensibilidade que a dos filmes depositados a 5 mTorr.

Com relação à concentração total de hidrogênio incorporado ao filme, apesar do aumento da pressão de 5 para 10 mTorr ter acarretado na diminuição do conteúdo total de hidrogênio, a concentração de ligações $\mathrm{SiH}_{2}$ dobramento e $\mathrm{SiH}_{3}$ dobramento foi maior para os filmes depositados na maior pressão. A alta concentração destas ligações foi acompanhada pela grande diminuição da concentração de ligações $\mathrm{SiH}$ estiramento, que quase se extinguiram, reforçando a hipótese de ter havido alguma nucleação.

A fim de se tentar aumentar a fotosensibilidade dos filmes, foram realizadas tentativas de tratamentos térmicos em fornos RTP no LME às temperaturas de 200, 225, 250 e $275{ }^{\circ} \mathrm{C}$. Todavia, devido ao aquecimento por irradiação das amostras, que foram colocadas sobre um substrato de quartzo, o aquecimento não foi uniforme, havendo um sobreaquecimento de algumas amostras acarretando na formação de superfícies muito rugosas e difusão excessiva dos contatos metálicos para dentro dos filmes. Apesar de muitas amostras terem sido danificadas com estes tratamentos, as que permaneceram intactas foram submetidas ao levantamento de curvas I-V, sendo que a condutividade das amostras que apresentaram contatos ôhmicos, não variou significativamente após os tratamentos térmicos. Assim, podese concluir que este tratamento não produziu alterações significativas na densidade de estados dos filmes investigados neste trabalho. 


\section{CONCLUSÃO}

Neste trabalho foi investigado todo o conjunto de amostras de a-Si:H depositadas pelo sistema magnetron sputtering, em temperaturas menores do que $100^{\circ} \mathrm{C}$. Este conjunto se subdividiu em amostras depositadas a pressões de 5 e 10 mTorr, sendo que em cada uma delas foram obtidos filmes a partir de diferentes potências de RF e várias concentrações de hidrogênio nos gases de descarga.

Os filmes com as maiores fotosensibilidades, depositados a 10 mTorr, apresentaram as menores concentrações de hidrogênio incorporado ao filme durante a deposição e maiores concentrações de ligações $\mathrm{SiH}_{2}$ dobramento e $\mathrm{SiH}_{3}$ dobramento que a dos filmes depositados a 5 mTorr. Desta forma este resultado pode ser indicativo de nucleação nos filmes depositados a 10 mTorr, uma vez que justamente eles foram os mais fotosensíveis sendo que eles apresentaram uma concentração de ligações $\mathrm{SiH}$ estiramento quase nula. Outra possibilidade seria a formação de estruturas com muitos espaços vazios do tipo microlacunas que atribuem um caráter poroso ao filme, já que a concentração de ligações $\mathrm{SiH}_{2}$ estiramento é sempre maior que a de $\mathrm{SiH}$ estiramento com pouca ordem em pequeno alcance, ficando mais desordenada com o aumento da pressão novamente devido ao aumento da concentração de ligações $\mathrm{SiH}_{2}$ dobramento e $\mathrm{SiH}_{3}$ dobramento, mas isso não justificaria o aumento da fotosensibilidade com 0 aumento da pressão.

O filme mais fotosensível obtido neste trabalho, depositado pela segunda vez a 10 mTorr de pressão total, $30 \%$ de hidrogênio nos gases de descarga e $250 \mathrm{~W}$ de potência, apresentou uma fotosensibilidade da ordem de $10^{3}$ compatível para a aplicação como sensores que poderiam ser fabricados sobre substratos flexíveis já que a temperatura de deposição é menor que $100{ }^{\circ} \mathrm{C}$.

Como em deposições convencionais por sputtering a temperatura utilizada fica em torno de $250{ }^{\circ} \mathrm{C}$, os filmes de a-Si:H produzidos em baixas temperaturas apresentam altas densidades de estados na banda de mobilidade, devido às altas concentrações de espaços vazios do tipo lacuna, com relação a estes filmes mais densos, formados durante o processo de deposição. Isso ocorre porque as espécies $\mathrm{SiH}_{\mathrm{x}}$ produzidas no plasma se depositam no substrato sem muita energia para a 
acomodação de seus elementos atômicos em sítios de menor energia como ocorre com os filmes depositados em temperaturas de 250 a $300^{\circ} \mathrm{C}$.

Apesar de terem sido reportados na literatura alguns trabalhos em que houve uma melhora nas propriedades semicondutoras de filmes de a-Si:H depositados a temperatura ambiente e posteriormente recozidos a aproximadamente $250{ }^{\circ} \mathrm{C}$, os tratamentos térmicos realizados nos filmes deste trabalho após a deposição não modificaram efetivamente suas características.

Além da alta densidade de espaços vazios do tipo microlacunas presentes nos filmes, a alta densidade de defeitos também resultou da alta concentração de contaminantes como o oxigênio e o nitrogênio, que variou de $10^{20}$ a $10^{21}$ átomos $/ \mathrm{cm}^{3}$. Com a redução desta concentração para níveis abaixo de $10^{19}$ átomos $/ \mathrm{cm}^{3}$ poderiam ser obtidos filmes mais fotosensíveis. Esta diminuição de contaminantes poderia ser alcançada tanto pelo aquecimento das paredes do reator antes da deposição como pela passagem do gás argônio por uma armadilha gelada de nitrogênio líquido.

A concentração dos contaminantes metálicas presentes nos filmes, que apareceu em apenas alguns filmes, foi baixa o suficiente para não comprometer as características fotoelétricas dos filmes. $\mathrm{O}$ argônio aprisionado durante o crescimento dos filmes ficou um pouco acima da faixa de concentração normalmente encontrada na literatura. Apesar de o oxigênio ter sido detectado em todos os filmes com uma concentração quase constante o carbono e o nitrogênio foram encontrados em apenas alguns filmes. Devido a pouca variação da concentração de oxigênio nos filmes com as condições de deposição a variação das características dos filmes pôde ser observada com a alteração da pressão total, potência de RF e concentração de hidrogênio nos gases de descarga.

Como esperado a taxa de deposição dos filmes aumentou com o aumento da potência de RF, mas não variou significativamente com a pressão e nem com a concentração de hidrogênio nos gases de descarga. Da mesma forma os valores de Eg obtidos para as amostras depositadas a 10 mTorr foram maiores que os obtidos para as amostras depositadas a 5 mTorr, provavelmente porque as primeiras apresentaram características semicondutoras melhores.

Por fim, neste trabalho, através da associação dos valores tanto de condutividade de escuro como dos de fotocondutividade com os valores de $\mathrm{Eg}$, B e 
modos de ligação entre os átomos de silício e hidrogênio as melhores condições de deposição puderam ser encontradas. 


\section{REFERÊNCIAS}

1. KIM, D.Y.; KIM I.S.; CHOI, S.Y. Elétrical properties of a-Si:H thin films as a function of bonding configuration. Sol. Energ. Mat. Sol. C., v. 93, p. 239-243, November, 2009.

2. WRONSKI, C.R. Amorphous silicon technology: Coming of age. Sol. Energ. Mat. Sol. C., v. 41/42, p. 427-439, 1996.

3. CHAJI, G.R.; NATHAN, A. Low -Cost Stable a-Si:H AMOLED display for portable applications, in Circuits and Systems. 2006, IEEE North-Weast Workshop on: Gatineau, Que. p. 97-100.

4. FUJIEDA, I., et al. Applications of a-Si:H radiations detectors. J. Non-Crys. Solids, v. 115, p. 174-176, 1989.

5. WONG, W.S.; SALLEO A. Flexible Electronics. Materials and Applications, ed. H.L. Tuller. New York: Springer Science+Business Media, 2009.

6. SOUKUP, R.J., et al. Deposition of high quality amorphous silicon, germanium and silicon-germanium thin films by a hollow cathode reactive suttering system. Surf. Coat. Tech., v.177-178, p. 676-681, 2004.

7. DUTTA, P., et al. Comparative Study of nc-Si:H deposited by reactive sputtering using crystalline and polycrystalline silicon targets. in Photovoltaic Specialists Conference, 33rd IEEE. 2008. San Diego, CA, USA.

8. TABATA, A.; FUKAYA K.; MIZUTANI T. Influence of substrate direct current bias voltage on microcrystalline silicon growth during radio-frequency magnetron sputtering. Vacuum, v. 82, p. 777-781, 2008.

9. PANWAR, O.S.; MUKHERJEE C.; BHATTACHARYYA R. Effect of annealing on the electrical, optical and structural properties of hydrogenated amorphous silicon films deposited in an asymmetric R.F. plasma CVD system at room temperatura. Sol. Energ. Mat. Sol. C., v. 57, p. 373-391, 1999.

10. Yue-Hui, H., et al. Nanomorph silicon thin films prepared by using an HWMWECR CVD system. Chin. Phys. Lett., v. 22 n.5, p. 1260-1263, 2005.

11. BAGHDAD, R., et al. Deposition of nanocrystalline silicon thin films: Effect of total pressure and substrate temperature. Thin Solid Films, v. 516, p. 39653970, 2008.

12. AMRANI, R., et al., Low-temperature growth of nanocrystalline silicon films prepared by RF magnetron sputtering: strutural and optical studies. J. NonCrys. Solids, v. 354, p. 2291-2295, 2008.

13. FUKAYA, K.; TABATA A.; SASAKI K. Enhancement of crystal growth in Si thin-film deposition by $\mathrm{H}$-radical-assisted magnetorn sputtering. Jpn. J. Appl. Phys., v. 49 n.015501, p. 1-5, 2010. 
14. OYAMA, A.; NAKAMURA, I.; ISOMURA, M. Micro-crystalline silicon thin films deposited by the reactive $\mathrm{RF}$ magnetron sputtering system. in Photovoltaic Energy Conversion, 4th World Conference. 2006. Waikoloa, HI: IEEE.

15. WEI, Y.; et al. Influence of substrate temperature on growth of a-Si:H films by reactive facing target sputtering deposition. Sci. China Ser. G, v. 53, n. 5, p. 807-811, 2010.

16. STREET, R.A. Hydrogenated amorphous silicon. Cambridge New York: Cambridge University Press, 1991.

17. CHOPRA, K.L. and S.R. DAS, Thin Film Solar Cells. New York: Plenum Press, 1983.

18. KAGAN, C.R.; ANDRY, P. Thin-film transistors. New York: Marcel Dekker, 2003.

19. KUO, Y. Thin Film Transistors Materials and Processes Volume 1: Amorphous Silicon Thin Film Transistors. Boston/ Dordrecht/ New York London: Kluwer Academic Publichers, 2004.

20. ABELSON, J.R.; MANDRELL, L.; DOYLE, J.R. Hydrogen release kinetics during reactive magnetron sputter deposition of a-Si:H: An isotope labeling study. J. Appl. Phys., v. 76 n. 3, p. 1856-1870, 1994.

21. PAUL, W.; et al. Doping, schotky barrier and $p-n$ junction formation in amorphous germanium and silicon by rf sputtering. Solid State Commun., v. 20, p. 969-972, 1976.

22. PIBRIL, G.; et al. Deposition of electronic quality amorphous silicon, a-Si:H, thin films by a hollow cathode plasma-jet reactive sputtering system. J. Vac. Sci. Technol. A, v. 19 n. 4, p. 1571-1576, 2001.

23. JUN, S.-I; RACK, P.D. Direct-current substrate bias effects on amorphous silicon sputter deposited films for thin film transistor fabrication. Appl. Phys. Lett., v. 87 n. 132108, p. 1-3, 2005.

24. PINARBASI, M.; et al. Hydrogenated amorphous silicon films deposited by reactive sputtering: the electronic properties hydrogen bonding and microstructure. Thin Solid Films, v. 171, p. 217-233, 1989.

25. RANTZER, R.; et al., Optical properties of intrinsic and doped a-Si:H films grown by d.c. magnetron sputter deposition. Thin Solid Films, v. 394, n. 1-2, p. 255-262, 2001.

26. KAGAN, C.R.; ANDRY, P. Thin Film Transistors. New York, USA: Marcel Dekker, 2009. 
27. FUJIYAMA, $\mathrm{H}_{\text {. }}$; et al. Ceramics inner coating of narrow tubes by a coaxial magnetron pulsed plasma. Surf. Coat. Tech., v. 98 n. 1-3, p. 1467-1472, 1999.

28. SHON, C.H.; LEE, J.K. Modeling of magnetron sputtering plasmas. Appl. phys. Sci., v. 192 n. 1-4, p. 258-259, 2002.

29. KAKATI, H.; et al. Sheath and potential characteristic in if magnetron sputtering plasma. J. Appl. Phys., v. 100 n. 8, p. 083303-083303-6, 2006.

30. FRANCOMBE, M.H.; VOSSEN, J.L. Plasma sources for thin film deposition and etching. v. 18, New York: Academic Press, inc., 1994.

31. SWANN, S., Spatial distribution of sputtered atoms from magnetron source. J. Vac. Sci. Technol. A, v. 5 n. 4, p. 1750-1754, 1987.

32. SPENCER, A.G.; BISHOP, C.A.; HOWNON, R.P. The design and performance of planar magnetron sputtering cathodes. Vacuum, v. 37 n. 3-4, p. 363-366, 2002.

33. Yong-Kang, Y. A method of increasing the utilization ratio of planar magnetron sputtering targets. Surf. Coat. Tech., v. 37 n. 3, p. 315-319, 1988.

34. GRILL, A. Cold plasma in material fabrication: from fundamental to applications. New York: IEEE Press, 1994.

35. SHERMAN, A. Plasma-assisted chemical vapor deposition processes and their semiconductor applications. Thin Solid Films, v. 113 n. 2, p. 135-149, 1984.

36. PAUL, W.; ANDERSON, D.A.A. Properties of amorphous hydrogenated silicon, with special emphasis on preparation by sputtering. Sol. Energ. Mater., v. 5, p. 229-316, 1981.

37. MOUSTAKAS, T.D.; ANDERSON, D.A.; PAUL, W. Preparation of highly photoconductive amorphous silicon by RF sputtering. Solid State Commun., v. 23, p. 155-158, 1977.

38. BRODSKY, M.H. Amorphous Semiconductors, ed. M.H.B.e. al., Berlin New Yourk: Springer-Verlag, 1979.

39. ZALLEN, R.; WELEY, J. The Physics of Amorphous Solids. New York: A Wiley-Interscience publication, 1983.

40. BRODSKY, M.H., CARDONA, M.; CUOMO, J.J. Infrared and Raman spectra of the silicon-hydrogen bonds in amorphous silicon prepared by glow discharge and sputtering. Phys. Rev. B, v. 16 n. 8, p. 3556-3571, 1977. 
41. LANGFORD, A.A.; FLEET, M.L.; NELSON, B.P. Infrared absorption strength and hydrogen content of hydrogenated amorphous silicon. Phys. Rev. B, v. 45 n. 23, p. 367-377, 1992.

42. FREEMAN, E.C.; PAUL, W. Infrared vibrational spectra of rf-sputtering hydrogenated amorphous silicon. Phys. Rev. B, v. 18 n. 8, p. 4228-4300, 1978.

43. HARAME, D.L. SiGe and Ge: materials, processing, and devices, Issue 7. New Jersey: The Electrochemical Society, Inc., 2006.

44. SMITH, B.C. Fourier transform infrared spectroscopy. Boca Raton: CRC Press, 1996.

45. LUCOVSKY, G.; NEMANICH, R.J.; KNIGHTS, J.C. Structural interpretation of the vabrational spectra of a-Si:H alloys. Phys. Rev. B, v. 19, p. 2064-2074, 1979.

46. GEKKA, Y.; et al. Effect of hydrogen pressure on the deposition of amorphous silicon films by tetrode RF sputtering. Appl. Surf. Sci., v. 22/23, p. 899-907, 1985.

47. HOSSAIN, M.; et al. Characterization of hydrogenated amorphous silicon thin films prepared by magnetron sputtering. J. Non-Cryst. Solids, v. 352, p. 1823, 2006.

48. MIRZA, A.R., et al., R.F. magentrons sputtering of a-Si:H. Journal of Physique, 1981. Colloque C4(supplément au n¹0, Tome 42): p. 659-662.

49. FREEMAN, E.C.; PAUL, W. Optical constants of rf sputtered hydrogenated amorphous Si. Phys. Rev. B, v. 20, n. 2, p. 716-728, 1979.

50. LIANG, S.L.; WANG, K.W.; LIU, Y.C. Argon Concentration of RF Sputtered Silicon Films. Chinese J. Phys., v. 17, n. 2, p. 102-106, 1979.

51. KONZ, D.W.; SOUKUP, R.J. Quality hydrogenated amorphous silicon deposited by triode assisted reactive sputtering. Sol. Energ. Mat. Sol. C., v. 56 , p. 175-182, 1999.

52. SHIMIZU, T.; et al. Nature of Localizes States in Hydrogenated Si-Based Amorphous Semiconductor Films Elucidated from LESR and CPM. Jpn. J. Appl. Phys., v. 28 n. 4, p. 586-592, 1989.

53. MORIMOTO, A.; et al. Doping effect of oxygen or nitrogên impurity in hydrogenated amorphous silicon films. Appl. Phys. Lett., v. 21, p. 2130-2132, 1991.

54. ISHIDA, H.; NODA, M.; SHIMIZU, H. Microstructures and Hydrogen Bonding Environments of a-Si:H Films Prepared by RF Sputtering in Pure Hydrogen. Jpn. J. Appl. Phys., v. 22 n. 2, p. L73-L75, 1983. 
55. SHANKS, H.; et al. Infrared Spectrum and Structure of Hydrogenated Amorphous Silicon. Phys. status solidi B, v. 100, p. 43-56, 1980.

56. SAITO, N.; et al. Dependence of properties of hydrogenated microcrystalline and amorphous silicon films prepared by planar magnetron sputtering in inert gas. Appl. Phys. A: Mater., v. 35 n. 4, p. 241-247, 1984.

57. NODA, M.; ISHIDA, H. Microstructures and Hydrogen Bonding Enviroments of Sputter-Deposited a-Si:H films. Jpn. J. Appl. Phys., 1982. v. 21 n. 4, p. L195L197, 1984.

58. CUNIOT, M.; J. DIXMIER; ELKAIM, P. Unusual magnetron sputtered a-Si:H materials obtained at high deposition rates as favourable precursors for the preparation of large-grain-size crystallized thin silicon films. J. Non-Cryst. Solids, v. 164-166, p. 99-102, 1993.

59. JIRANAPAKUL, K.; SHIRAFUJI, J. Effect of oxygen incorporation on properties of RF sputtering a-Si:H films. J. Non-Cryst. Solids, v. 81, p. 29-40, 1986.

60. PHUONG, N.M.; et al. Characterization of Photoconductive Amorphous Si:H Films for Photoconducting Sensor Applications. Electochem. Solic. St., v. 10 n. 9, p. H284-H286, 2007. 
APÊNDICE A - Gráficos de absorção óptica na região do ultravioleta-visível

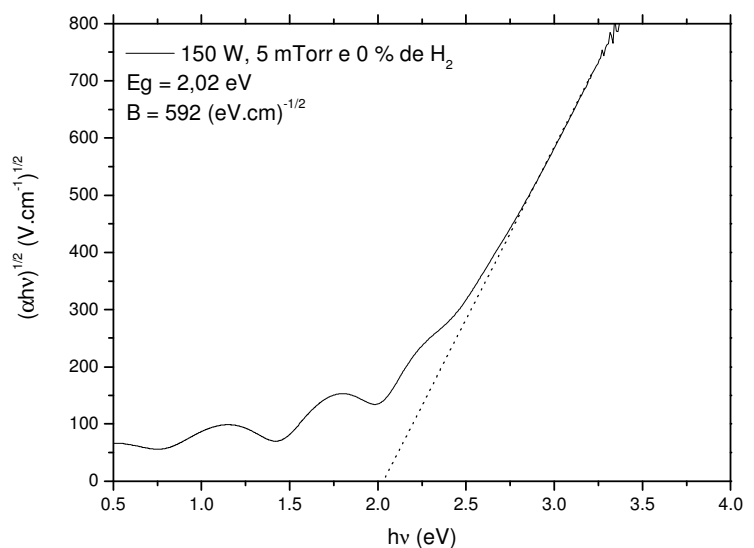

(a)

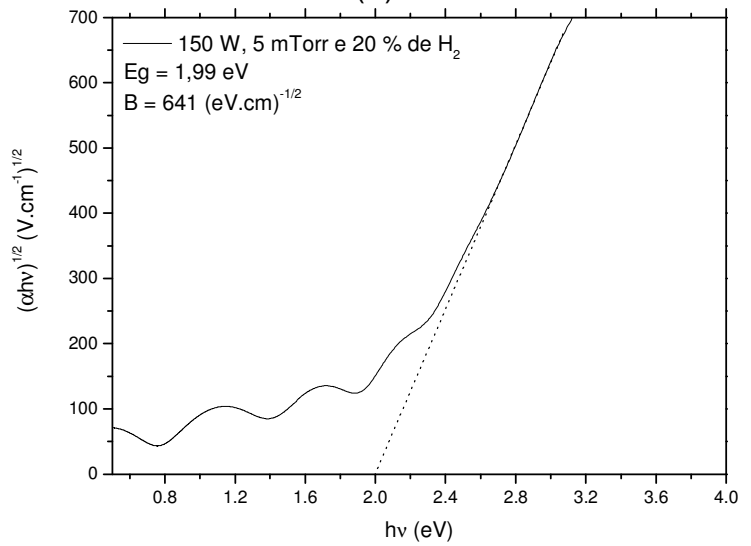

(c)

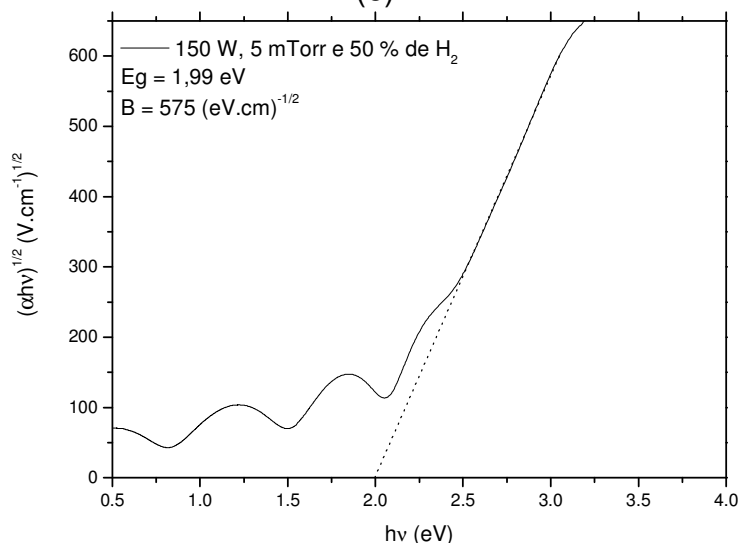

(e)

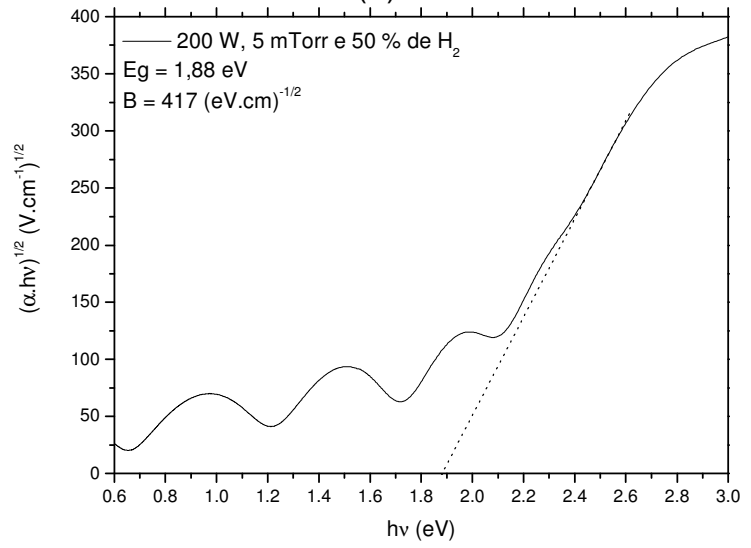

(g)

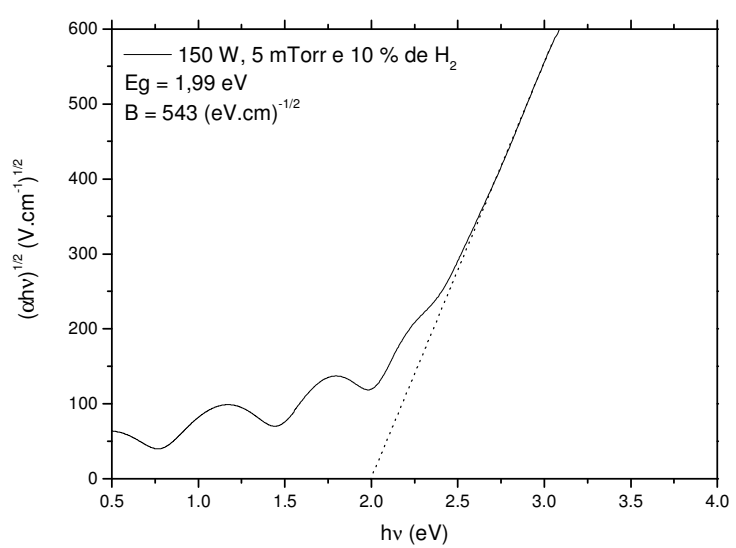

(b)

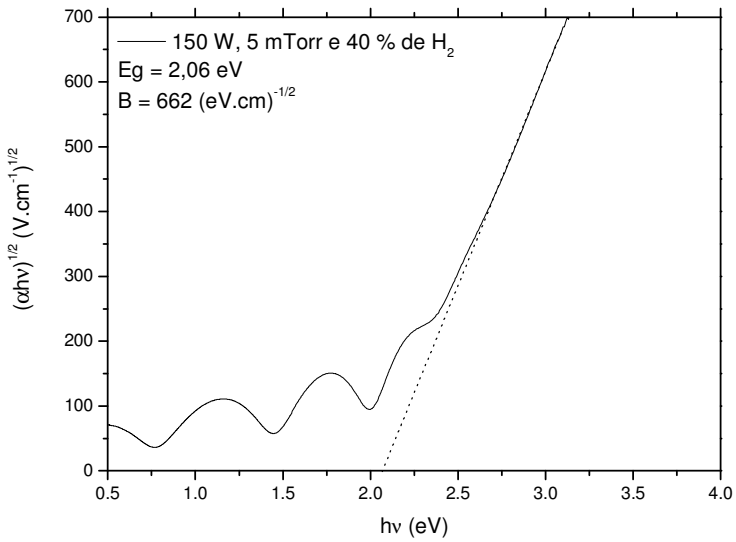

(d)

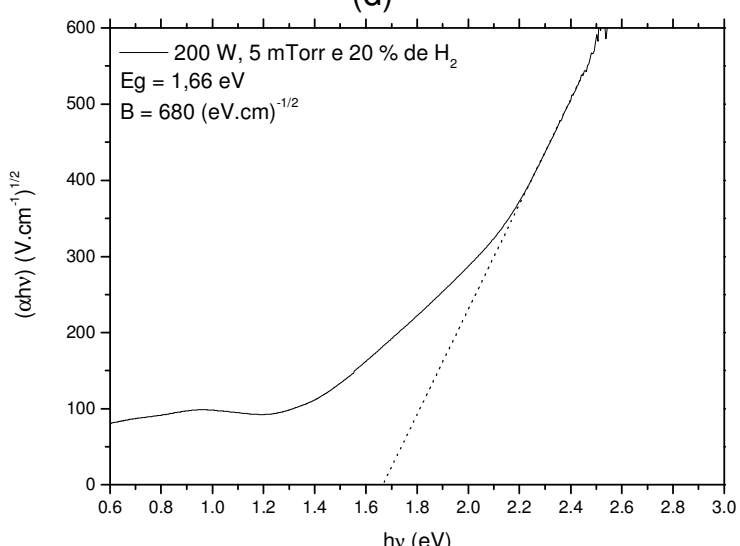

(f)

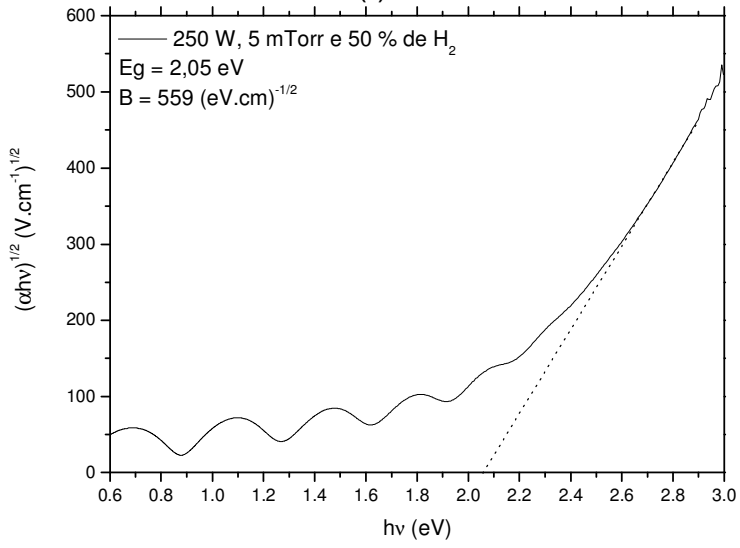

(h) 

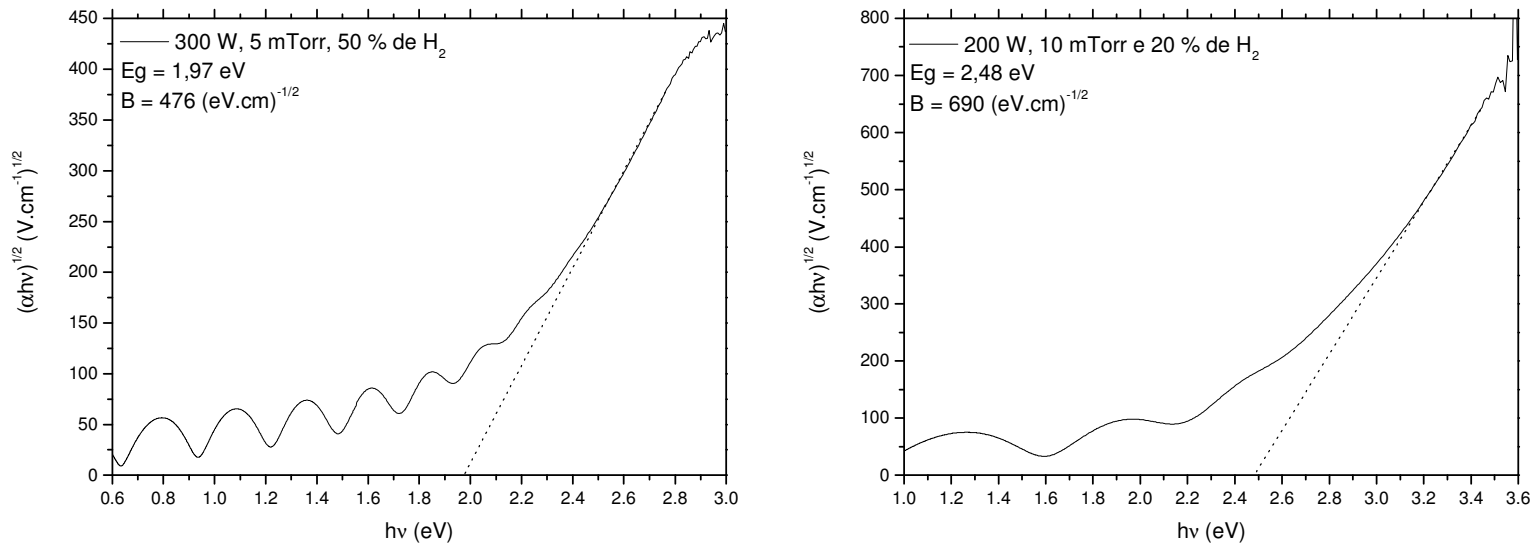

(i)

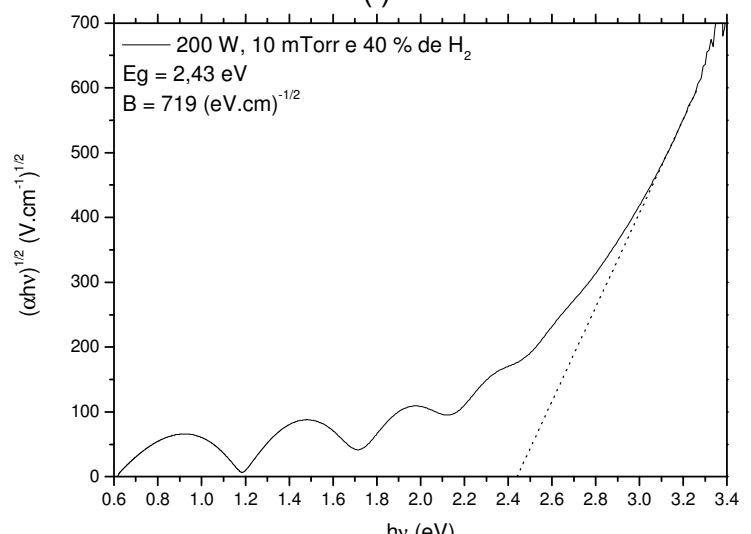

(j)

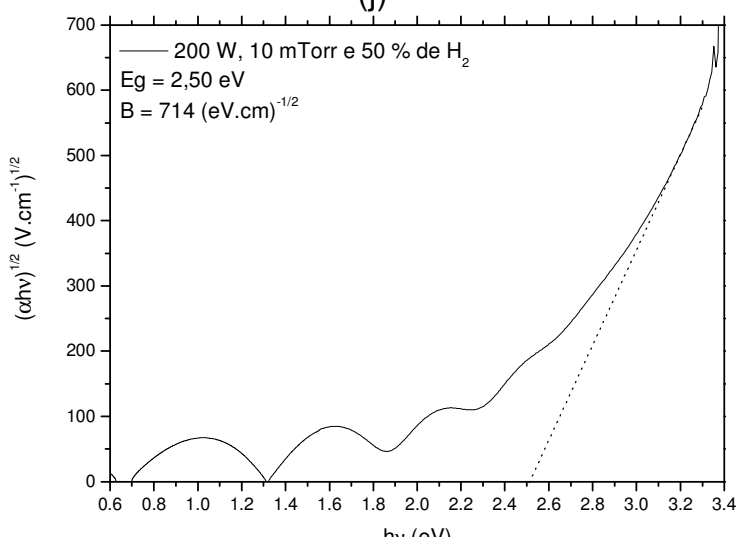

(k)

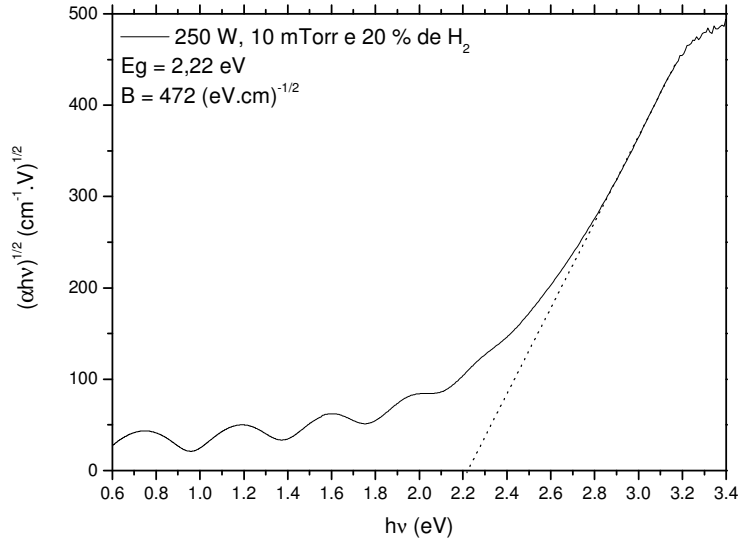

(I)

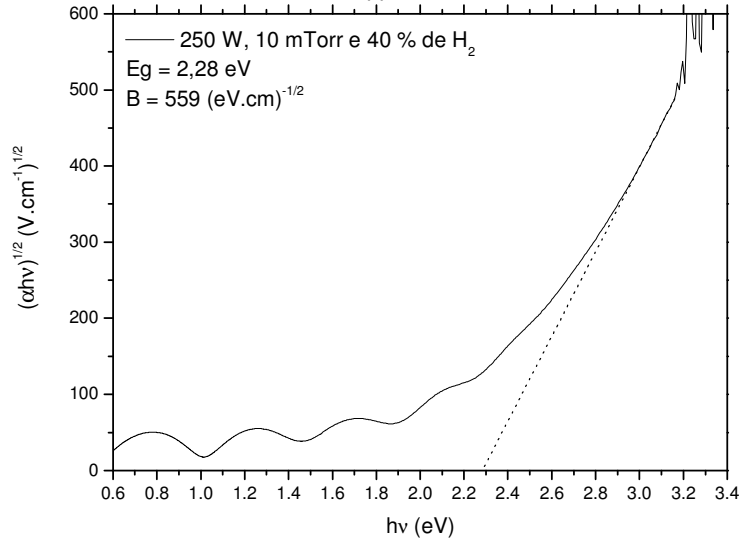

(m)

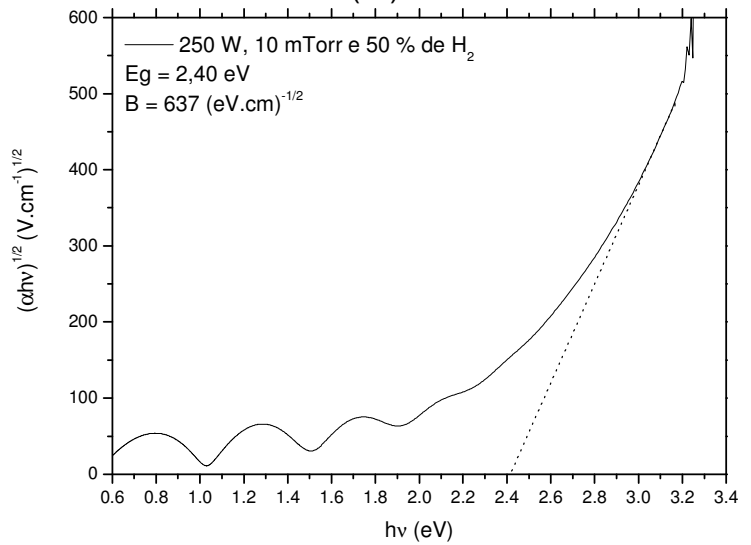

(o)

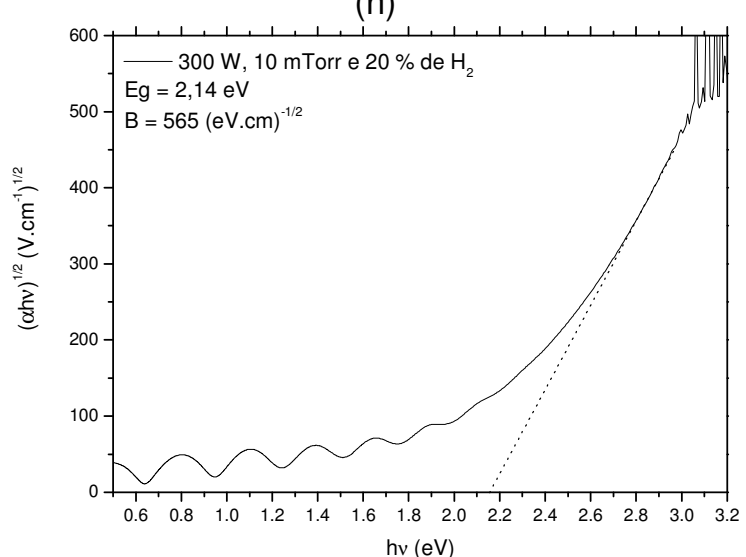

(p) 


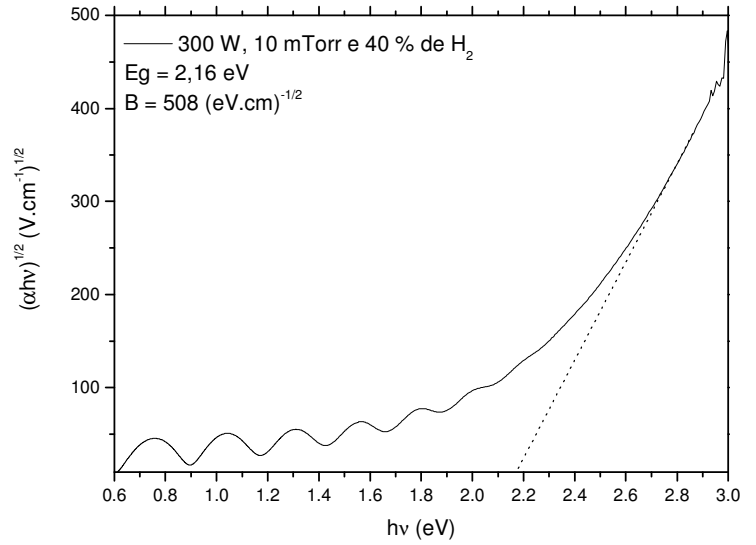

(q)

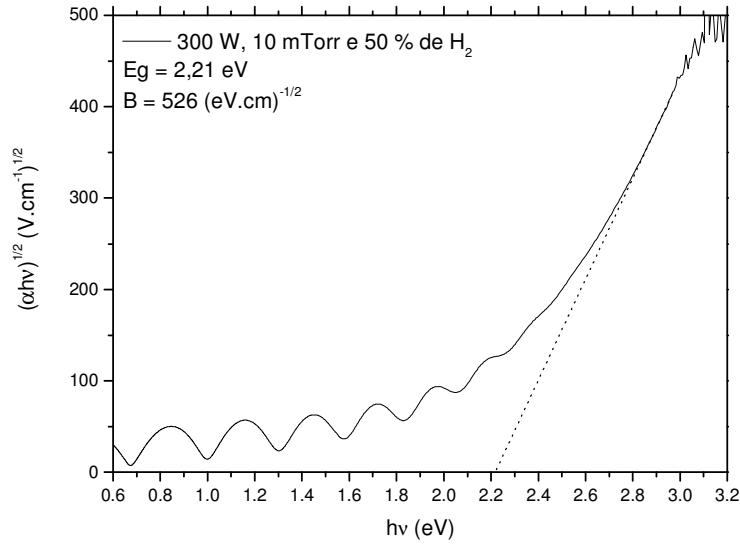

(r) 
APÊNCIDE B - Características das bandas de absorção a $630 \mathrm{~cm}^{-1}$.

Amostras do depositadas pela primeira vez (A)

\begin{tabular}{cccccc}
\hline Pot RF (W) & $\mathbf{P}$ (mTorr) & {$\left[\mathbf{H}_{\mathbf{2}}\right](\%)$} & Pico & Área & Conc (at. \%) \\
\hline \multirow{4}{*}{150} & 0 & 656,0 & 93 & 3 \\
& & 10 & 644,2 & 108,8 & 3,5 \\
& 20 & 40 & 640,4 & 242,7 & 7,8 \\
& & 50 & 640,4 & 262,6 & 8,4 \\
\hline
\end{tabular}

Amostras do depositadas pela segunda vez (B)

\begin{tabular}{|c|c|c|c|c|c|}
\hline Pot RF (W) & P (mTorr) & {$\left[\mathrm{H}_{2}\right](\%)$} & Pico & Área & Conc (at. \%) \\
\hline \multirow{4}{*}{250} & \multirow{4}{*}{5} & 0 & 640,4 & 121,2 & 3,9 \\
\hline & & 20 & 640,4 & 203,1 & 6,5 \\
\hline & & 40 & 636,5 & 241,7 & 7,7 \\
\hline & & 60 & 640,4 & 273,3 & 8,7 \\
\hline \multirow{4}{*}{250} & \multirow{4}{*}{10} & 0 & 648,1 & 81,0 & 2,6 \\
\hline & & 20 & 628,8 & 123,8 & 4 \\
\hline & & 30 & 632,7 & 115,6 & 3,7 \\
\hline & & 50 & 628,8 & 126,4 & 4 \\
\hline
\end{tabular}

Amostras do depositadas pela terceira vez (C)

\begin{tabular}{cccccc}
\hline Pot RF (W) & $\mathbf{P}$ (mTorr) & {$\left[\mathbf{H}_{\mathbf{2}}\right] \mathbf{( \% )}$} & Pico & Area & Conc (at. \%) \\
\hline \multirow{2}{*}{200} & \multirow{2}{*}{5} & 20 & 642,2 & 232,3 & 7,4 \\
& & 50 & 640,3 & 452,2 & 14,5 \\
\hline \multirow{2}{*}{200} & \multirow{2}{*}{10} & 20 & 634,5 & 203,2 & 6,5 \\
& & 40 & 630,7 & 210,9 & 6,7 \\
\hline \multirow{2}{*}{250} & 5 & 50 & 628,7 & 195,8 & 6,3 \\
\hline \multirow{2}{*}{250} & \multirow{2}{*}{10} & 20 & 630,7 & 442,2 & 5,6 \\
& & 40 & 634,5 & 175,6 & 5 \\
\hline \multirow{2}{*}{300} & 50 & 50 & 630,7 & 156,2 & 5 \\
\hline \multirow{2}{*}{300} & \multirow{2}{*}{10} & 20 & 628,7 & 155,9 & 13,3 \\
& & 40 & 630,7 & 416,5 & 7,7 \\
\end{tabular}


APÊNDICE C - Gráficos do Ajuste das bandas entre 840 e $880 \mathrm{~cm}^{-1}$.
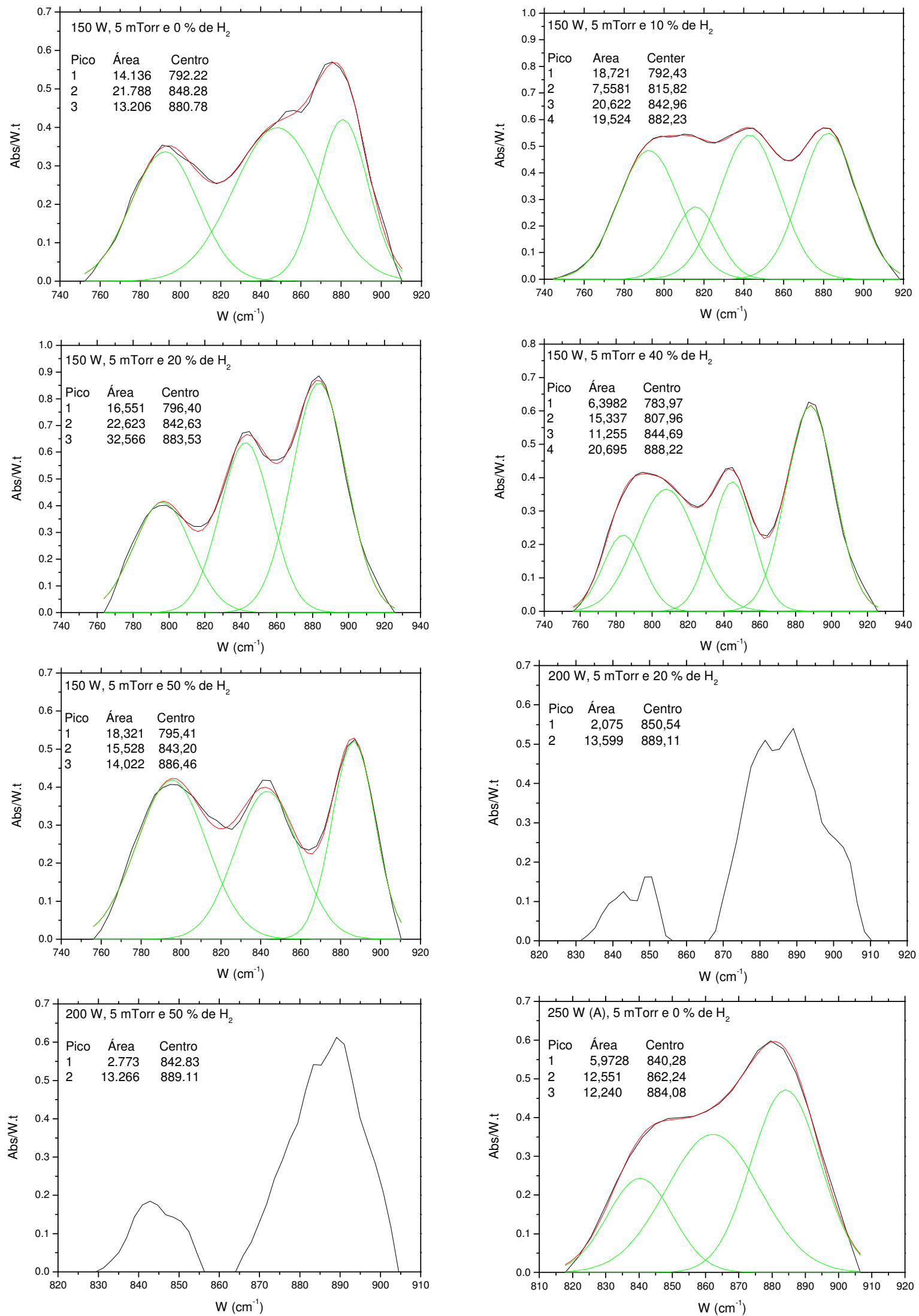


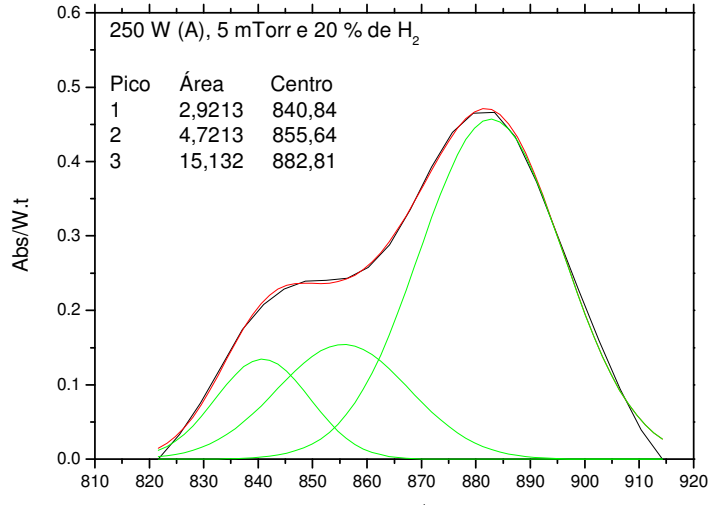

W $\left(\mathrm{cm}^{-1}\right)$
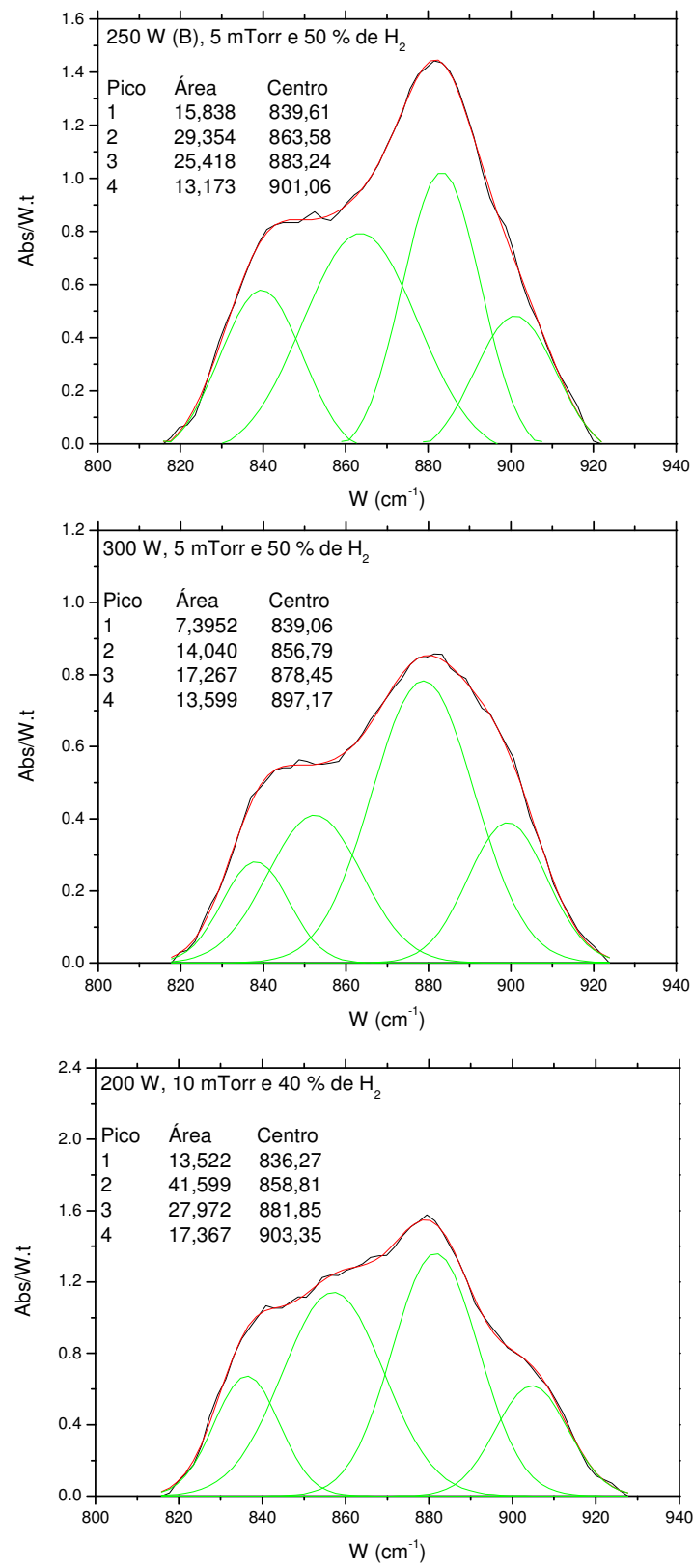
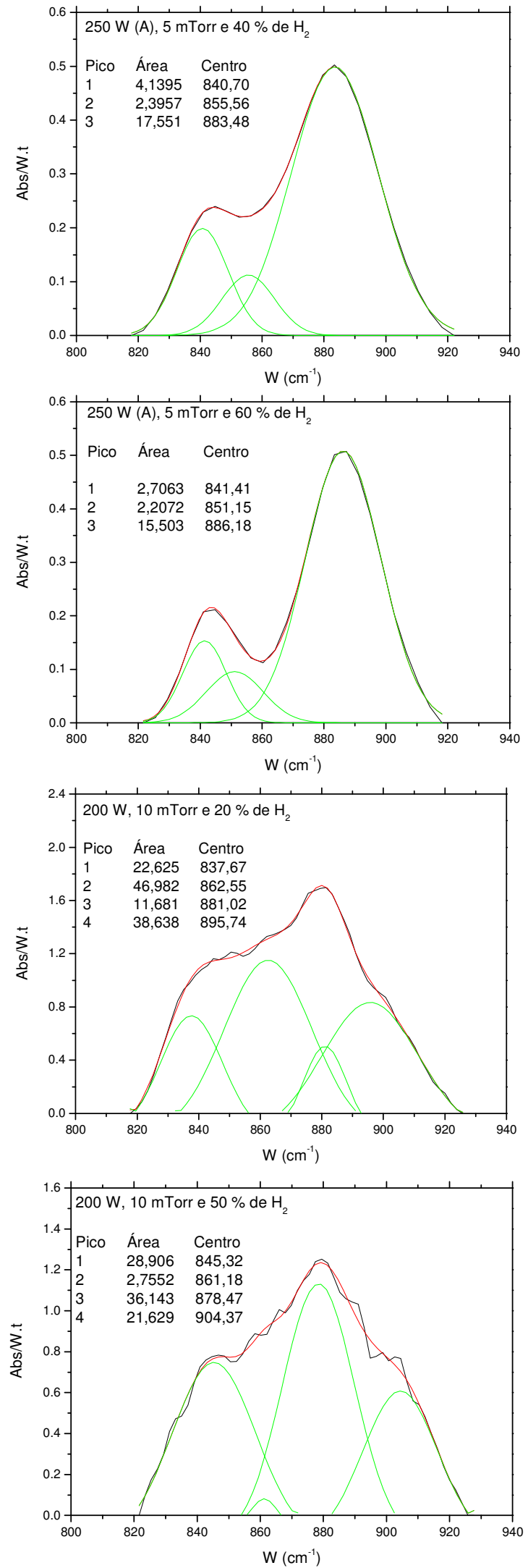

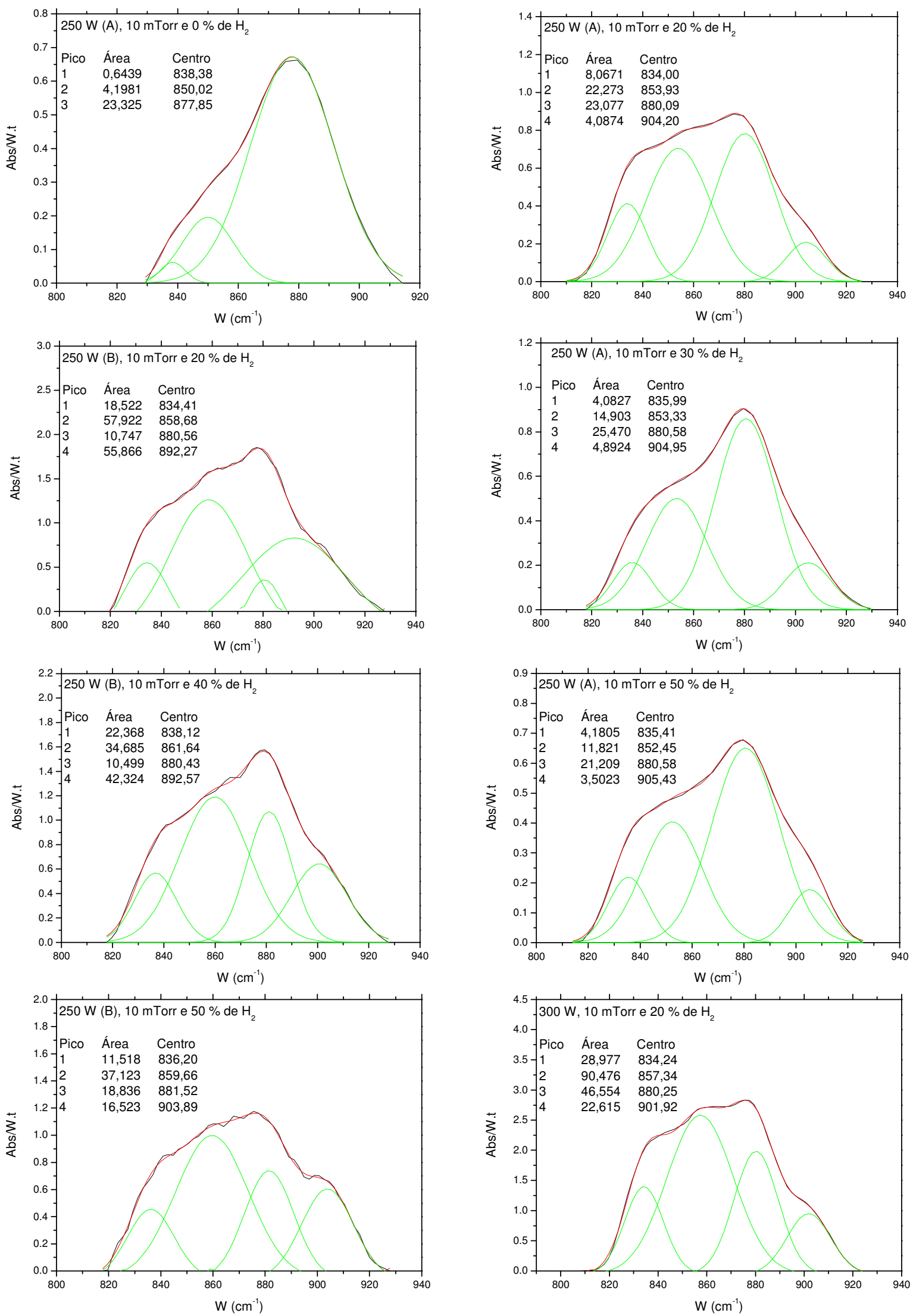

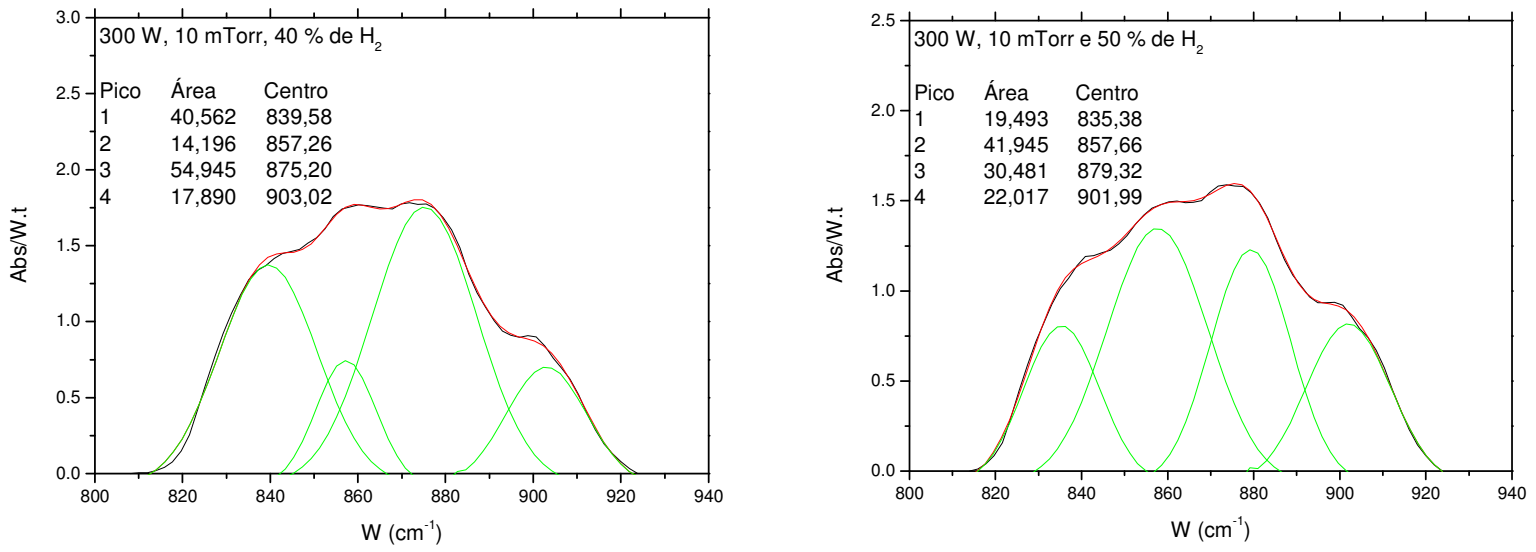
APÊNDICE D - Caracterização das bandas de absorção a 2000 e $2090 \mathrm{~cm}^{-1}$.

Amostras do depositadas pela primeira vez (A)

\begin{tabular}{ccccccccc}
\hline Pot RF (W) & P (mTorr) & {$\left[\mathbf{H}_{\mathbf{2}}\right](\%)$} & Pico 1 & Área 1 & $\begin{array}{c}\text { Conc. } \\
\text { (at. \%) }\end{array}$ & Pico 2 & Área 2 & $\begin{array}{c}\text { Conc. } \\
\text { (at. \%) }\end{array}$ \\
\hline \multirow{3}{*}{150} & & 0 & 2042,0 & 8,7493 & 2,27 & 2091,2 & 11,803 & 3,30 \\
& & 10 & 2000,7 & 6,7975 & 1,77 & 2087,6 & 8,1002 & 2,27 \\
& 20 & 2029,0 & 12,366 & 3,22 & 2087,0 & 26,175 & 7,33 \\
& & 40 & 2028,6 & 16,992 & 4,41 & 2085,1 & 29,969 & 8,39 \\
& 50 & 2031,2 & 14,625 & 3,80 & 2085,0 & 26,777 & 7,50 \\
\hline
\end{tabular}

Amostras do depositadas pela segunda vez (B)

\begin{tabular}{ccccccccc}
\hline Pot RF (W) & $\mathbf{P}$ (mTorr) & {$\left[\mathbf{H}_{\mathbf{2}}\right] \mathbf{( \% )}$} & Pico 1 & Área 1 & $\begin{array}{c}\text { Conc. } \\
\text { (at. \%) }\end{array}$ & Pico 2 & Área 2 & $\begin{array}{c}\text { Conc. } \\
\text { (at. \%) }\end{array}$ \\
\hline \multirow{3}{*}{250} & \multirow{2}{*}{5} & 0 & 2005,6 & 7,9589 & 2,07 & 2078,2 & 10,429 & 2,92 \\
& & 20 & 2004,4 & 5,5462 & 1,44 & 2088,5 & 2,0255 & 1,13 \\
& & 40 & 2022,6 & 4,7433 & 1,23 & 2083,0 & 7,8777 & 2,21 \\
& 60 & 2021,3 & 11,564 & 3,00 & 2089,9 & 14,387 & 4,03 \\
\hline \multirow{3}{*}{250} & \multirow{2}{*}{10} & 0 & 2013,6 & 1,204 & 0,31 & 2092,4 & 7,887 & 2,21 \\
& & 20 & 2017,0 & 0,653 & 0,17 & 2089,8 & 14,590 & 4,09 \\
& & 30 & 2016,9 & 0,935 & 0,24 & 2085,2 & 11,792 & 3,30 \\
& & 50 & 2013,2 & 0,505 & 0,13 & 2084,2 & 14,436 & 4,04 \\
\hline
\end{tabular}

Amostras do depositadas pela terceira vez (C).

\begin{tabular}{|c|c|c|c|c|c|c|c|c|}
\hline Pot RF (W) & P (mTorr) & {$\left[\mathrm{H}_{2}\right](\%)$} & Pico 1 & Área 1 & $\begin{array}{l}\text { Conc. } \\
\text { (at. \%) }\end{array}$ & Pico 2 & Área 2 & $\begin{array}{l}\text { Conc. } \\
\text { (at. \%) }\end{array}$ \\
\hline \multirow{2}{*}{200} & \multirow{2}{*}{5} & 20 & 2024,8 & 24,189 & 6,30 & 2084,6 & 28,445 & 7,60 \\
\hline & & 50 & 2019,6 & 37,711 & 9,80 & 2080,6 & 48,118 & 13,47 \\
\hline \multirow{3}{*}{200} & \multirow{3}{*}{10} & 20 & 2019,1 & 1,944 & 0,51 & 2092,1 & 39,997 & 11,20 \\
\hline & & 40 & 2022,5 & 2,592 & 0,67 & 2088,3 & 37,502 & 10,50 \\
\hline & & 50 & 2028,2 & 0,395 & 0,10 & 2088,6 & 36,079 & 10,10 \\
\hline \multirow[t]{2}{*}{250} & 5 & 50 & 2021,6 & 17,191 & 4,47 & 2084,4 & 19,826 & 5,55 \\
\hline & & 20 & 2024,6 & 2,367 & 0,62 & 2087,5 & 27,007 & 7,56 \\
\hline \multirow[t]{2}{*}{250} & 10 & 40 & 2019,0 & 3,139 & 0,82 & 2083,0 & 23,876 & 6,69 \\
\hline & & 50 & - & - & - & 2081 & 20,216 & 5,66 \\
\hline \multirow[t]{2}{*}{300} & 5 & 50 & - & - & - & 2100,3 & 19,070 & 5,34 \\
\hline & & 20 & 2018,1 & 2,3230 & 0,60 & 2094,7 & 30,412 & 8,52 \\
\hline \multirow[t]{2}{*}{300} & 10 & 40 & 2020,9 & 1,4845 & 0,39 & 2095,8 & 30,742 & 8,61 \\
\hline & & 50 & - & - & - & 2090,6 & 15,256 & 4,27 \\
\hline
\end{tabular}




\section{APÊNDICE E - Gráficos de condutividade de escuro e fotocondutividade}

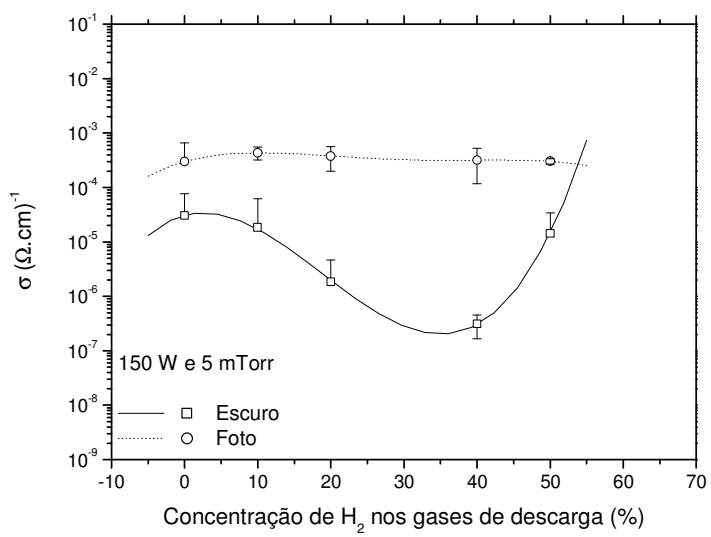

(a)

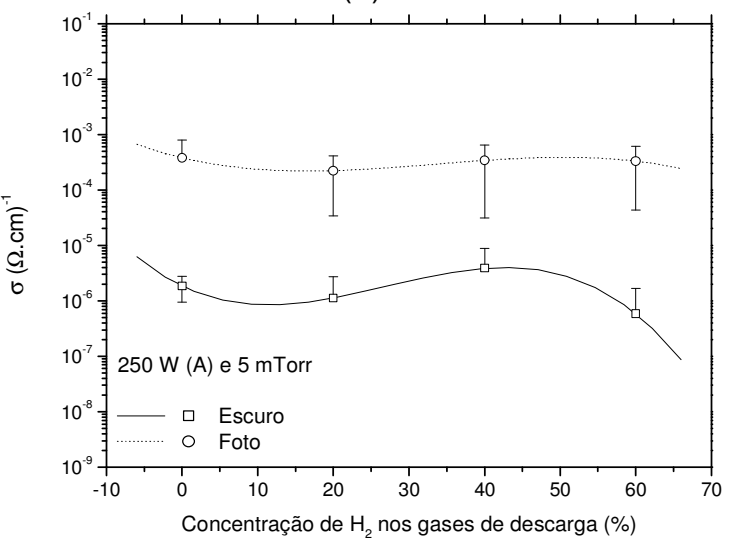

(c)

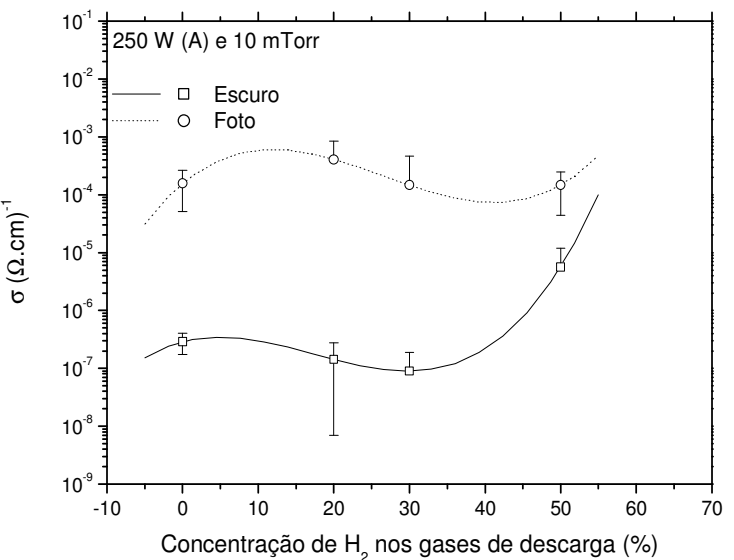

(e)

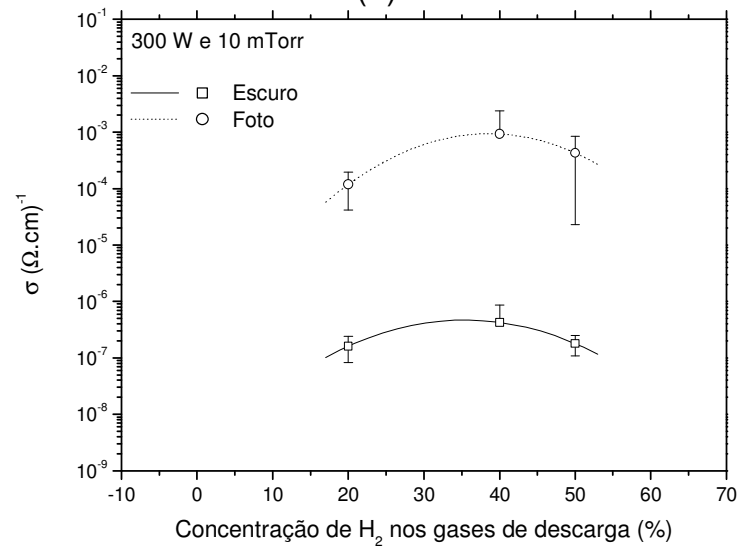

(g)

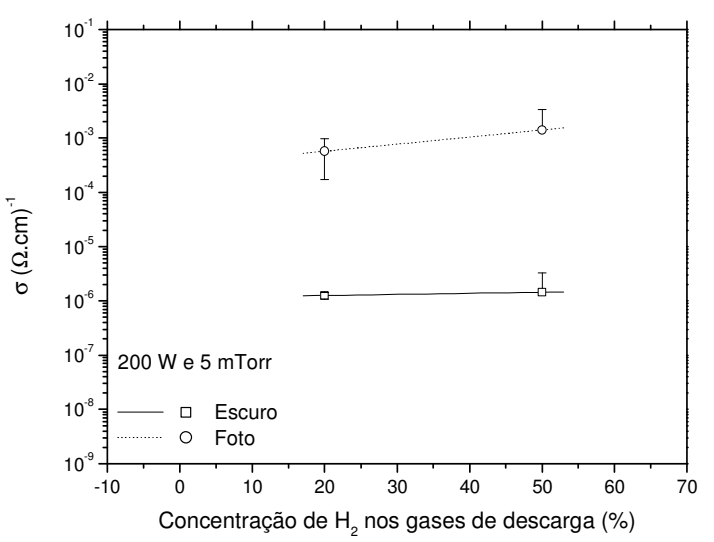

(b)

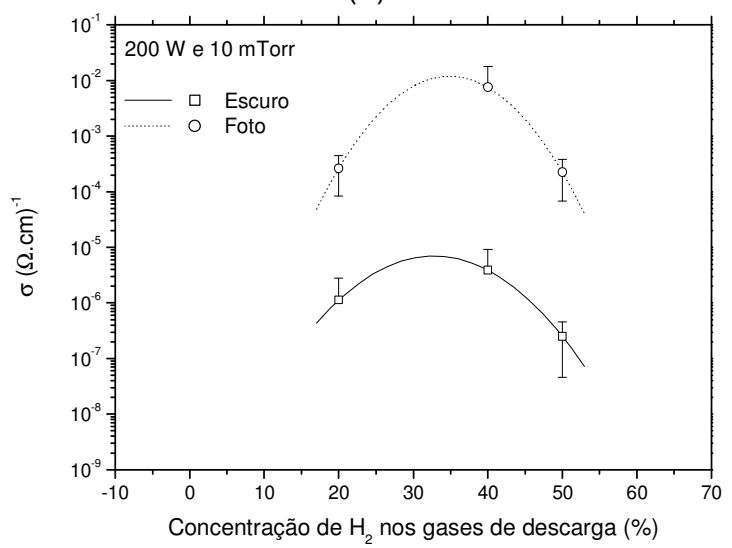

(d)

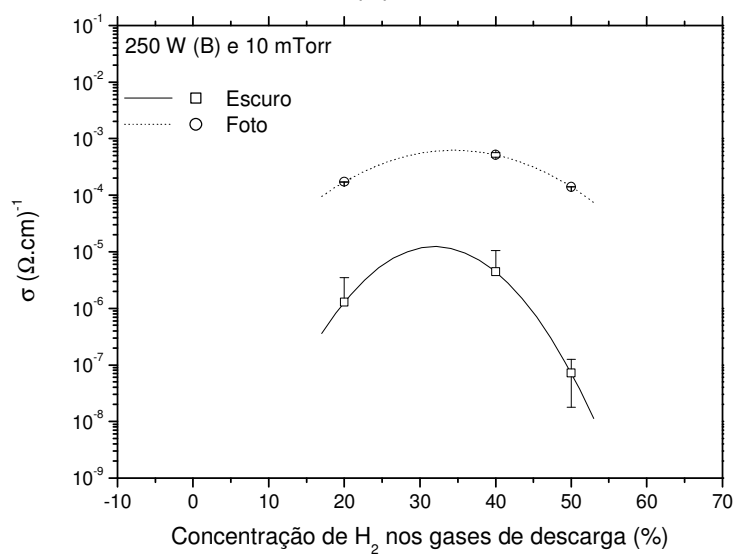

(f) 